\title{
Circulation and suspended sediment transport in a coral reef lagoon: The south-west lagoon of New Caledonia
} \author{
S. Andréfouët ${ }^{\mathrm{d}}$, J.Y. Panché ${ }^{\mathrm{d}}$, R. Fichez $^{\mathrm{c}}$ \\ ${ }^{a}$ Université de Toulouse, UPS (OMP-PCA), LEGOS, 14 av. Edouard Belin, Toulouse F-31400, France \\ ${ }^{\mathrm{b}}$ IRD, LEGOS, 14 av. Edouard Belin, Toulouse F-31400, France \\ ' IRD, UAM, Dpt Hidrobio - DIV de Ciencas Bio y Salud, AV. San Rafael Atlixco 186 - Col. Vicentina 09340, Mexico DF, Mexico \\ 'IRD Nouméa, BP A5, 98848 Nouméa cedex, New Caledonia \\ e Université de Bordeaux, CNRS, UMR 5805, Bordeaux F-33000, France \\ ${ }_{\mathrm{f}}^{\mathrm{L}}$ LGGE, CNRS, Université Joseph Fourier, 54 rue Molière, Saint Martin d'Hères cedex F-38402, France \\ ${ }^{g}$ DYNECO/PHYSED, Ifremer, BP 70, Plouzané F-29280, France \\ ${ }^{\mathrm{h}}$ Université Paris Diderot - Paris 7, Case 7001, 75205 Paris cedex 13, France \\ i IRD, IMARPE/CIMOBP, Instituto del Mar del Perù, Esquina de Gamarra y General Valle S/N Chucuito, Callao, Peru
}

S. Ouillon ${ }^{\mathrm{a}, \mathrm{b}, *}$, P. Douillet ${ }^{\mathrm{c}}$, J.P. Lefebvre ${ }^{\mathrm{c}}$, R. Le Gendre ${ }^{\mathrm{d}}$, A. Jouon ${ }^{\mathrm{e}}$, P. Bonneton ${ }^{\mathrm{e}}$, J.M. Fernandez ${ }^{\mathrm{d}}$, C. Chevillon ${ }^{\mathrm{d}}$, O. Magand ${ }^{\mathrm{f}}$, J. Lefèvre ${ }^{\mathrm{d}}$, P. Le Hir ${ }^{\mathrm{g}}$, R. Laganier ${ }^{\mathrm{h}}$, F. Dumas ${ }^{\mathrm{g}}$, P. Marchesiello $^{\mathrm{a}, \mathrm{d}}$, A. Bel Madani ${ }^{\mathrm{i}}$,

\section{A R T I C L E I N F O}

\section{Keywords:}

Hydrodynamics

Suspended sediment

New Caledonia

Coral reef lagoon

Sediment

Turbidity

Resuspension

\begin{abstract}
A B S T R A C T
The south-west lagoon of New Caledonia is a wide semi-open coral reef lagoon bounded by an intertidal barrier reef and bisected by numerous deep inlets. This paper synthesizes findings from the 2000-2008 French National Program EC2CO-PNEC relative to the circulation and the transport of suspended particles in this lagoon. Numerical model development (hydrodynamic, fine suspended sediment transport, windwave, small-scale atmospheric circulation) allowed the determination of circulation patterns in the lagoon and the charting of residence time, the later of which has been recently used in a series of ecological studies. Topical studies based on field measurements permitted the parameterisation of wave set-up induced by the swell breaking on the reef barrier and the validation of a wind-wave model in a fetch-limited environment. The analysis of spatial and temporal variability of suspended matter concentration over short and long time-scales, the measurement of grain size distribution and the density of suspended matter $\left(1.27 \mathrm{~kg} \mathrm{l}^{-1}\right)$, and the estimation of erodibility of heterogeneous (sand/mud, terrigenous/biogenic) soft bottoms was also conducted. Aggregates were shown to be more abundant near or around reefs and a possible biological influence on this aggregation is discussed. Optical measurements enabled the quantification of suspended matter either in situ (monochromatic measurements) or remotely (surface spectral measurements and satellite observations) and provided indirect calibration and validation of a suspended sediment transport model. The processes that warrant further investigation in order to improve our knowledge of circulation and suspended sediment transport in the New Caledonia lagoon as well as in other coral reef areas are discussed, as are the relevance and reliability of the numerical models for this endeavour.
\end{abstract}

() 2010 Elsevier Ltd. All rights reserved.

\section{Introduction}

\footnotetext{
* Corresponding author at: Université de Toulouse, UPS (OMP-PCA), LEGOS, 14 av. Edouard Belin, Toulouse F-31400, France. Tel.: +33 561332902.

E-mail addresses: sylvain.ouillon@ird.fr (S. Ouillon), pascal.douillet@ird.fr (P. Douillet), j-p.lefebvre@orange.fr (J.P. Lefebvre), romain.le.gendre@ird.fr (R. Le Gendre), a.jouon@epoc-u.bordeaux1.fr (A. Jouon), p.bonneton@epoc-u.bordeaux1.fr (P. Bonneton), fernand@noumea.ird.nc (J.M. Fernandez), christophe.chevillon@province-sud.nc (C. Chevillon), magand@lgge.obs.ujf-grenoble.fr (O. Magand), lefevre@noumea.ird.nc (J. Lefèvre), plehir@ifremer.fr (P. Le Hir), richard.laganier@univparis-diderot.fr (R. Laganier), franck.dumas@ifremer.fr (F. Dumas), patrick.marchesiello@ird.fr (P. Marchesiello), abelmadani@gmail.com (A. Bel Madani), andrefou@noumea.ird.nc (S. Andréfouët), panche@noumea.ird.nc (J.Y. Panché), renaud.fichez@ird.fr (R. Fichez).
}

\subsection{General}

A main interest (and also difficulty) of scientific research in coastal waters is due to the overlap of large variety of biotic and abiotic processes, the biological richness of these systems, the socio-economic importance of these areas and the interrelationship between all these factors. Particle dynamics is a topic which illustrates this complexity. The south-west lagoon of New Caledonia is of particular interest because it is typical example of a South Pacific barrier reef lagoon. In addition, sediment transport is intrinsically 
linked with metal contamination resulting from industrial and urban waste, coastal management, changes in land use and, above all, mining activities, all of which have an impact on the lagoon ecosystem.

New Caledonia is currently the third largest producer of nickel in the world. The saprolitic layers and enriched laterites have been exploited for more than a century using the opencast mining technique. Moreover, the prospecting and open cast mining on the hilltops has resulted in major alterations to landscape and habitat strongly enhancing natural soil erosion and subsequent river transport of terrigenous material and associated metals toward the lagoon (Bird et al., 1984). Although all pelagic and benthic communities are affected to some extent by the increases in sediment deposition and decreases in light penetration, fringing reefs are especially sensitive to these changes.

This paper synthesizes findings from the 2000-2008 French "Programme National Environnement Côtier" (PNEC) relative to the circulation and the transport of suspended particles in the south-west lagoon of New Caledonia. The questions asked in this project are detailed in Section 1.2. Section 2 presents the study area, its geomorphology, climate, temperature and salinity climatology, tide and wave regimes. Hydrodynamic results (circulation, residence time, exchanges with the ocean, wind waves, atmospheric forcing) are presented and discussed in Section 3. After a detailed presentation of the lagoon sedimentology, Section 4 deals with suspended sediment transport. This section analyzes the spatial and temporal variability of turbidity, the grain size distribution of suspended particles, the optical measurements, modelling of sediment transport, erodibility of sediment beds, and ends with a sedimentary budget.

\subsection{Historic studies and the PNEC program}

The Institute of Research for Development (IRD, formerly called ORSTOM) initiated a pluridisciplinary scientific program ("ECOTROPE") in 1996 to study the impact of anthropogenic activities on the functioning of the south-west lagoon of New Caledonia (e.g. Bujan et al., 2000). Based on ECOTROPE, the PNEC funded a large interdisciplinary study where scientists from the IRD and other French scientific institutions such as the universities and CNRS worked together to improve our knowledge of its physical, chemical, biological functioning in relation to its use.

Physical processes in coral reef lagoons have already been individually studied in detail and the variability of some physical parameters have been synthesized. Hydrodynamics has been widely studied (Wolanski and Pickard, 1985; Hearn and Parker, 1988; Atkinson et al., 1992), occasionally on the basis of numerical models (Smith, 1985; Frith and Mason, 1986; Prager, 1991; Tartinville et al., 1997; Kraines et al., 1998, 1999; Douillet et al., 2001). Wave-associated processes in lagoons have been investigated by, e.g. Hardy (1993), Symonds et al. (1995), Hearn (1999), Callaghan et al. (2006). The impact of hydrodynamics on lagoon functioning was analyzed by Bradbury and Young (1981), Hamner and Wolanski (1988), Roberts et al. (1992), Wolanski (2001). Studies have also dedicated to variability in temperature (Liston et al., 1992; Nadaoka et al., 2001a; Ouillon et al., 2005) and in salinity (Ouillon et al., 2005) in lagoons. Among coastal systems, coral reefs are thought to be particularly vulnerable to the amount of sediment provided by anthropogenic activities (Smith and Buddenmeier, 1992). As sedimentation is a potential factor driving reef degradation (Rogers, 1990), sediment transport and fluxes have been monitored and analyzed over coral reef lagoons (Hamilton, 1994; Larcombe et al., 1995, 2001; Orpin et al., 1999; Kraines et al., 2001), with some studies describing and quantifying the impact of storms and hurricanes on sediments (Bonem, 1988; Gagan et al., 1990). Although the variability of suspended matter concen- trations at different time scales has been analyzed in continental shelves and bays (Castaing et al., 1999; Schoellhamer, 2002), few authors have conducted such studies in coral reef lagoons (Thomas et al., 2003).

Even if physical processes in reef lagoons have been investigated, few studies have yet presented integrated physical functioning of coral reefs over areas of great extent, with the exception of the Great Barrier Reef (Wolanski, 1994). Macroscale processes influence large portions of a continental shelf, mesoscale processes determine the degree to which individual reef systems are connected to their oceanic environment, and microscale processes affect zones within reefs (Andrews and Pickard, 1990). Physical analysis integrating temperature, salinity, currents and waves have been presented by Wing and Leichter (1997) and Nadaoka et al. (2001b). However, it is clear that additional integrated physical studies of reefs at different scales and over extended periods are needed. This paper is an attempt to summarize and synthesize the physical studies (circulation and suspended sediment transport) which were performed in the south-west lagoon of New Caledonia.

This program follows on from research funded by the IRD and from the French National Program on Coral Reefs, led by Jacques Clavier and Renaud Fichez. During these two programs, a large number of hydrological and current measurements were made (Douillet et al., 1989, 1990), enabling the set up a 2D model of tide propagation (Douillet, 1998) followed by the development of a 3D model of hydrodynamics in collaboration with Ifremer. At the same time, the leading paper by Hearn (2001) of the special issue of Coral Reefs devoted to "Coral reef hydrodynamics" highlighted the context and importance of such studies. Hearn explained that the 9th International Coral Reef Symposium in Bali in 2000 saw for the first time a session devoted entirely to hydrodynamics that "in a sense, marked the coming of age of 'coral reef hydrodynamics' ". Obviously, prior to this conference, scientists had not been ignoring the study of lagoon hydrodynamics, particularly given the nuclear testing that was carried out by the United States and France in some Pacific atolls (e.g. von Arx, 1948). Andrews and Pickard (1990) wrote a brilliant synthesis of this pioneer work on lagoon hydrodynamics. However, the massive coral bleaching episodes in the 1980's and that of the El Niño event of 1997-98 brought renewed interest in the physics, biology, chemistry and ecology of coral reef environments.

The physics-focused paper published in the special issue of Coral Reefs, Douillet et al. (2001), presented the first application of a 3D model of fine suspended sediment transport in the south-west lagoon of New Caledonia and posed the central questions relevant to this review:

(1) What kind of easy-to-use parameters can we propose for characterization of hydrodynamics for chemical or biological applications?

(2) Is it possible to estimate the fluxes of water and momentum above the barrier reef induced by the swell surge?

(3) Is it possible to estimate the wind wave action on resuspension within the lagoon?

(4) How can we take into account a realistic wind stress field rather than a uniform stress in the circulation model (in relation with orographic effects)?

(5) What is the size distribution of in-water particles and their density?

(6) What is the sediment erodibility and how can it be connected to sedimentological parameters?

These questions were approached progressively during the PNEC program from 2000 to 2008. The answers are synthesized in the present paper. As always in research, the initial questions 
have evolved and some new directions that may help structure of future research are given at the end of the paper.

\section{The study area}

\subsection{Geomorphology}

New Caledonia is located $1500 \mathrm{~km}$ east of Australia, at the southern end of the Melanesian Arc near the Tropic of Capricorn (Fig. 1). The main island is surrounded by barrier reefs that delimit large lagoon areas. The reefs of New Caledonia cover a total area of $4537 \mathrm{~km}^{2}$ and the non reef areas (lagoons, terraces, enclosed basins and inlets) $31,336 \mathrm{~km}^{2}$ (Andréfouët et al., 2009).

Most of the population lives along the shore of the south-west lagoon where Nouméa, the main city, is located. Geomorphologically, the lagoon is funnel shaped, with the coast on the eastern side and the barrier reef on the west side. The distance from the coast to the barrier ranges from $5 \mathrm{~km}$ (at North) to $40 \mathrm{~km}$ (at South; see Fig. 1) and the length along the North-West-South-East axis is about $100 \mathrm{~km}$. Deep channels cut the barrier reef with the crest emergent during the lowest tides. This area is called the southwest lagoon of New Caledonia (hereafter denoted SLNC). Its mean water depth is $17.5 \mathrm{~m}$, but maximum depths of about $60 \mathrm{~m}$ are observed in narrow canyons located in the channels.

The SLNC is open to the southern lagoon at its southeastern end where it receives the main input of oceanic waters. The tides are mainly semi-diurnal with a tidal range varying from about $1.4 \mathrm{~m}$ at spring to $0.6 \mathrm{~m}$ at neap (Douillet, 1998).

Three geomorphological zones can be distinguished: the bays or inner lagoon, the outer lagoon, and the inner reef (Dandonneau et al., 1981). The current morphology of the SLNC results from the last great variation of sea level which occurred during the Würmien Ice Age $(18,000$ years BP). When sea level was about $120 \mathrm{~m}$ below the current zero, valleys, canyons and channels in the lagoon and in the reef barrier were created (Coudray, 1975).

In the south-western part of the mainland of New Caledonia, soils are composed of peridotites, harzburgites with orthopyroxenes composed of magnesium and iron silicates, and infiltrated by transition metals like $\mathrm{Ni}, \mathrm{Co}, \mathrm{Cr}$, Fe and Mn (Lillie and Brothers, 1970; Paris, 1981). The weathering of peridotites results in the formation of nickel- and iron-rich smectites, serpentine, goethite and hematite (Trescases, 1973), and in the migration of transition met- als. The latter are strongly concentrated along the weathered profile in the saprolite (also called "garnierite") and laterite layers which are subject to mining extraction (Fernandez et al., 2006). The extensive extraction method requires, initially, the elimination of vegetation, the extraction of the ferralitic layer, followed by the laterites of low content before reaching the exploitable saprolites. This method produces significant volumes of deads (approximately 2.5 times the volume of actually exploited ore), that are generally left next to the extraction site or are contained by filtering dams of uncertain efficiency (Fernandez et al., 2006). It is estimated that a total of $300 \mathrm{M} \mathrm{m}^{3}$ of soil has been displaced by direct extraction since the beginning of mining activities (Labrosse et al., 2000).

\subsection{Climate, rainfall and river discharge}

Climate in New Caledonia is mainly characterized by a dry-tropical regime with alternation of dry and wet seasons. The system is strongly influenced by the El Niño Southern Oscillation (ENSO), has south-easterly trade winds, irregular rainfall, episodic cyclones, long swell coming irregularly from the South and South-East, and torrential hydrological regimes.

Climate is mainly constrained by the position of the Intertropical Convergence Zone (ITCZ) and South Pacific Convergence Zone (SPCZ) (Pesin et al., 1995). From January to March (warm season), the ITCZ is in its southernmost position, rainfall is heavy and tropical storms or cyclones can affect New Caledonia. When the ITCZ moves to the northern hemisphere (mid-May to mid-September) cold fronts carrying polar air from the Tasman Sea can occasionally bring heavy rainfall. The intermediate periods (April-May and September-December) are characterized by sunny and dry weather.

Mean seasonal variations of wind regime are characterized by two major seasons (Pesin et al., 1995). From October to May, south-easterly $\left(\sim 110^{\circ}\right)$ trade winds dominate with a mean velocity of $\sim 7 \mathrm{~m} \mathrm{~s}^{-1}$. From June to September, wind velocity is weaker and direction is more variable. Inter-annual variations elicit stronger (weaker) winds during El Niño (La Niña) (Ouillon et al., 2005).

Average freshwater inputs to the lagoon are weak since the catchment areas are small and, when freshwater inputs occur, they are generally reduced to a period of a few days at most. The main freshwater inputs to the SLNC come principally from the Dumbera River (drainage area: $\left.238 \mathrm{~km}^{2}\right)$, La Coulée River $\left(85 \mathrm{~km}^{2}\right)$ and Les Pirogues River $\left(140 \mathrm{~km}^{2}\right)$ (Fig. 1). Over the 1997-2001 period,

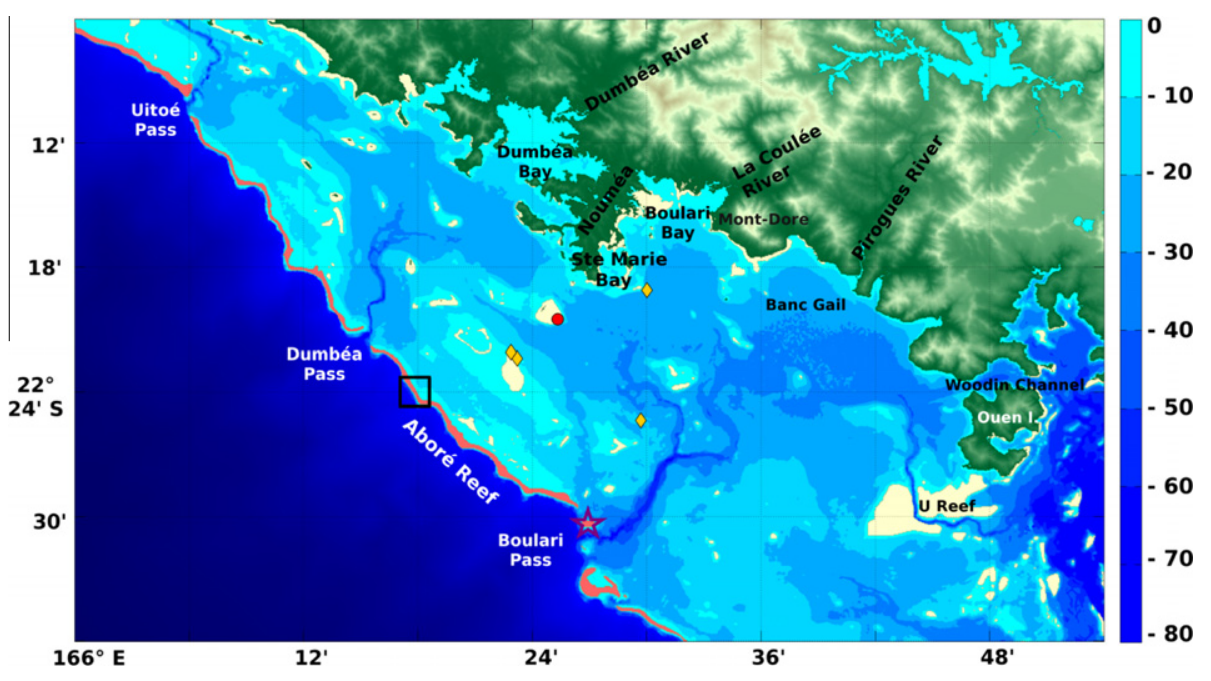

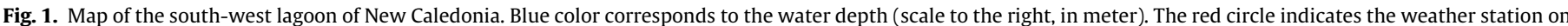

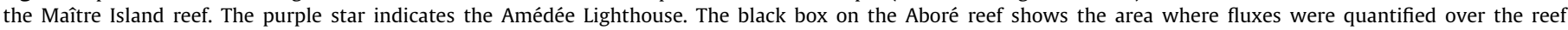
(Section 3.3). Wave measuring locations are shown by yellow diamonds (Section 3.4). 
mean flows were $11.5 \mathrm{~m}^{3} \mathrm{~s}^{-1}$ for the Dumbéa River, $3.5 \mathrm{~m}^{3} \mathrm{~s}^{-1}$ for the Coulee River and $5.2 \mathrm{~m}^{3} \mathrm{~s}^{-1}$ for the Pirogues River; mean monthly discharges are shown on Fig. 2. The 5-year period is too short to estimate long-term values because of the high inter-annual variability of rainfall and river discharge and because it included both one El Niño and one La Niña events (Ouillon et al., 2005). However, the order of magnitude of river discharge can be compared to the flow of ocean water entering and leaving the SLNC resulting from tidal currents and trade wind-induced circulation. Ocean water flow is generally on the order of $80,000 \mathrm{~m}^{3} \mathrm{~s}^{-1}$ regardless of water inputs over the reef (Jouon et al., 2006) and so the lagoon waters are therefore mainly of oceanic origin.

Rainfall and river discharge vary from one year to another significantly. Nicet and Delcroix (2000) analyzed the correlation between anomalies in precipitation or river discharge in New Caledonia with the Southern Oscillation Index (SOI), which is a good indicator of ENSO variations. They showed that: (1) ENSO modulates rainfall regime in New Caledonia with a $20-50 \%$ decrease (increase) during El Niño (La Niña) events; (2) the flow rate of two rivers at the north end of the SLNC can almost double during La Niña and decrease by more than 50\% during El Niño; (3) the best lagged correlations are obtained when SOI leads rainfall by 23 months and river flow rates by 3-6 months.

The major rivers of the south-western part of New Caledonia are characterized by an upper course with abrupt relief and a lower course made up of piedmont deposits and bedrock weathering material. Due to the torrential regime, sediment supply is very low in the absence of rainfall because of the low flow energy (Baltzer and Trescases, 1971b; Dugas and Debenay, 1982). On the contrary, as rainfall can reach up to $700 \mathrm{~mm}$ in $24 \mathrm{~h}$, the induced intense weathering results in extremely high quantities of suspended matter. In one $24 \mathrm{~h}$ period, more than 20,000 tonnes of solid matter were delivered by the Dumbéa River during cyclone Brenda in 1968 (Baltzer and Trescases, 1971a). These particles strongly colour the river waters and plume and can be visible by spatial observations.

\subsection{Temperature and salinity}

To understand the main variations in temperature and salinity within the lagoon under non-storm conditions, it is necessary to compare their distributions against seasonal and ENSO-related variations of oceanic SSS (Sea Surface Salinity) and SST (Sea Surface Tem- perature) outside the lagoon, which were described by Gouriou and Delcroix (2002). This analysis was proposed by Ouillon et al. (2005) based on 20 field surveys spanning a 4-year period (1997-2001).

They concluded that ENSO related regional SSS anomalies $(\sim 0.2)$ were twice as large as the seasonal variations and that this brought less saline waters into the lagoon during a La Niña event. The SSS in coastal areas was also influenced by the meteorological and hydrological consequences of ENSO with salinity differences within the lagoon $(<0.5)$ varying less than the seasonal (0.7) and inter-annual (up to 0.8 ) variations of mean monthly SSS near shore. During El Niño, freshwater inputs are low, and evaporation is enhanced due to stronger winds and to a reduced cloud cover. This induces inverted horizontal salt gradients in summer resulting in saltier waters in the bays than in the lagoon. During the La Niña events, freshwater inputs increase and evaporation decreases leading to much lower salinity in coastal zones than in the lagoon. Thus salinity varies in the same way near shore as on a regional scale, with variations amplified due to the meteorological and hydrological influence of ENSO.

Seasonal changes in SST in the lagoon are larger than inter-annual variations. The spatial distribution of temperature presents cross-shore temperature gradients that inverse seasonally. Temperature is higher in the bays and near the coast than in the lagoon during summer. The inverse is true in winter. Temperature thus varies similarly in the lagoon as in the region with seasonal variations amplified nearshore. ENSO related nearshore temperature variations parallel those on the regional scale, but with seasonal variations amplified. The saltier waters in the bays during an El Niño summer were also warmer with the cross-shore temperature difference being at its maximum $\left(>2{ }^{\circ} \mathrm{C}\right.$ in December 1997; Ouillon et al., 2005).

Thermal stratification sets up during the warm and dry season from October to December and a thermo-haline stratification is observed during the warm and wet season from January to April. The existence of a haline stratification all the year long depends on the river discharges and is thus more likely during La Niña periods. Thermo-haline stratification is thus enhanced in summer during La Niña periods. Haline stratification, if any, is enhanced in coastal areas.

Accordingly, the bays and coastal zones amplify seasonal and inter-annual regional salinity variations due to ENSO and amplify the regional variations of temperature leading to higher crossshore thermal gradients in summer during El Niño.

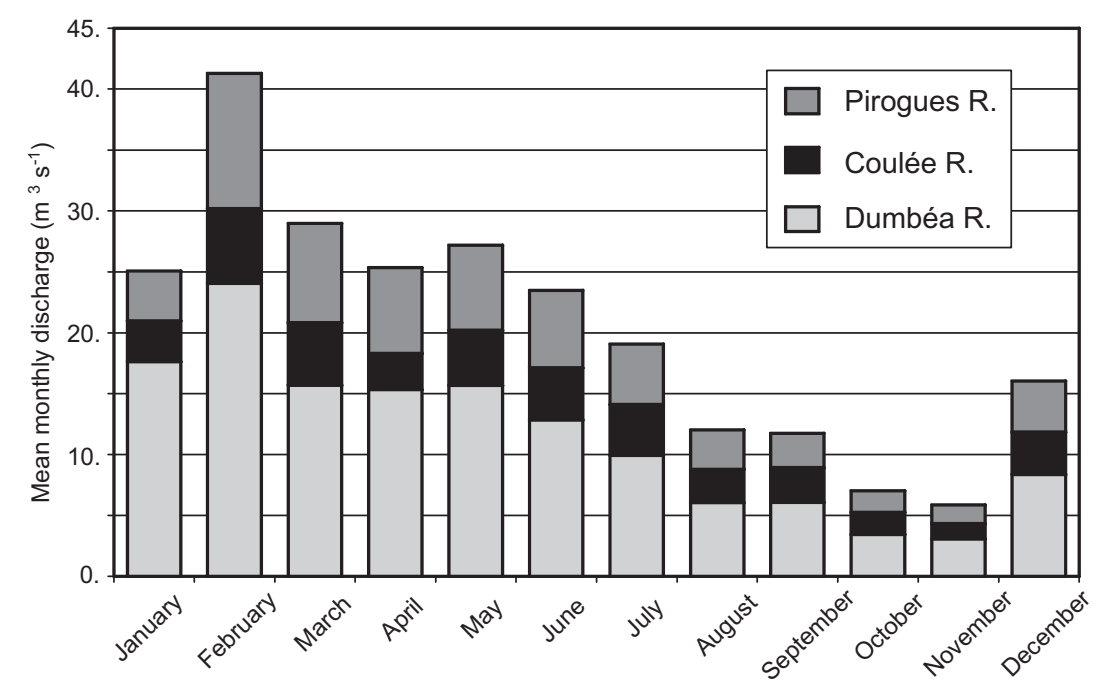

Fig. 2. Mean monthly discharge of the Pirogues, Coulée and Dumbéa Rivers calculated for the period 1997-2001. 


\subsection{Tide and wave regimes}

The harmonic analysis of tidal gauge measurements showed that $\mathrm{M}_{2}$ is the dominant tidal signal in the SLNC (roughly $3 \times \mathrm{K}_{1}$, $5 \times \mathrm{O}_{1}, 9 \times \mathrm{P}_{1}, 5 \times \mathrm{N}_{2}, 3 \times \mathrm{S}_{2}$ ) (Douillet, 1998). Using the amplitude ratio $\left(\mathrm{O}_{1}+\mathrm{K}_{1}\right) /\left(\mathrm{M}_{2}+\mathrm{S}_{2}\right)$, the tide is determined as mixed and mainly semi-diurnal. Tidal streams are mostly generated by the $\mathrm{M}_{2}$ constituent. Amplitude and phase of $\mathrm{M}_{2}$ increases regularly from the South to the North (Douillet, 1998). Mean tidal current velocity is about $0.05-0.1 \mathrm{~m} \mathrm{~s}^{-1}$ inside the lagoon and about $0.2-$ $0.3 \mathrm{~m} \mathrm{~s}^{-1}$ in the passages (Jarrige et al., 1975; Douillet et al., 1989). $M_{2}$ currents are maximum in the South and in the passages. Currents generated by $S_{2}$ are one third of $M_{2}$, and those by $K_{1}$ are one tenth of $\mathrm{M}_{2}\left(\approx 0.01 \mathrm{~m} \mathrm{~s}^{-1}\right)$, except at the inlets. $\mathrm{S}_{2}$ amplitude increases from South to North more slowly than $\mathrm{M}_{2} . \mathrm{S}_{2}$ propagates from North-West to South-East. $S_{2}$ currents are around $0.03 \mathrm{~m} \mathrm{~s}^{-1}$ over most of the lagoon but can locally reach $0.1 \mathrm{~m} \mathrm{~s}^{-1}$ at the inlets.

Waves in the lagoon have two origins: the oceanic swell that penetrates into the lagoon and the wind-waves that develop within the lagoon. Oceanic swell breaks along the barrier reef and penetrates through the passages. Swell breaking induces fluxes of water and momentum to the lagoon (see Section 3.3). To our knowledge, no specific review of wave climate around New Caledonia has been performed. However some parameters can be estimated from the available world wave climatologies obtained from a combination of satellite remote sensing and model predictions (e.g. Young, 1999) or from model reanalysis (Sterl and Caires, 2005; Caires et al., 2005). The mean yearly significant wave height is approximately $2 \mathrm{~m}$ (Young, 1999) or $2.1 \mathrm{~m}$ (Caires et al., 2005). Three periods can be roughly distinguished from Caires et al. (2005): the highest swell comes from the South-South-East between March and May (mean monthly values range: $2.3-2.4 \mathrm{~m}$ ), high swell also occurs from June to September and comes from the South (2.1-2.2 m), and the lowest swell comes from the South-East between October and January (1.9-2 m). Estimations of the mean yearly wave period around the southern part of New Caledonia ranges from $7.1 \mathrm{~s}$ (Caires et al., 2005) to $8.7 \mathrm{~s}$ (Young, 1999), with slightly longer periods from March to October than from November to February but the differences are on average low (around $0.4 \mathrm{~s}$ between the lowest and the highest mean monthly wave periods). The influence of swell inside the lagoon strongly depends on its direction. Short episodes of westerly swell bring high energy up to the shore of the SLNC. The impact of other swell conditions is generally less important and strongly depends on the vicinity to the inlets and, sometimes, to the barrier reef (see Section 3.3).

Wind waves quickly develop and propagate in the lagoon. No wind wave climatology in the lagoon of New Caledonia is yet available in the literature. The highest wind waves in the outer lagoon occur when the fetch is the longest, i.e. during south-easterly trade wind episodes. During these episodes, the significant wave height and period in the SLNC are typically between 0.8 and $1.4 \mathrm{~m}$ and around $3 \mathrm{~s}$, respectively (Jouon et al., 2009 - see also Section 3.4). The highest wind waves near shore are observed during the short and highly energetic episodes of westerly wind and, obviously, during cyclones.

\section{Hydrodynamic characterization}

\subsection{Circulation}

Hydrodynamics in the SLNC has been studied for 30 years. The first analysis showed that wind and tide were the main forces generating circulation (Jarrige et al., 1975; Morlière and Crémoux,
1981; Morlière, 1985; Rougerie, 1985). Intensive measurements of tide, wind and currents were performed at the end of the 1980's (Douillet et al., 1989, 1990). During the 1990's, a 3D hydrodynamic model precursor of MARS3D developed by IFREMER (Lazure and Salomon, 1991; Lazure and Dumas, 2008) was adapted and validated for the SLNC (Douillet, 1998).

The governing equations of the hydrodynamic model express the conservation of mass, momentum and salinity, and assume the hydrostatic and Boussinesq approximations. The equations are solved in the $\sigma$-coordinate system using a finite difference technique and the resolution is based on the mode splitting technique (Blumberg and Mellor, 1987). The version used at the beginning of the PNEC program involved a mixing length turbulence model (Douillet et al., 2001). The mesh grid extended from the south of the main island to the north of Nouméa under an alongshore distance of $150 \mathrm{~km}$, the horizontal grid size was $500 \mathrm{~m}$ and each water column was divided into $10 \sigma$-levels (Douillet, 1998; Douillet et al., 2001). This model was one of the first 3D models applied to hydrodynamics in coral reef environments after Tartinville et al. (1997). This 3D hydrodynamic model was also used to calculate the fluxes within the lagoon in a 3D biogeochemical model (Pinazo et al., 2004).

The semi-diurnal tide propagates from the South to the North (Douillet, 1998). Local south-easterly trade winds drive a general North-West drift (Douillet et al., 2001). Response of the dynamics to the wind action is fast. In the absence of local wind, velocity at $20 \mathrm{~m}$ depth shows two peaks per tidal cycle during flood and ebb. During trade wind episodes, velocity direction in the lagoon remains in the same quadrant and presents only one significant peak during flood. Trade winds generate a strong sub-surface gyre north of Ouen Island (Fig. 3b). Blowing from the south-east, wind drives the surface water to the North-West which creates a gradient in the sea-surface. A sub-surface return current develops along the coast to equilibrate the pressure gradient and feeds the subsurface gyre (Douillet et al., 2001).

The long term tidal water displacement is well described by the mean lagrangian residual velocity. Its value for the $M_{2}$ constituent (Fig. 3a) can locally reach $0.03 \mathrm{~m} \mathrm{~s}^{-1}$, but is generally close to $0.01 \mathrm{~m} \mathrm{~s}^{-1}$ (Douillet, 1998). Water mainly enters the SLNC at the South between Ouen Island and the barrier reef. One part flows directly to the passage while the other part flows northwards and leaves the lagoon by the Dumbéa pass. A cape effect generates a vortex on the West side of Ouen Island and near shore, residual currents are weak. Considering long term transport, the lagrangian residual velocity generated by the tidal circulation is one order of magnitude lower than the mean vertical current due to trade winds (Fig. $3 \mathrm{a}$ and $\mathrm{b}$ ). Although instantaneous tide-induced and wind-induced currents are of the same order, the tidal lagrangian residual velocity is around $1 \mathrm{~cm} \mathrm{~s}^{-1}$ whereas wind-induced velocity is $10 \mathrm{~cm} \mathrm{~s}^{-1}$ or higher.

Tide- and wind-induced circulation flushes the lagoon which empties through the inlets. Over the reef, the flow may alternatively enter and leave the lagoon during trade wind episodes. Under West wind or weak wind, when the oceanic swell is high, flow can be positive towards the lagoon above the reef regardless of the tidal period (see Section 3.3). This flow and the corresponding setup generate a current along the internal reef which flushes the white sand areas and leaves the lagoon through the inlets.

In 2007-2008, an exercise of model validation was performed using drifters (Niiler et al., 1995). Monitoring of water layers by means of Argos drifters attached to a weighted drogue ('holey sock') is mainly used in coastal oceanography to investigate rip currents (e.g. Kennedy and Thomas, 2004; Reniers et al., 2007). The thickness of layers to be monitored was fixed to $5 \mathrm{~m}$ and the $15 \mathrm{~m}$ sock was cut accordingly. Tests have been conducted to estimate the vertical shear and the variation of vertical position 

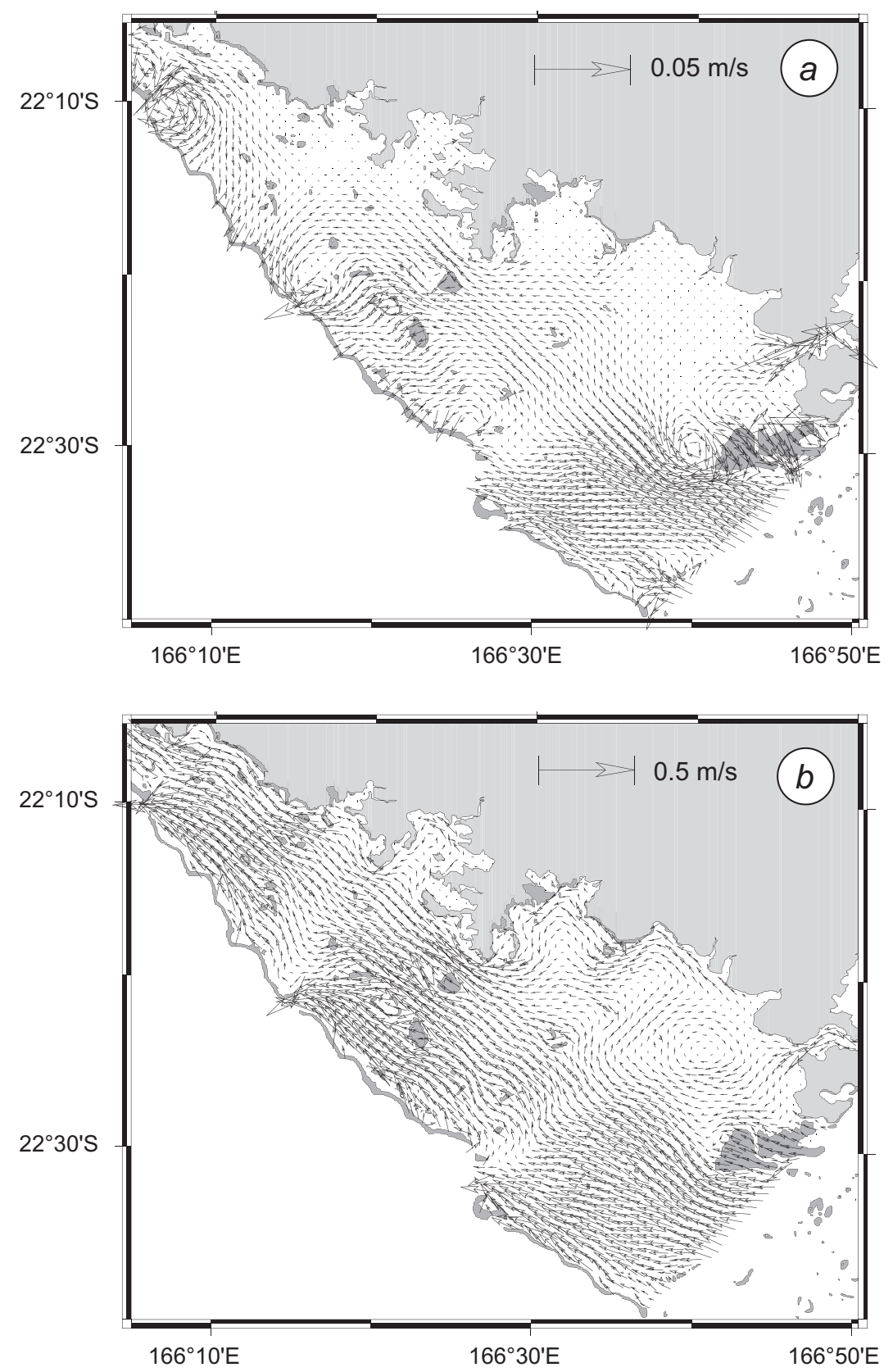

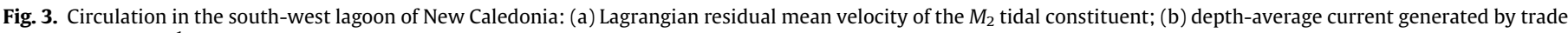
wind $\left(110^{\circ}, 8 \mathrm{~m} \mathrm{~s}^{-1}\right)$ with no tide.

around the nominal depth of the sock. A pressure gauge (precision pressure sensor, Drück) and acoustic Doppler velocimeter (ADV, Sontek) have been alternatively fixed to the top and at the bottom of the drifter. The results showed that, apart from when the drifter contacted the seabed as detected by the velocity deduced from Argos positions, the slip and variation of height in the water column of the drifters were negligible, compared to mean monitored velocity and wave heights. Comparisons were performed between measurements and simulations for the trajectories and velocities and an example is given in Fig. 4. The analysis of combined drifter experiments and numerical simulations in the SLNC is in progress.

\subsection{Residence time}

The immediate products of a 3D hydrodynamic model such as current fields or fluxes between boxes are not always useful for chemical, geochemical, biological or ecological applications where only simple indicators of dynamics are required. These data are often a consequence of the transformation processes, chemical reactions, and mechanisms of exchange between benthos and pelagos or between dissolved and particulate elements that are applied to the water mass after its entrance into the lagoon. It is therefore interesting to produce hydrodynamic models that provide responses on similar timescales.

This question was examined in the SLNC within the multi-disciplinary context of the PNEC. The literature on hydrodynamic time parameters refers to different variables commonly called "residence time". The paper by Jouon et al. (2006) proposed a synthesis of these global and local parameters, calculated them in the SLNC considering a simplified tide represented by $M_{2}$ and $S_{2}$ and mean constant trade wind, then compared the results. On the global scale, the water exchange time, the average export time and the 


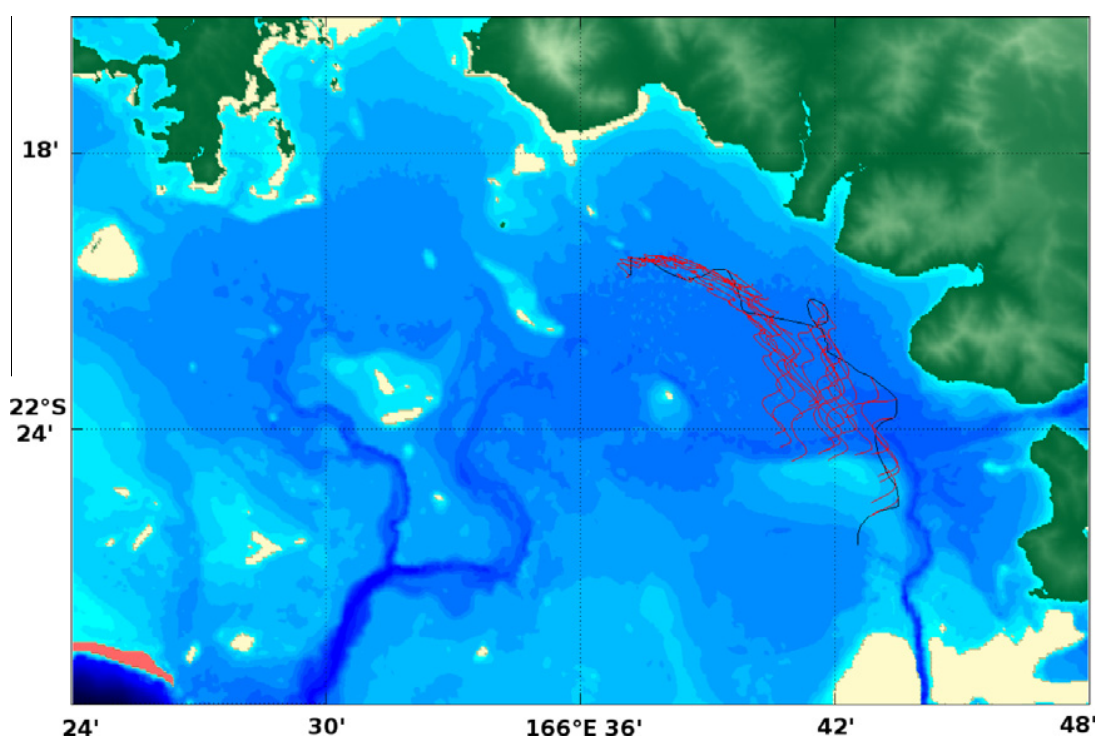

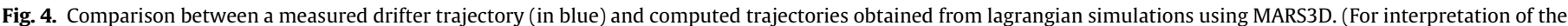
references to colour in this figure legend, the reader is referred to the web version of this article.)
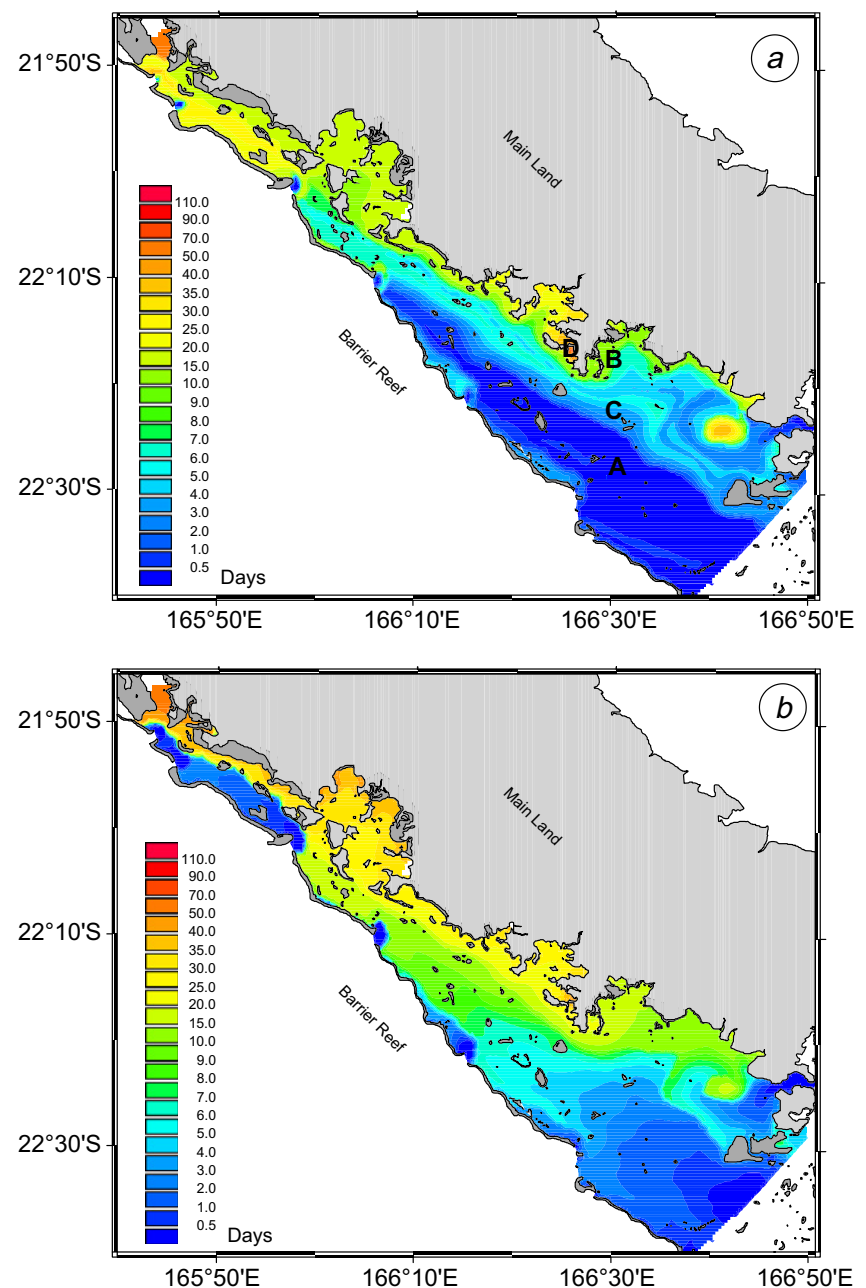

Fig. 5. Local e-flushing time (a) and flushing lag (b) within the SLNC (in days). Four main water types are distinguished from their e-flushing time. A: water rapidly renewed ( $<2$ days); B: littoral "river" flowing alongshore (residence time of 925 days); $C$ : intermediate waters resulting from the tidal mixing of types $A$ and $B$ waters (residence time of 2-9 days); D: long residence waters at the head of bays (residence time $>25$ days). e-flushing time (as defined hereafter, in concordance with Jouon et al., 2006) were calculated over three embedded control volumes. The export time, flushing lag and local e-flushing time were also mapped over the SLNC.

Water exchange time is defined as the ratio between the total volume and the daily volume flux entering or leaving the domain. Its value is 6.8 days in the SLNC. Export time is locally defined as the time needed for a water particle to leave the lagoon, and is calculated by lagrangian tracers. Its average value over the calculation domain is called the average water export time ( 10.8 days over the SLNC).

At an initial time, the water mass in the domain is uniformly "colored" by a virtual tracer at concentration $C_{0}$, then every new water parcel entering the domain is associated to a nil concentration of that tracer. The time at which the average tracer concentration is reduced by a factor $1 / e$ is called the e-flushing time. It takes in average 12.5 days for $65 \%(\sim 1-1 / e)$ of initial water to leave the lagoon. Locally, the time needed for the concentration to be reduced by a factor $1 / e$ was called the local e-flushing time, and the one required for the concentration to be reduced by $5 \%$ (i.e. the time required for a significant amount of renewed water to reach the considered point) is called the flushing lag (Fig. 5b). The flushing lag relates to the minimum age of water mass. Its addition to the export time gives a low estimate of the transit time. The map of local e-flushing time (Fig. 5a) shows how the residence time is very heterogeneous within the lagoon, from very short values (less than one day around channels) up to two months at the head of bays. The gyre extending between the North-West of the Ouen Island and the "banc Gail" area is characterized by long eflushing time of around one month. Excepting this characteristic, the e-flushing time distribution shows four types of waters which can be distinguished from their history (Fig. 5a): water renewed very quickly, with e-flushing time less than two days and located at the South of a line running from the U Reef at the South to the Uitoé pass at the North (type A); a littoral "river" flowing alongshore, with residence time of 9-25 days, draining the waters that enter the lagoon through the Woodin channel (type B); intermediate waters between them, with residence time of 2-9 days, which result from the mixing of type $A$ and type $B$ waters by the tidal oscillation (type $\mathrm{C}$ ); and old waters with e-flushing time higher than 25 days at the head of bays (type D). 
Amongst global residence times, the average export time was shown to be nearly 0.7 times the e-flushing time in the case where concentration decrease is exponential, while the comparison between average export time and exchange time were shown to provide information on the relative effectiveness of export and exchange processes, i.e. to distinguish short transit areas and retention zones. Local residence times in a calculation domain provide more refined information about mixing, and enable the identification of areas of particular hydrodynamic regime. Calculations in the whole SLNC and in two sub-domains showed a higher sensitivity in the actual values of residence times than in the general patterns of their spatial distributions.

The study by Jouon et al. (2006) had some limitations: calculations were made considering uniform and constant wind conditions, and without the exchange of breaking oceanic swell on the reef. It is now possible to estimate the influence of waves breaking over the reef (Section 3.3) and to take into account an actual wind distribution (Section 3.5). However, taking into account true nonstationary meteorological conditions may be problematic. Despite these limits, the paper by Jouon et al. (2006) provided relevant information for the most frequent case of trade wind. Moreover, these values have recently been used to understand the dynamics of biological productivity (phytoplankton: Torréton et al., 2007; organic matter particle dynamics: Mari et al., 2007), residence time and dissolved metal concentrations (Migon et al., 2007), and as an indicator of anthropogenic influence on water quality around Noumea, in relation to the fish populations (Sasal et al., 2007).

\subsection{Flux over the barrier reef}

As waves break on a reef, they create a radiation stress gradient that drives wave-setup and wave-induced currents. These mechanisms which are typical of coral reef environments exert a major influence on the hydrodynamics, morphology and biological variability of shallow submerged reefs. Since the set-up can achieve $20 \%$ of the swell height (Tait, 1972; Gourlay, 1996), these processes

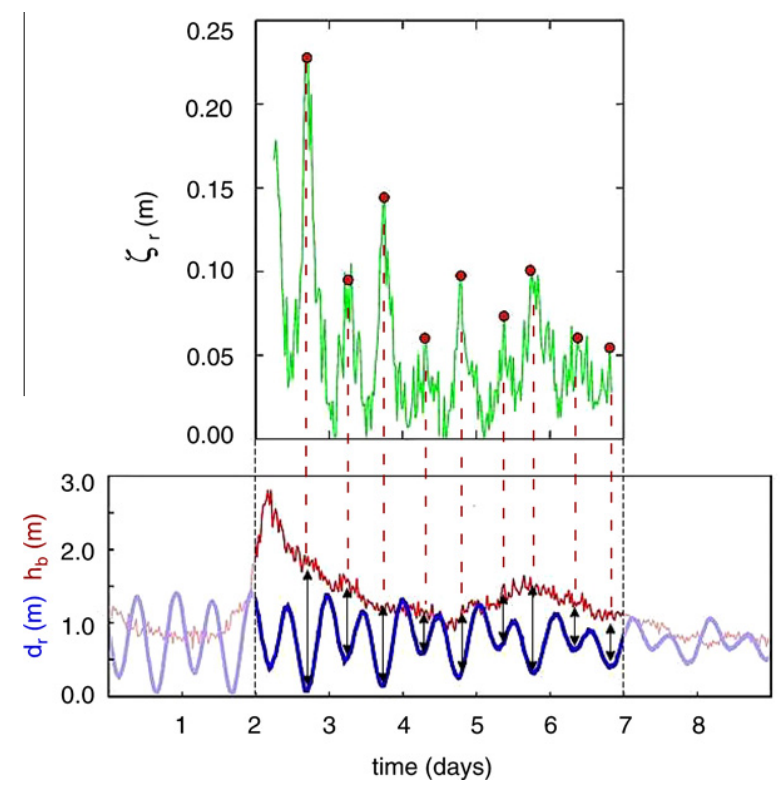

Fig. 6. Measured wave setup $\zeta_{r}$ on the reef-top (top, green line) and comparisons between the mean water depth at the reef-top (with no setup), $d_{r}$ (blue bold line) and the water height at the breaking point, $h_{b}$ (red thin line), during the experiment. In abscissa, numbers refer to successive days. The points where $\zeta_{r}$ is maximum are indicated in red on top and with arrows below. (For interpretation of the references to colour in this figure legend, the reader is referred to the web version of this article.)

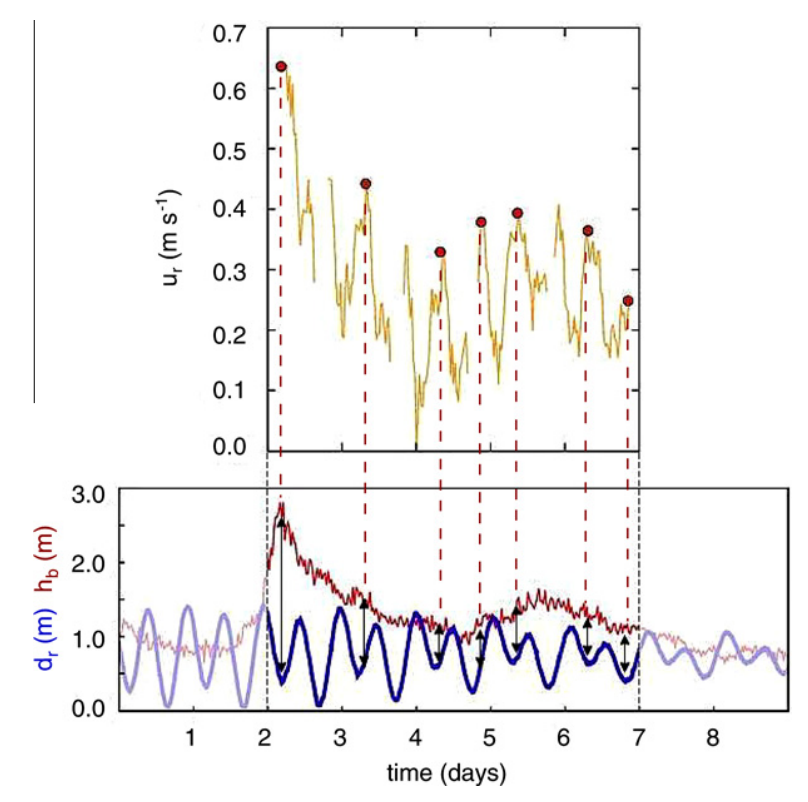

Fig. 7. Measured cross-reef current $u_{r}$ on the reef-top (top, yellow line) and comparisons between the mean water depth at the reef-top (with no setup), $d_{r}$ (blue bold line) and the water height at the breaking point, $h_{b}$ (red thin line), during the experiment. In abscissa, numbers refer to successive days. The points where $u_{r}$ is maximum are indicated in red on top and with arrows below. (For interpretation of the references to colour in this figure legend, the reader is referred to the web version of this article.)

may significantly alter the circulation and flushing of lagoons. The tidal evolution of water depth over the reef top strongly influences wave-induced phenomena (Gourlay and Colleter, 2005). However, only a few field experiments have been devoted to the analysis of both tidally modulated wave-induced current (e.g. Tartinville and Rancher, 2000) and tidally modulated wave-setup as the deployment of instruments on a reef is not simple. In the hydrodynamic model presented by Douillet et al. (2001), the exchanges between the ocean and the lagoon over the barrier reef were only schematic. Therefore, it was important to characterize wave-setup and waveinduced flows over the New Caledonia reef.

A field experiment was conducted on the Aboré coral reef in October 2005 in order to measure the wave induced flow over the reef. A series of sensors were deployed along a reef transect to obtain measurements of the cross-shore propagation of the waves. Measurements were made of the tidal level evolution and incident wave characteristics on the external reef slope by a nondirectional Wave and Tide Recorder (WTR9, Aanderaa). Velocity and pressure on the reef flat were measured using two acoustic Doppler velocimeters (ADV Vector, Nortek), each of them being coupled with two pressure sensors, and the current at the inner end of the transect was measured by a S4 InterOcean electromagnetic current meter (see the cross-shore profile in Fig. 2, Bonneton et al., 2007). The bathymetry of the study area was measured using a DGPS (Trimble 5700). Pressure measurements, corrected for atmospheric variations, were converted to water depth, and by taking in account topography elevation, to sea surface elevation $\zeta$. On the reef flat, the ratio of water depth to wavelength was very small; consistent with the shallow-water approximation, $\zeta$ was estimated assuming a hydrostatic pressure distribution.

Bonneton et al. (2007) present the first analysis of these data, focused on the first sea-state regime (from days 0 to 7 ) when cross-reef current $u_{r}$ was mainly positive (i.e. lagoonward) and reached a maximum value of $0.65 \mathrm{~m} \mathrm{~s}^{-1}$. They show that tidally modulated wave setup and wave-induced current on the Aboré reef are mainly controlled by the difference between depth at 


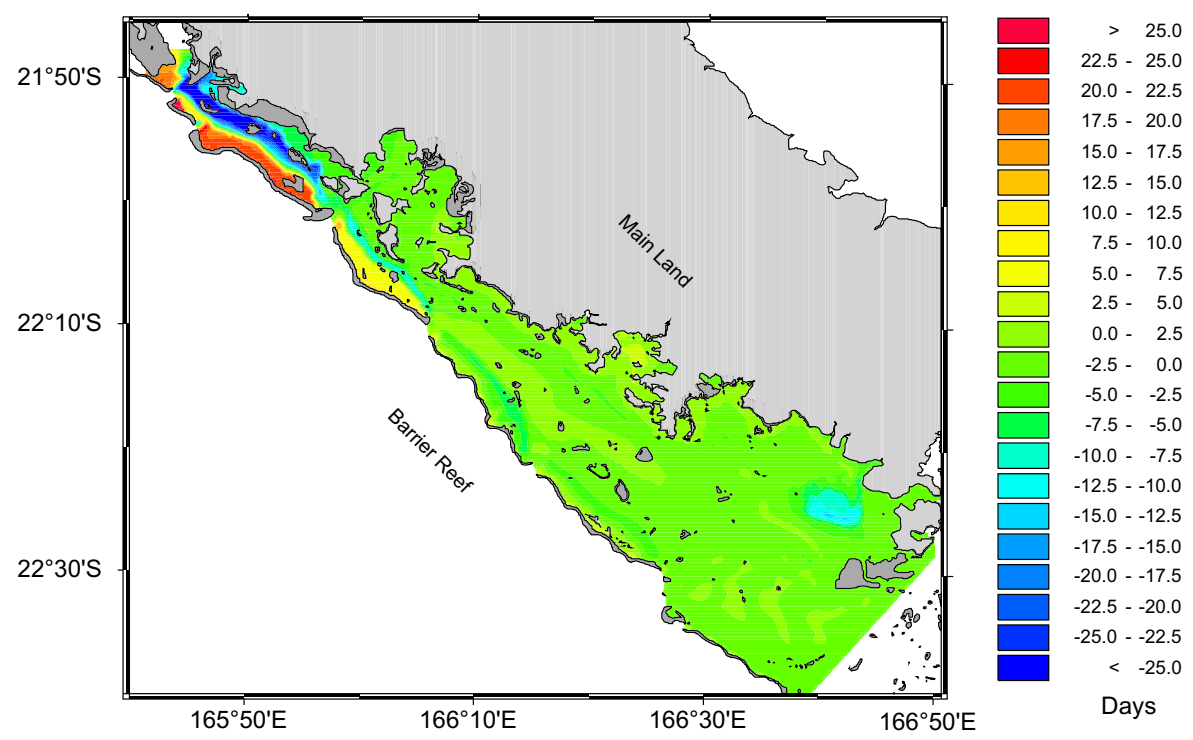

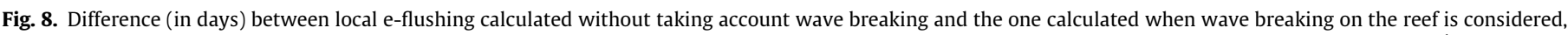

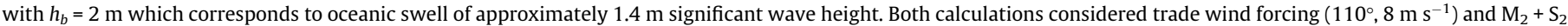
tide.

breakpoint, $h_{b}$, and the mean water depth over the reef-top (with no set-up), $d_{r}$. The wave setup was shown to evolve in agreement with the analytical model proposed by Symonds et al. (1995) following:

$\zeta_{r}=\alpha\left(h_{b}-d_{r}\right)$

with $\alpha=0.081(r=0.83)$. The cross-reef wave-induced current was shown to evolve in agreement with the analytical model proposed by Hearn (1999) following:

$u_{r}^{2}=K_{H} d_{r}\left(h_{b}-d_{r}\right)$

with $K_{H}=0.22 \mathrm{~s}^{-2}(r=0.83)$.

From Eq. (1), Bonneton et al. (2007) show that $\zeta_{r}$ is maximum when $\left(h_{b}-d_{r}\right)$ is maximum, i.e. when $d_{r}$ is minimum or near to its minimum (see red points on Fig. 6). From Eq. (2), they checked that if $\min \left(d_{r}\right)<h_{b} / 2, \max \left(u_{r}\right)$ is reached for $d_{r}=h_{b} / 2$ (see red points on Fig. 7). In the latter case, $u_{r}$ oscillates with two maxima occurring during each tidal cycle, out of phase with $d_{r}$. They also show that when min $\left(d_{r}\right)>h_{b} / 2$ (during the days 7-12, not shown on Fig. 7), there was only one maximum of $u_{r}$ per tidal cycle when $d_{r}$ was minimum, in concordance with Eq. (2), i.e. at low tide, $180^{\circ}$ out of phase with $d_{r}$.

These new results mean that reef fluxes can now be taken in account in models of lagoon hydrodynamics. This is particularly important where significant exchanges induced by the breaking of oceanic swell occur. The deriving flow is probably responsible for the flushing of the "inner slope hydraulic sand bank" (Battistini et al., 1975). The induced current may also be responsible for the spread of biogenic particles derived from the abrasion of the reef complex during wave episodes of high energy.

The resulting flux is expected to impact residence time along the inner reef. On day 2 of the experiment, during spring tide, velocity averaged over one tidal cycle was higher than $0.4 \mathrm{~m} \mathrm{~s}^{-1}$ (Fig. 7). If we extrapolate this value along the barrier reef (approximate length: $100 \mathrm{~km}$ ), the total flux of water above the reef is estimated to be $4 \times 10^{4} \mathrm{~m}^{3} \mathrm{~s}^{-1}$. This value corresponds to one third of the incoming tide-related fluxes from the South and the inlets during spring tide. From days 3 to 7, averaged velocity ranged from 0.15 to $0.25 \mathrm{~m} \mathrm{~s}^{-1}$, and the flux was between 1.5 and 2.5 $10^{4} \mathrm{~m}^{3} \mathrm{~s}^{-1}$, i.e. around $20 \%$ of the incoming flux from the South and through the inlets between spring and neap tide. These estimations indicate that residence time must be significantly changed in this case.

Simulations taking into account the water inputs through the barrier reef were performed. The velocity given by Eq. (2) was added at each grid points of the barrier reef to the currents calculated by the hydrodynamic model, after each time step. The difference between the local e-flushing time without taking account wave breaking and the one calculated taking into account wave breaking is mapped on Fig. 8. These preliminary results show that when waves break on the reef, residence time changes significantly along the barrier reef in the northern inner reef where water renewal is dramatically constrained by narrow passages. Along the southern part of the reef the decrease is less important since water is mainly renewed from the water entrance to the South and above all because the e-flushing time was very low. It decreases from 45 days without wave breaking to $\sim 1$ day with wave breaking in the behind Aboré reef area. In contrast, between the inner reef and the outer lagoon, residence time increases by 3-5 days. Along the coast and in the bays, the change in residence time is very low and almost uniformly distributed and the spatial patterns of residence time are not altered. The gyre with long residence time which extends to the West of the Woodin channel is probably slightly enlarged. The flushing lag (not shown) drops off in the back-reef areas far from the passages. The full analysis of the results is still underway and the complete results will be submitted for publication.

The paper by Bonneton et al. (2007) quantified the global mass and momentum fluxes over the reef in case of weak wind and high oceanic swell propagating nearly normally to the reef as encountered during the first week of measurement. The applicability of a wave pumping model by Callaghan et al. (2006) to our dataset and a finer analysis of the wave transformation processes over the reef (Bonneton et al., 2008) are being determined.

\subsection{Wind waves}

Apart from river inputs which are very episodic, the main mechanism responsible for turbidity is the combined effect of waves and currents in resuspension of particles (Clavier et al., 1995). Under 


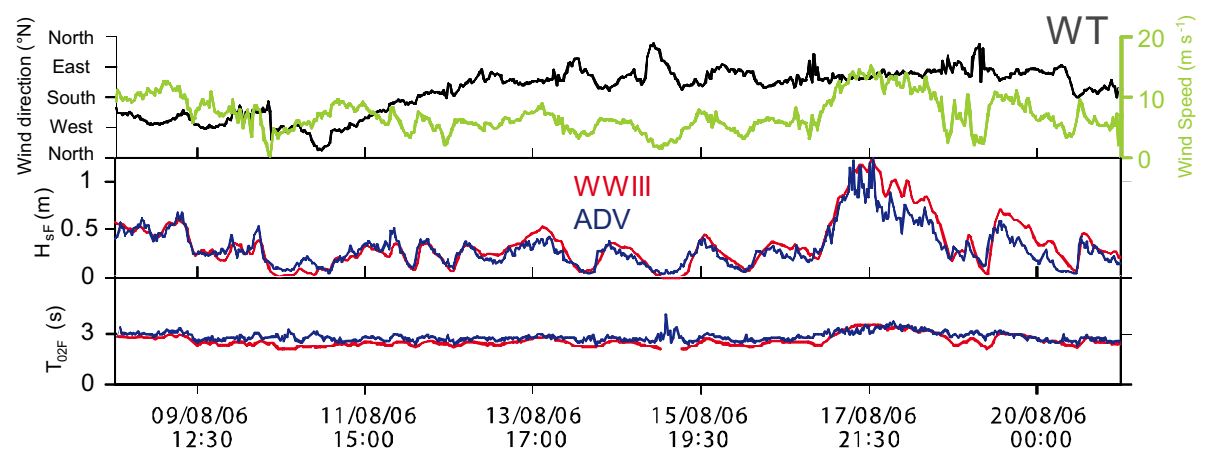

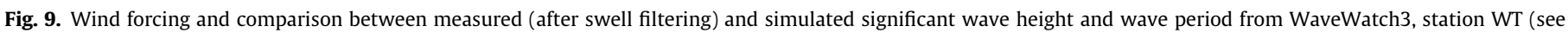
location Fig. 10), August 8-21, 2006.

usual wind conditions, resuspension is particularly significant where the water depth is less than approximately $20 \mathrm{~m}$ similar to the situation in the Great Barrier Reef area (Larcombe et al., 1995, 2001). At greater depths, the effect of waves becomes negligible, except during storms. Studying particulate transport thus also requires studying generation and propagation of wind waves in the lagoon, since the locally generated wind waves are the main component of the sea state.

We therefore both measured and modeled waves. The NOAA wave model WaveWatch3 (Tolman 1991, 1999) was used to simulate wave distribution in the lagoon, and wave parameters were measured in situ by a wave and tide recorder (WTR9 Aanderaa) and by an acoustic Doppler velocimeter (ADV Sontek). More details on wave modeling are given in Jouon et al. (2009). Model validation in the SLNC was necessary because the lagoon is a semi-enclosed and fetch-limited basin. Furthermore, a validated wave model is required to simulate the extreme wind seas during storms.

Special care was taken in the validation step as, on one hand the wave model did not simulate the propagation of low-frequency $(<0.1 \mathrm{~Hz})$ oceanic waves inside the lagoon, and on the other hand there is an intrinsic limitation of measured spectra at high frequencies due to their attenuation with depth. The latter limitation is severe for wind wave measurement in fetch-limited areas. As it is assumed that the signal-to-noise is too weak at depth greater than half the wave length, this limitation forced us to moor the wave

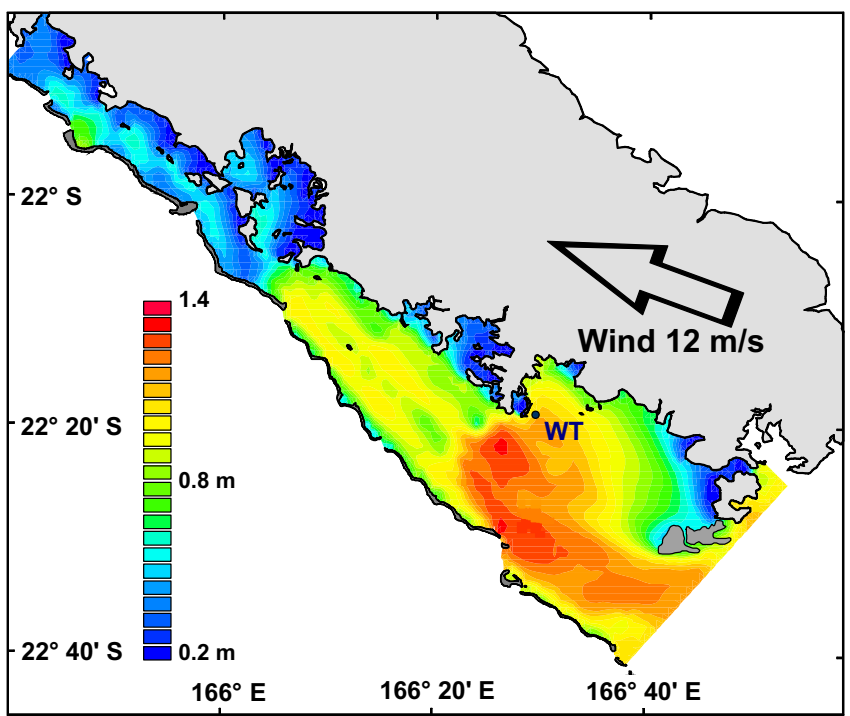

Fig. 10. Significant wave height distribution after $12 \mathrm{~h}$ of trade wind blowing $\left(110^{\circ}\right.$, $12 \mathrm{~m} \mathrm{~s}^{-1}$ ). gauges at a maximum depth of $5 \mathrm{~m}$ so as to be able to detect waves under trade wind conditions. The locations of instrument deployment were chosen on the windward sides of small reefs or small islands, within the outer lagoon where the wind waves have the greater fetch. Four stations were monitored (see Fig. 1).

Numerical simulations provide a directional wave spectrum at each point. The WTR9 used in this study gives access to the significant wave height, $H_{s}\left(=4 \sqrt{m_{0}}\right)$, and to the mean zero crossing period, $T_{02}\left(=\sqrt{m_{0} / m_{2}}\right)$, deduced from the zero- and second-order moments of the wave spectrum, $m_{0}$ and $m_{2}$, respectively given by:

$m_{k}=\int_{f_{l}}^{f_{c}} P_{n}(f) f^{k} d f$

where, $P_{\eta}(f)$ is the power spectrum density of sea surface elevation bounded by a low frequency $\left(f_{l}\right)$ and the cut-off frequency $\left(f_{c}\right)$. In order to compare simulations and measurements, we chose to bound the modelled spectra up to the cut-off frequency imposed for the measurements and the measured spectra down to the lowest modelled frequency in order to filter the swell. The obtained bandwith corresponded to the wind wave field truncated by a cut-off frequency of $0.5 \mathrm{~Hz}$ for WTR9 $(0.46 \mathrm{~Hz}$ for the ADV), and the filtering of frequencies lower than $0.17 \mathrm{~Hz}$ allowed to filter swell without filtering wind waves.

The comparisons of simulations and measured wave spectra over a windowed frequency spectrum enabled the validation of the model applications. An example is given in Fig. 9. The directional-spreading of wind waves and the wave periods obtained by ADV and WaveWatch3 are consistent and vary in agreement with wind. The rms error between modelled and measured wave parameters, when swell was filtered from measurements, were on average $0.11 \mathrm{~m}$ for wave height and $0.28 \mathrm{~s}$ for wave period. The resulting field of wave height in the case of constant and uniform trade wind $\left(110^{\circ}, 12 \mathrm{~m} \mathrm{~s}^{-1}\right)$ is presented on Fig. 10 . Waves are considerably reduced behind the small islands in front of Noumea.

The comparison of non filtered and filtered wave components from measurements (i.e. with and without swell, respectively) showed that sea state is mainly dominated by wind waves close to Noumea. With the exception of the inlets, the influence of the swell was shown to be significant only during low intensity wind episodes or when wind direction did not generate long fetch in the SE to NW oriented lagoon. Under established trade wind forcing, the contribution of oceanic swell to overall wave height in the outer lagoon did not exceed 3\% during the experiments.

Measurements and simulations are extensively presented in Jouon et al. (2009). These exercises demonstrate the ability of WaveWatch 3 to simulate the intensity and direction of the spectral components of the fetch limited wind wave field in the SLNC. At the end of the paper, the use of a more realistic wind distribution 

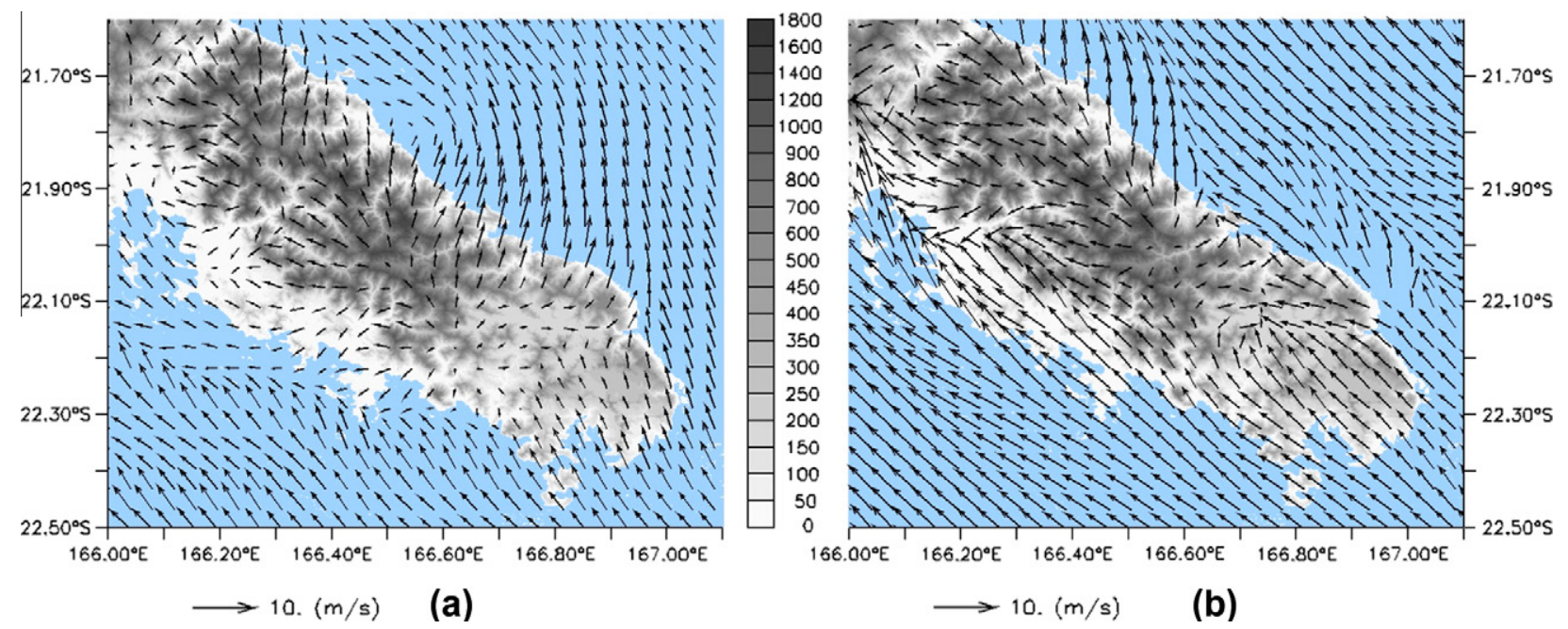

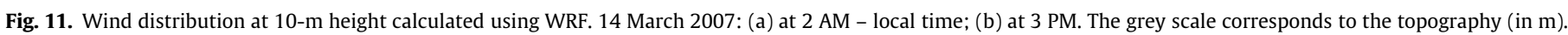



Fig. 12. Wind direction (dashed line) and velocity (solid line) measured at the Amédée Lighthouse (see Fig. 1), March 2007.

hind-casted by a high-resolution atmospheric model is suggested in order to obtain a more accurate wave model.

The available wind-wave model should now be coupled to the general 3D hydrodynamic and suspended sediment transport model (by the introduction of additional radiation stress). This will allow the taking into account of wave influence on resuspension and the quantification of its specific contribution as compared to that of tide- and wind-induced currents.

\subsection{Atmospheric forcing and regional circulation}

In the first 3D simulations of lagoon hydrodynamics, the wind measured in the outer lagoon (at Maître Island, see Fig. 1) was uniformly imposed over the whole lagoon. However, wind records from weather stations deployed by Meteo-France clearly show that near-shore winds are strongly modulated by the diurnal thermal cycle. In addition, orographic effects are expected. For example, during our field experiments, we noticed a strong diurnal variability of wind direction in Boulari Bay. In the early morning, the wind blows from land to sea, funnelled by the NE-SW surrounding valley, while in the late morning the wind rotated south-easterly and accelerated, as a result of the sea breeze combining with the SE trade wind.

Atmospheric simulations around New-Caledonia and their validation have been recently performed (Lefèvre et al., 2010). The WRF (Weather and Research Forecast) model with a 4-km mesh grid definition was validated from measurements by the SeaWinds scatterometer onboard QuikSCAT at $12-\mathrm{km}$ resolution and from Meteo-France weather stations. Four dominant weather regimes during the warm season are detailed in Lefèvre et al. (2010) and the island-scale, orographic and diurnal circulation associated with the most prevalent weather regime (strong trade winds) is investigated. The results point out the important role of Mont Humboldt on the dynamical behaviour of the low-level flow in the SLNC, while the diurnal heating cycle in the vicinity of the mainland also modulates the local circulation. Fig. 11 shows the simulated $10-\mathrm{m}$ wind pattern at $2 \mathrm{AM}$ and $3 \mathrm{PM}$ on 14th March 2007 during the high SE trade wind conditions presented in Fig. 12. The low-level circulation over Boulari Bay is strongly modulated by the diurnal heating cycle, in agreement with our observations. The wind accelerates in the afternoon along the western and eastern flanks of Mont Humboldt, as a result of flow splitting induced by the orography when the sea breeze combines with the trade-winds. This confirms the important variability of wind speed and direction at small-scales (both temporal and spatial) and show that the variability is larger near shore than offshore, as expected. Furthermore, these simulations provide suitable wind forcing for future hydrodynamic calculations.

\subsection{Conclusion}

At the end of the PNEC program, tide- and wind-induced circulation, wind-wave parameters and residence time were mapped in the SLNC. A formulation has been proposed to parameterize water 


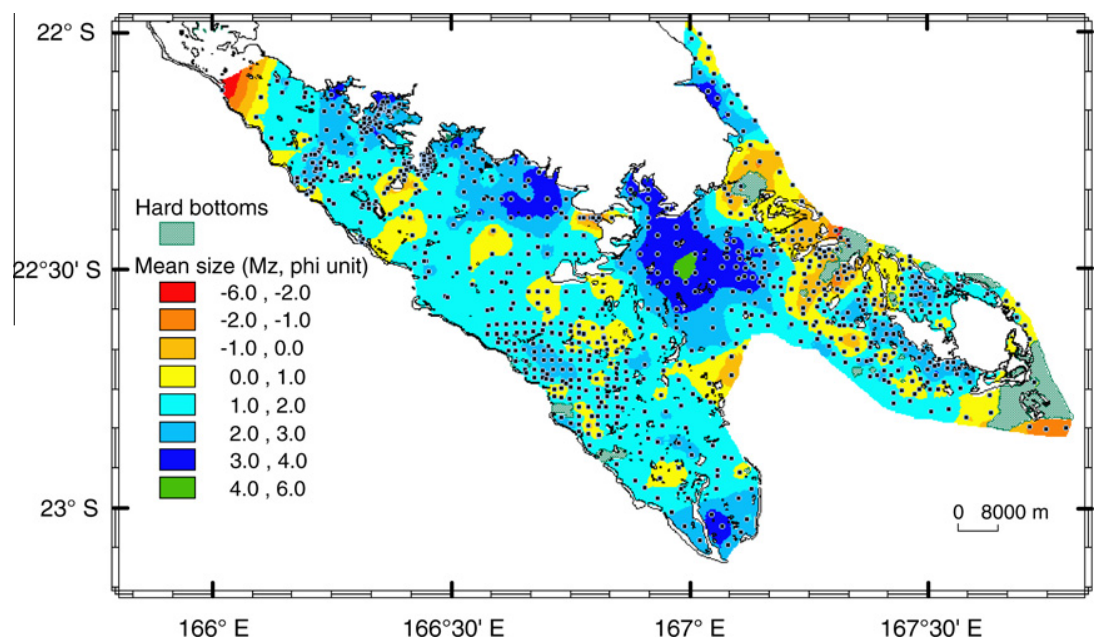

Fig. 13. Mean size of superficial sediments in the Southern lagoon of New Caledonia ( 860 stations indicated by dots).

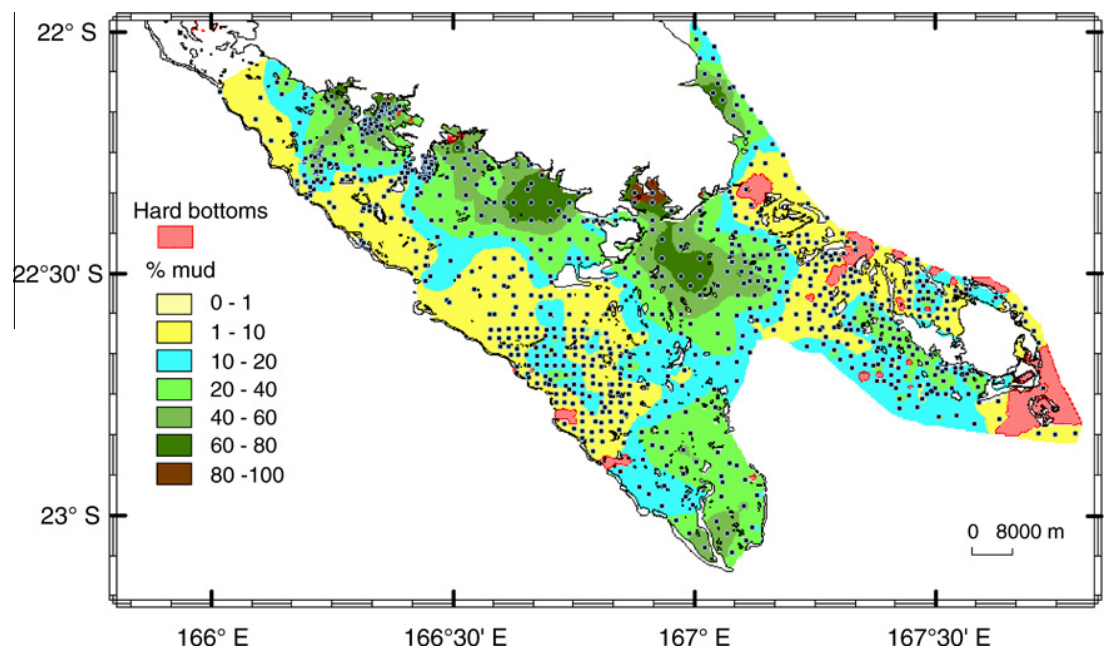

Fig. 14. Mud content of superficial sediments in the Southern lagoon of New Caledonia (859 stations).

inputs (wave setup and wave-induced current) generated by the breaking of oceanic swell on the reef, a method has been proposed to validate wind-wave models in fetch limited coastal areas, and a series of models (2D tide model, 3D hydrodynamic model, windwave model, small-scale atmospheric model) are now available for the simulation of more realistic circulation patterns within the SLNC and in turn, its impact on biogeochemistry and sediment transport.

\section{Suspended sediment transport}

\subsection{Sedimentology}

The grain size distribution of superficial sediments around Nouméa was mapped by Dugas and Debenay (1982) and analyzed by Debenay (1987). Debenay reports the existence of three stocks of particles in the lagoon, between 0.5 and $0.25 \mathrm{~mm}$ (I), around $0.125 \mathrm{~mm}$ (II), and around $63 \mu \mathrm{m}$ and below (III). Stocks I and III exist in most parts of the lagoon but in coastal areas, river mouths and canyons stock I is absent, whereas in the back-reef area stock II prevails. A transition zone between this latter area and the inner part of the lagoon is composed of stocks I and II (Debenay, 1987).
Measurements by Chevillon were added to the database by Dugas and Debenay and allowed the mapping of:

(1) mean size Mz of the superficial sediment as defined by Folk and Ward (1957) within the whole Southern lagoon of New Caledonia. $\mathrm{Mz}=\left(\phi_{16}+\phi_{50}+\phi_{84}\right) / 3$, where the sediment diameter $D$ expressed in $\mathrm{mm}$ is converted in $\phi$-unit by $\phi$ $=-\log _{2} D$, and where $\phi_{n}$ is the size such that particles finer to $\phi_{n}$ weigh $n \%$ of the total sediment weight (Fig. 13),

(2) the mud content of the superficial sediment (Fig. $14-\mathrm{a}$ zoom on the SLNC is given in Douillet et al., 2001, their Fig. 5).

O'Callaghan (1999) performed complementary measurements of grain size distribution of superficial sediment samples from Dumbea Bay using a laser sizer. These measurements showed a predominance of silts with an equivalent diameter of around $6 \mu \mathrm{m}$ in the mud fraction.

In parallel to purely sedimentological studies, Chardy et al. (1988) identified the major soft bottom benthic communities of the SLNC on the basis of the faunal composition at sampling stations. Three major communities were identified and discriminated from sedimentological parameters. They correspond to muddy 


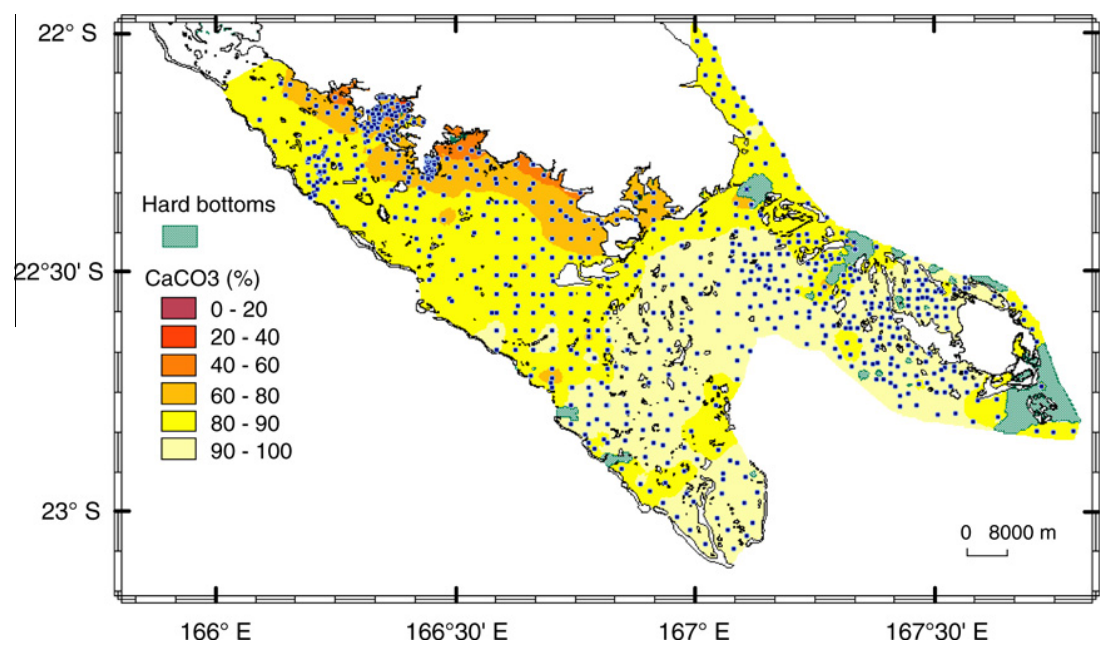

Fig. 15. Carbonate percentage in the fine superficial sediments in the Southern lagoon of New Caledonia (711 stations indicated by dots).

deposits, grey sand bottoms and white sand bottoms which occupy 35,50 and $15 \%$ of the SLNC area, respectively. Generally, mud deposits which occupy the bays and submarine canyons form a structure that is perpendicular to the median axis of the lagoon, grey sand bottoms are found on hardground areas which are covered by a thin layer of sediment, and white sand bottoms are located in the inner reef area. Recently, acoustic remote sensing has been used to map habitats in the SLNC and to link habitats to sediment parameters.

Sediments include particles injected into the system (allochtonous) and produced in situ (autochtonous) (Perry and Taylor, 2006). In the SLNC, carbonates contained in the sediments are of mainly benthic biogenic origin (Chevillon 1992, 1996). Bioclastic particles consist of debris of shells, calcareous algae like Halimedas, Foraminifera and coral. Foraminifera and molluscs (bivalves and gastropods) are the main sources. Although coral debris is never dominant, it is significant close to the reefs, i.e. near inlets and in the back-reef slope (Debenay, 1987; Chevillon, 1996). Apart from a very minor siliclastic biogenic component, the fraction complementary to carbonates corresponds to the terrigenous fraction, i.e. the fraction formed from rocks and minerals transported into the depositional basin. The terrigenous fraction, which is extremely low in the sandy fraction (>63 $\mu \mathrm{m}$ ), except for in the near-shore areas (Clavier et al., 1995), has traditionally been measured in the particles $<63 \mu \mathrm{m}$ in the lagoon of New Caledonia. Carbonate distribution within the lagoon (Fig. 15) ranges from high terrigenous facies $\left(\mathrm{CaCO}_{3}<20 \%\right)$ at the river mouths to pure carbonate facies $\left(\mathrm{CaCO}_{3}>80 \%\right)$ along the reef, as defined by the classification of Maxwell (1968). Canyons are dominantly filled with marine muds. Content of the residual fraction varies inversely with carbonate contents indicating the terrigenous origin of these particles. Close to river mouths, they vary from $77 \%$ (B03, la Coulée R. mouth), 62\% (P04, Pirogues R. mouth), 54\% (D36, Dumbéa Bay), 33\% (N12, Sainte-Marie Bay), to $10 \%$ or less in the vicinity of inlets (Magand, 1998).

Resuspension occurs within the lagoon during each tidal cycle. Clavier et al. (1995) show that at each of five stations typical of the three bottom types, more than $80 \%$ of the total sedimentation was linked to deposition of resuspended benthic material. This feature was particularly conspicuous for their two muddy substrate stations where a $90 \%$ rate was determined. The seafloor geology appears to be well correlated to the sediment transport pattern, as shown by the agreement of erosion and deposition areas determined from numerical simulation (distinguished by the local bed shear stress) and the map of mud content in the superficial sediment in Douillet et al. (2001). Sediment transport and resuspen- sion have led to a strongly sediment-partitioned shelf, with modern mud-rich sediments almost exclusively restricted to the inner and inner-middle shelf, to northward-facing embayments and in the lee of headlands. Hardground indicates an erosional environment, and mud deposits evidently suggest depositional environments.

Mineralogy of surface sediments determined by X-ray diffractometry shows larger differences between the bays than does the mineralogy of suspended particulate matter (SPM). Among terrigenous sediments, quartz and goethite dominate at the Pirogues River mouth, talc and goethite at the Couleee River mouth, antigorite and quartz at the Dumbéa River mouth. Moreover, the Coulée River also discharges kaolinite which was undetectable in the Pirogues and Dumbéa Rivers (Magand, 1998). Carbonated compounds (calcite, magnesium calcite and aragonite) are always present and in increasing quantities as one moves away from the bay heads.

The sedimentological maps (Dugas and Debenay, 1982) and the geochemical analyses (Magand, 1999) reveal the mixture of fine limestone sands and of lutites of siliceous origin (terrigenous) in the sand-muddy deposits in gray bottoms, canyons and at the vicinity of mouths.

It is a delicate exercise to compare the particle inputs resulting from land erosion to sedimentation within the lagoon. Indeed, most of the terrigenous input is trapped in deltas and mangroves, and only a minute part reaches the lagoon (Clavier et al., 1995). The terrigenous influence is lower in Dumbéa Bay than in Boulari Bay and near the Pirogues River mouth for two distinct reasons. Firstly, the early trapping of material in alluvial plain slows down particulate transit between the Dumbéa catchment area and the middle of bay. Baltzer and Trescases (1971a) estimated that three quarters of the particles brought by the Dumbéa River settle in the delta and that another significant part is also retained in mangroves. Secondly, in addition to a lower terrigenous input, Dumbéa Bay also shelters fringing reefs and alive or dead corals on its bottom (Launay, 1972) and these constitute an important source of carbonates as compared to the Coulée and Pirogues River mouths. Moreover, the Coulée and Pirogues Rivers have particularly striped basins as a consequence of scrubbing of lateritic soils. The absence of a deltaic plain and weak mangrove coverage at the mouth further supports the hypothesis of increase discharge of terrigenous material in the lagoon. The higher percentage of sediments of terrigenous origin in Boulari Bay has been confirmed by geochemical analyses (Magand, 1999). The fringing reefs in the west of Boulari Bay (around Tina and Sainte-Marie Bay) probably explain the higher presence of biogenic particles in this zone. 
Sainte-Marie Bay shelters a fringing reef, receives terrigenous inputs from the Coulée River (Fernandez et al., 2006), and collects domestic and urban waste waters. It is thus a particularly complex zone from the sedimentological point of view.

It should be also noted that the content of residual fraction of sediments, like that of total carbon, decreases with depth in sedimentary cores. This indicates that terrigenous particles deposited on the surface are resuspended during high-energy events like storms and are redistributed by currents. Thus the distribution of freshly deposited particles is spread over the long term after a succession of transient episodes of resuspension/transport and deposit.

\subsection{Suspended matter concentration and turbidity: spatial patterns and variability}

\subsubsection{Nature and characteristics of the suspended matter}

The input of elements into the lagoon occurs in three forms: dissolved, colloidal and particulate, each of which corresponds to distinct biological and physico-chemical reactivities. The oceanographic community has adopted an arbitrary threshold at $0.45 \mu \mathrm{m}$ to distinguish dissolved and particulate elements by filtration (Stumm and Morgan, 1981) and the colloidal state, a state of transition, relates to particles whose size lies between $1 \mathrm{~nm}$ and $1 \mu \mathrm{m}$ (Vold and Vold, 1983). Suspended particles have high capacities of chemical exchange and thus are vectors of metals, chemical and organic pollutants (Ouillon, 1998). In New Caledonia, the study of elementary fluxes has focused on the fate of suspended particles and of dissolved and particulate metals.

Suspended particles in coastal waters include non cohesive mineral particles, fragments, plankton and aggregates. Plankton temporal variability is described in a companion paper (Le Borgne et al., 2010). Aggregates (from several micrometer to several mm) consist of inorganic and organic matter, marine snow, fecal pellets, plankton, mineral particles, microbial communities, particulate organic matter originating from dissolved organic matter like Transparent Exopolymer Particles (TEP; Azetsu-Scott, 2004) and other Extracellular Polymeric Substances (EPS) or a mixing of these ingredients with water (Droppo, 2001). Microbial secretions of EPS form a framework and provide structural stability of the aggregates. Physico-chemical processes and biological activities continuously modify aggregate size, stability, density, porosity, and biochemical processes (Droppo, 2004) with their buoyancy varying as a function of the particles contained within the aggregate. Moreover, these suspended particles react quasi-instantaneously to the forcing applied to the studied system.

Semi-quantitative mineralogical analysis by X-ray diffractometry showed the joint presence of terrigenous and carbonaceous detritic minerals in SPM collected in May-June 1998 (Magand, 1998). The most abundant detritic terrigenous minerals were, in decreasing order of importance, quartz and two magnesium clays, antigorite and talc. SPM in bays also contained nontronite (ferralitic clay; Dumbéa, Boulari, Pirogues) and goethite (iron hydroxides; Dumbéa, Boulari). The main carbonaceous minerals were calcite, magnesium calcite and aragonite. The terrigenous fraction was more abundant in the heads of bays, while the carbonaceous fraction dominated in the lagoon (Magand, 1998).

Scanning electronic microscope (SEM) allowed the identification of three main phytoplankton groups in the SPM from the lagoon: diatoms are dominant in the bays except Dumbéa; coccolithophorids are abundant in Dumbéa Bay, close to the reefs, canyons and inlets; dinoflagellates are somewhat abundant, with slightly higher abundances in Sainte-Marie Bay than elsewhere. Pelagic diatoms dominate in biomass, benthic diatoms in number. The presence of benthic diatoms (in particular Diploneis sp. and Amphipora augustata) in sediment traps results from the resuspen- sion of deposited surface materials. River inputs of dissolved nutrients, in particular in silica, probably explain the abundance of diatoms in coastal areas compared to further offshore. Abundant coccoliths are characteristic of the near ocean (Jacquet et al., 2006). The organomineral particles, observed by SEM, resulted from a mixture of two distinct populations (Magand, 1998): abundant large aggregates of several hundred microns containing carbonated detrital minerals (mainly coral fragments composed of fibrous aragonitic structures), and smaller, less abundant aggregates of about $10 \mu \mathrm{m}$, containing finer terrigenous detrital minerals (smoothed or polished siliceous particles). These smaller particles were comparable with those described at the Dumbéa River mouth by Baltzer and Trescases (1971b).

Rivers export sedimentary material composed of products from scrubbing and hydrolysis of peridotitic cover (laterites and saprolites) of the catchment areas as well as the sedimentary rocks from the piedmont or alluvial plain. The origin of material explains the quasi-total absence of carbonated compounds $(<1 \%)$ and the prevalence of residual fractions made up of terrigenous detrital material (Magand, 1998). Exported carbon is primarily organic carbon originating from the sedimentary clay fractions.

The exported sediments are composed primarily of iron hydroxides (goethite), antigorite, quartz, talc, nontronite and kaolinite. The greater than $40 \mu \mathrm{m}$ sedimentary fraction contains antigorite and talc (magnesian clays) and quartz. These minerals typically result from the ultrabasic soils carried to the alluvial plain (Baltzer and Trescases, 1971b). The fine fraction, composed of talc, goethite, nontronite and kaolinite is more related to the piedmont and alluvial plain formations. In the Dumbéa basin, Baltzer and Trescases (1971a) showed that the coarse particles brought by the river during floods (cyclone Brenda, January 1968) were primarily deposited in the alluvial plain and that the finest phase, transported in suspension, dominated at the mouth. Material injected into the lagoon included $35 \%$ of particles of size $<2 \mu \mathrm{m}$ and $65 \%$ of particles between 2 and $40 \mu \mathrm{m}$. Clavier et al. (1995) confirmed the absence of sands of terrigenous origin in the particles transported in suspension in the SLNC. Carbonated material of biogenic origin, coarser than the terrigenous fraction $(>40 \mu \mathrm{m})$, was however observed in SPM (Magand, 1998).

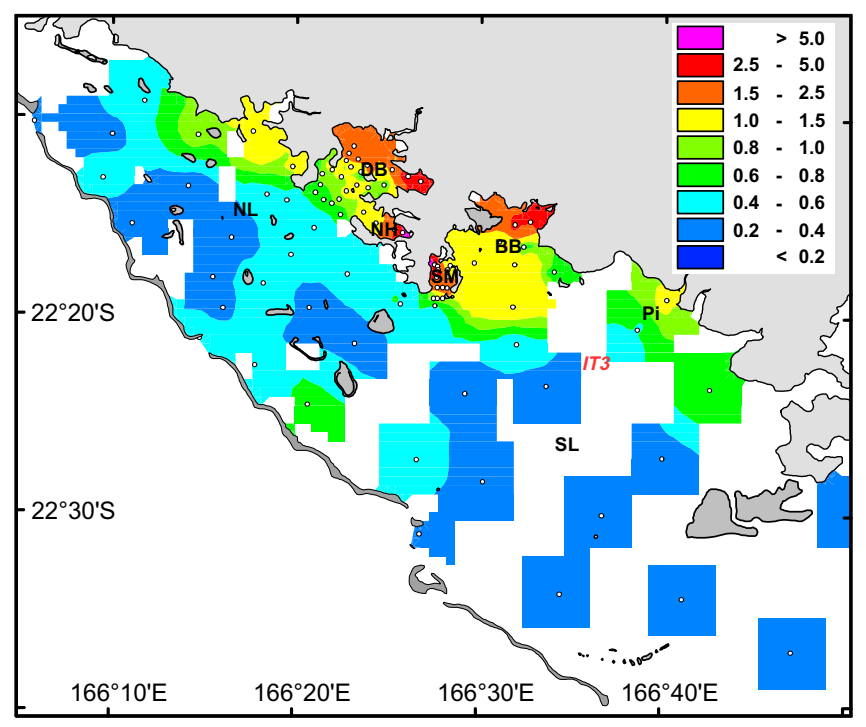

Fig. 16. Turbidity distribution (in FTU) within the SLNC measured from 18 to 26 September 2000. Turbidity values were averaged from $3 \mathrm{~m}$ depth to $5 \mathrm{~m}$. Sea stations are indicated by small dots. The analysis distinguished 7 zones: Dumbéa Bay (DB), Boulari Bay (BB), Sainte-Marie Bay (SM), Nouméa Harbour (NH), the Pirogues River Mouth (Pi), North Lagoon (NL) and South Lagoon (SL). 


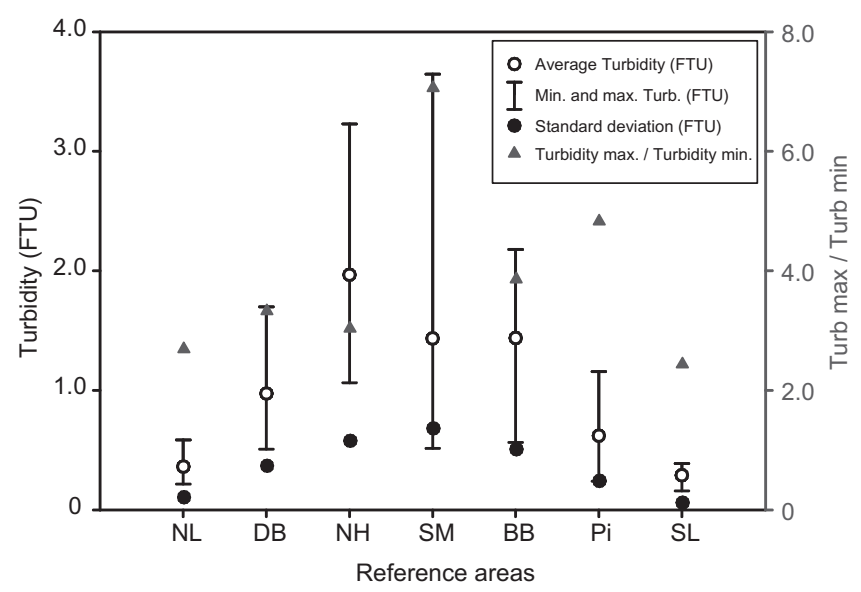

Fig. 17. Temporal variation of turbidity (in FTU) averaged within the seven reference zones (see Fig. 16) during 19 field campaigns, 1997-2001.

\subsubsection{Spatial variability of turbidity}

Turbidity is often considered as a proxy for suspended matter concentration. In the SLNC, turbidity was measured with a Seapoint turbidimeter connected to a SBE19 CTD probe. The Seapoint turbidimeter detects light scattered by particles and uses a $0.88 \mu \mathrm{m}$ light source wavelength. The sensor was factory adjusted to a Formazin Turbidity Standard measured in Formazin Turbidity Units (FTU). The spatial and temporal variability of SPM can be rapidly estimated by turbidity as turbidimeters are cheap, relatively easy to use and can rapidly provide depth-profiles of suspended matter. The relationship between turbidity and SPM in the SLNC is further described in Section 4.4.2.

The variability of turbidity under non-storm conditions was studied on the basis of 19 field surveys spanning a 5-year period (1997-2001). Each cruise included between 27 and 114 turbidity depth-profiles which were performed over 2-8 consecutive days and at all tidal stages. Turbidity values were averaged between $3 \mathrm{~m}$ and $5 \mathrm{~m}$ depth as the influence of short-term variations in the bottom nepheloid layer and in the surface plume, which is of $3 \mathrm{~m}$ maximum thickness, were negligible. The turbidity distribution measured from 18 to 26 September 2000 is shown in Fig. 16; it can be considered as typical of trade wind conditions during the wet season, with the exception of Sainte-Marie Bay where dredging activities had doubled turbidity levels. Additional SPM distributions are presented in Ouillon et al. (2004; surface turbidity distribution derived from Landsat ETM+ data) and in Jouon et al. (2008; distribution of volumetric concentration averaged over 8 field campaigns and water depth).

An overview of the 19 turbidity maps shows that distinct zones have different sensitivities to forcing and inputs. Strong variations in bathymetry caused by the canyons and small islands, as well as the land topography, mean that the SLNC is a system where acrossshelf and along-shelf sediment dispersion and fluxes can not be easily distinguished as it is the case in most shelves (e.g. Wiberg et al., 2002). Seven zones were thus delimited for the analysis (see Fig. 16):

Dumbéa Bay (hereafter denoted DB),

Boulari Bay (BB),

Sainte-Marie Bay (SM),

Nouméa Harbour ( $\mathrm{NH})$,

the Pirogues River Mouth (Pi),

North Lagoon (NL),

South Lagoon (SL).

"Averaged" values of turbidity per field campaign were calculated inside each zone from the available measurements. Comparing the zones (Fig. 17 and Table 1) allows an estimation of the temporal, cross-shore and alongshore turbidity variations. An overall analysis highlighted three main characteristics: (1) turbidity is higher near shore than in the outer lagoon (SL or $\mathrm{NL}$ ), indicating that inputs from the ocean are reduced, and that turbidity is higher in Nouméa (NH and SM zones) than elsewhere; (2) spatial and temporal turbidity variations are much greater that those of salinity and temperature (Ouillon et al., 2005); (3) contrary to salinity and temperature, spatial variations in turbidity are higher than temporal variations.

Hydrodynamic circulation during the main trade wind condition (Fig. 3b) suggests that the Pirogues River mouth area receives waters from the South Lagoon; thereafter the water flows into the bays of Boulari and Sainte-Marie where they are mixed with SL waters. The cross-correlation analysis showed that when two zones were compared their turbidity was generally slightly correlated. Two pairs of turbidity values provided significant correlation coefficients, NL-SL $(r=0.632)$ and Pi-BB $(r=0.624)$, while a coefficient 0.53 or less was obtained for the remaining pairs. Other above-median correlation values are obtained for Pi-SM, SL-SM, SL-BB, SM-NL, DB-NL, Pi-NH, SM-NH and SM-DB. These correlations indicate that turbidity values are consistent with the hydrodynamic scheme: turbidity at Pi and SL influence BB and SM, while NL is most sensitive to SL, DB and SM turbidities. Large bottom shear stress, associated with high velocities, prevents sediment

Table 1

Turbidity distribution per zone and sensitivity analysis with river discharge and wind forcing.

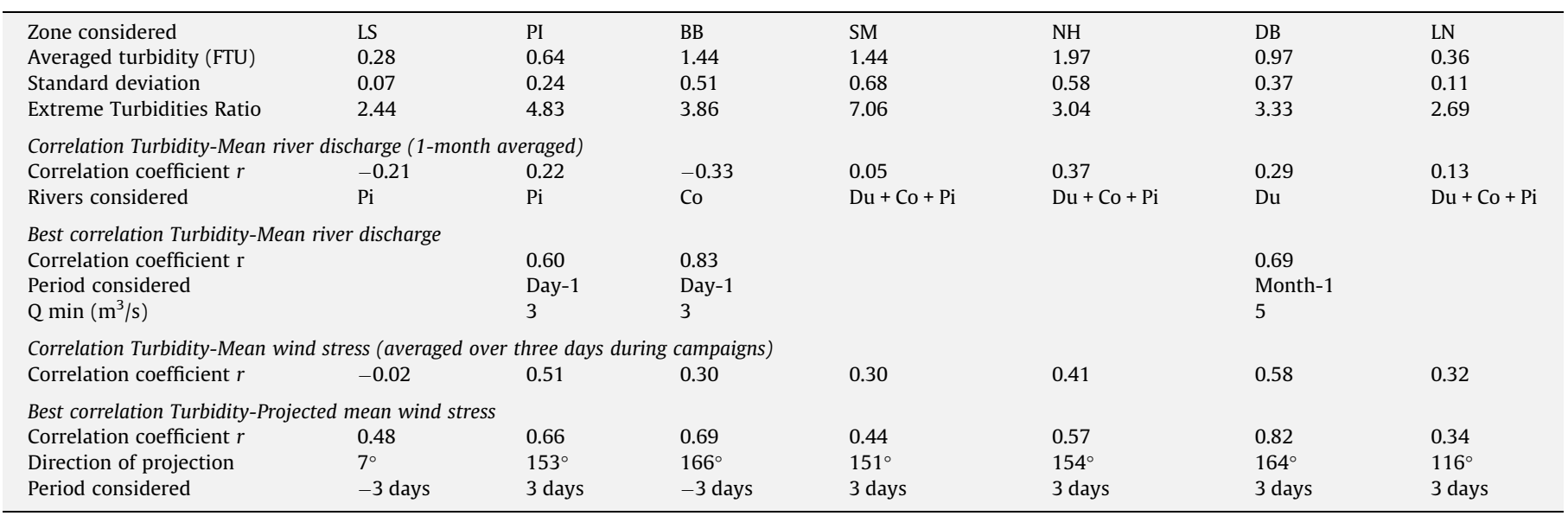


deposition and induces longshore sediment transport towards Noumea from the south. The turbidity in NH is not related to that at $\mathrm{Pi}$ or at SM. The above-median correlations obtained for Pi-NH and $\mathrm{SM}-\mathrm{NH}$ are due to the similar forcing experienced by these three zones. The sensitivity of turbidity in the seven zones to river runoff and to wind, and thus the origins of suspended particles (river inputs, resuspension), is discussed below.

Nouméa Harbour is the most turbid zone. The turbidity level in the enclosed bay of Nouméa Harbour is due to industrial and domestic inputs and seems to be less dependent on adjacent areas that other reference zones. Mari et al. (2007) proposed that water residence time and organic matter age determine the positive buoyancy of aggregates in this bay. Thus the positive buoyancy of old aggregates (see residence time in Fig. 5) is probably responsible for the elevated turbidity levels in $\mathrm{NH}$, even in calm conditions during the dry season.

Turbidity in Dumbéa Bay is higher in its inner and shallower part (Fig. 16), and its distribution is consistent with the local circulation, with lagoon waters coming into the south of DB and returning to the lagoon along the northern part of the bay under trade wind conditions (Fig. 3b). The North Lagoon received turbid waters from DB (e.g. in March 1998, August 1999 and March 2001), making NL more turbid that the SL as it is sensitive to turbidity in both SL and DB.

Schematically, flushing of the lagoon is driven by water coming from the South; the water loads particles during its transit through the lagoon and thereafter leaves by the inlets. The particulate flux expelled in the Dumbéa inlet is thus higher than in the Boulari inlet. Turbidity and SPM increase from the barrier reef to the shore. As explained by Clavier et al. (1995), these gradients are linked to the higher proportion of particles of terrigenous origin near shore. The river inputs, mainly composed of silts and clays, settle off the mouth. These particles are then resuspended by the combined action of wave and tide with a high proportion leaving the lagoon through the inlet channels (Baltzer and Trescases, 1971b; Launay, 1972). When significant salinity gradients are present inside the bays, even if they are not sharp enough to be considered as 'fronts', turbidity and salinity patterns may become superimposed. Salinity fronts are thought to intensify the trapping of suspended sediment in the lagoon in the rainy season, similar to what is observed in estuaries (Woodruff et al., 2001). Flushing of fine particles of terrigenous origin generally requires many successive resuspension episodes. In contrast, water which enters over the reef and leaves the lagoon through the inlet channels undergoes little or no mixing with near shore waters.

Jouon et al. (2008) calculated that, over 8 field campaigns randomly performed as regards forcing condition, the spatial variability of SPM volume concentration was higher than temporal variability (coefficients of variation of $63 \%$ and $26 \%$, respectively). The averaged turbidity calculated for the 7 zones during 19 field campaigns provided similar results: coefficients of variation of the spatial and temporal variability of turbidity were $71 \%$ and 28 $\%$, respectively.

\subsubsection{Short-term variability of turbidity}

The temporal variability of turbidity is related to various factors however it is not significantly impacted by ocean variability, as SPM concentration is always low in the surrounding waters (around $0.2 \mathrm{mg} \mathrm{l}^{-1}$, see SL, Fig. 17, and Section 4.2.4).

Local increases in turbidity are mainly controlled by resuspension and river inputs. Eddy diffusivity and resuspension rates are highly sensitive to wind sequences over the shallower areas, to turbulence induced at the sea surface and to the combined wave- and current-induced bed shear stress. Clavier et al. (1995) correlated suspended sediment concentration with wind velocity. They obtained the best relationship with average wind velocity during the few days preceding sampling ( $r=0.75)$, and indicated that this supports the wind-driven resuspension of bottom sediments in the lagoon. Furthermore, freshwater runoffs into the bays, which occur sporadically during the wet season, are the main cause of the variability of terrigenous particle inputs.

In order to discriminate the possible origins of turbidity in each zone, correlation analyses were separately conducted between locally averaged turbidity, river discharge, and wind measured during 19 field campaigns (Table 1).

River inputs are significant during storm-induced floods with deposition occurring in the first few days post-flood, whereas sediment inputs from the rivers are extremely low during non-storm conditions (Baltzer, 1982; Laganier, 1994). Unfortunately, the available field measurements occurred mainly during low discharge conditions. Correlations calculated between turbidity and river discharge averaged over one day or over one month preceding the campaign were very poor $\left(r_{\max }=0.37\right)$. Table 1 reports these correlations and the rivers that were included in the analysis. Low correlations were obtained mainly because turbidity is uncorrelated with low river discharge. Correlations were also calculated between turbidity off the three river mouths and the local discharge averaged over different periods (Table 1 ). Turbidity in BB appeared well-correlated to the discharge of the Coulée River when it exceeded $3 \mathrm{~m}^{3} \mathrm{~s}^{-1}(r=0.83)$ with a time-lag of one-day. Turbidity off the Pirogues River mouth was also correlated with the discharge of the Pirogues River when it exceeded $3 \mathrm{~m}^{3} \mathrm{~s}^{-1}$ with a time-lag of one-day $(r=0.60)$. In Dumbéa Bay, turbidity was better correlated with the discharge of the Dumbéa River when it exceeded $5 \mathrm{~m}^{3} \mathrm{~s}^{-1}(r=0.69)$ with a time-lag of one-month.

Correlations between turbidity and wind were performed considering the square wind velocity to which momentum flux at the sea surface is proportional. Correlation between turbidity and wind stress is an indicator of the sensitivity of turbidity to resuspension. Wind was measured at the Amédée Lighthouse (see Fig. 1), and the considered velocities were averaged over 3 days during the field campaigns. Rather low correlation coefficients were obtained when the wind direction was not taken into account (Table 1). Two main reasons explain that local wind action is not accurately represented by wind at the Amédée Lighthouse: (1) the wind strength and direction in the coastal fringe may significantly differ from that near the reef (see Section 3.5); (2) the major impact of wind on turbidity is the wave-induced resuspension that is very sensitive to the local fetch (see Fig. 10 and Section 3.4) and thus to wind direction. In order to study the effect of wind direction, correlations were also calculated between turbidity and the square of wind velocity projected along different directions, with wind averaged over 3 days during the campaigns or during the 3 days preceding the campaigns. The correlations were higher than those where wind direction is ignored and the best correlation coefficients, the corresponding directions of projection and considered periods are reported in Table 1 . The correlation coefficients were higher near the mouths (BB, DB, Pi) than in the urban bays $(\mathrm{NH}, \mathrm{SM})$, and the highest values were obtained in the shallower areas. Three reasons may be tentatively given : (1) terrigenous muds are more easily resuspendable than carbonate particles, turbidity is thus more correlated to wind near the mouths than further offshore, even for small wind stress (see Section 4.6); (2) fetch is shorter in the urban bays than near the mouths thus reducing wind-induced wave action in the urban bays; (3) turbidity in the urban bays does not depend solely on meteorological and hydrological forcing, but also on industrial and domestic inputs. The direction of wind projections that induce the best correlations are such that wind action is maximum (Table 1 ). Winds from SSE ( $\sim 160^{\circ}$ direction) generate long-fetch waves from the reef to the bays and a part of their energy is available for resuspension in the bays. The same reasoning applies in the South Lagoon where 
the highest turbidity was observed with wind flowing from the land to the reef, i.e. in condition of longest fetch. Boulari Bay differed from DB and Pi with a more southerly direction of projection and a better correlation with wind preceding the campaigns than during them, similar to that observed in the South Lagoon. This is characteristic of an inertial effect. The time-lag between wind and turbidity has also been noted during recent experiments with sediment traps (Fernandez et al., submitted for publication). From our measurements, a sensitivity study showed that correlations with wind varied within Boulari Bay from one station to another. This variability may be due to the marked mountain relief (see Section 3.5) and the fact that the stations near shore are more protected against wind waves (Fig. 10). Furthermore, the inertial effect indicated that wind waves were probably not the main process controlling resuspension in Boulari Bay. Two assumptions can be made: (1) the inertial effect may result from a gyre that develops during certain wind episodes and whose currents induce resuspension in the first days following the weakening of the wind episode (see Fig. 3B in Douillet et al., 2001); (2) the inertial effect may result from the flushing of an excess of water from along the coast leading to a post-wind episode resuspension. Other correlations provide interesting information on three areas, namely $\mathrm{Pi}, \mathrm{SM}$ and $\mathrm{NH}$, where turbidity levels are sensitive to a wind direction of around $153^{\circ}$. This probably explains why the cross-correlations in these zones are higher than the median value.

The tidal influence on resuspension and the variability of turbidity was also investigated. Bouron-Morin (2001) compared the influence of wind and tide on resuspension at two stations, using both turbidity measurements and numerical simulations. One station (A24) is located in the outer SL area over carbonate sands, and the other (D46) in DB over muddy bottoms. At each station, $24 \mathrm{~h}$ turbidity profiles were performed during the wet season in September 2000. Measurements showed that under trade wind conditions, only one major resuspension episode occurred per tidal cycle in the outer lagoon at flood when tidal currents and trade wind were superimposed. However, at ebb the resulting shear stress of those two opposing effects remained very low and prevented a second resuspension episode. In Dumbéa Bay, two distinct episodes of resuspension were observed per tidal cycle at flood and ebb. Numerical simulations confirmed the strong asymmetry in the tide- and wind-induced shear stress at station A24. Shear stresses of up to three times higher were computed during flood than during ebb at station A24, while the bottom shear stress at station D46 showed no significant asymmetry.

Other factors such as the feeding activities of benthivorous fish can be a major cause of suspended sediment in some coral reefs (Yahel et al., 2002) and these remain to be investigated in this system.

\subsubsection{Seasonal and inter-annual variations of turbidity}

The 19 field campaigns between 1997 and 2001 show that temporal variability was weaker in lagoon waters than along the coast (see Fig. 17 and the Extreme Turbidities Ratio, ETR, defined as the ratio turbidity maximum/turbidity minimum, per reference zone, in Table 1). Suspended material inputs in the south, linked to the ocean turbidity and to inputs from the Southern lagoon, weakly varied $(E T R=2.44)$. Variability was more pronounced near shore and was higher in DB (ETR = 3.33), BB (ETR = 3.86), Pi (ETR = 4.82) than in the more turbid $\mathrm{NH}$ zone $(\mathrm{ETR}=3.03)$ which is strongly influenced by anthropogenic activities. The high ETR value obtained in SM resulted from dredging activities in 2000.

This dataset and the other available turbidity data do not cover a long enough period for the proper analysis of long-term variations in turbidity. In particular, no measurements are available from immediately after storms or river floods. Nevertheless, an inter-annual variability can be tentatively sketched. The highest inputs of particles occur during river floods, particularly during tropical storms or hurricanes both of which also cause reef degradation. The 25 storms or hurricanes that had the greatest impact on New Caledonia during the period 1880-1995 (Pesin et al., $1995)$ were compared to the SOI values provided by the Australian Bureau of Meteorology. Ten of these events occurred during La Niña episodes, 13 during neutral ENSO periods, and 2 occurred in 1992 during unusual El Niño conditions (Trenberth and Hoar, 1996; Latif et al., 1997). Furthermore, precipitation anomalies are positive in New Caledonia during La Niña episodes. We can thus assume that terrigenous particles are mainly brought by floods that occur preferentially during neutral periods or during La Niña periods. Conversely, during fair weather conditions, resuspension is the main cause of turbidity in the SLNC. In other words, while significant sporadic river inputs mainly occur during La Niña events or neutral ENSO episodes, resuspension is assumed to be slightly enhanced during El Niño events because of stronger winds. However, the paucity of measurements in our dataset means that these relationships cannot be verified statistically.

It is also a delicate exercise to analyze seasonality in turbidity or SPM without long term measurements, even if general patterns can be sketched from the wind and river discharge variations. Clavier et al. (1995) proposed that average net sedimentation was high from February to June $\left(3.2-5.2 \mathrm{~g} \mathrm{~m}^{-2} \mathrm{day}^{-1}\right.$ ) and low from July to January (1.5-2.8 $\left.\mathrm{g} \mathrm{m}^{-2} \mathrm{day}^{-1}\right)$. The variations of several sedimentation rates (total rate, PIM, POM, POC, PON) suggested the occurrence of three main periods. These periods coincided with temporal changes in SPM concentration that were minimal from July to October, intermediate in November, December and January, and maximal from February to June. However, as inter-annual variability is high, it is delicate to consider a one-year period of measurement as representative of a typical year. The analysis of Clavier et al. (1995) was based on measurements performed from May 1986 to April 1987, at the beginning of a strong El Niño event. Thus, the specific impact of inter-annual variations can not be distinguished from the recurrent seasonal variability in their study, and the values provided should not be considered as typical of an "average" (or neutral) year.

\subsubsection{Stratification}

Stratification has a major impact on the vertical structure of turbulence in coastal waters. In particular, the reduced exchanges of particles and nutrients between the deeper waters and the surface mixed layer due to stratification have a major effect on the biological functioning of the ecosystem.

Thermal stratification usually sets up in the lagoon during the warm, dry season from October to December. This is followed by the set up of the thermo-haline stratification during the warm,

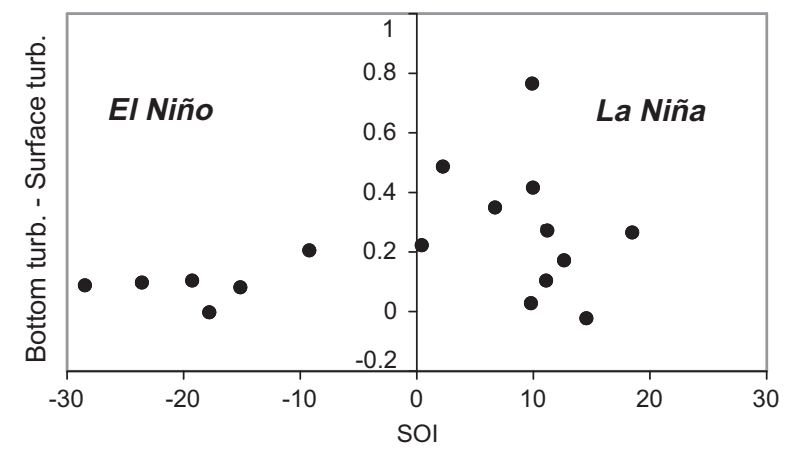

Fig. 18. Difference between bottom and surface turbidity (in FTU) in the southern part of the lagoon against SOI during 17 field campaigns, 1997-2001 (2 out of 19 field campaigns had no measurements in South Lagoon area). 
wet season from January to April. The occurrence of haline stratification during intermediate and fresh seasons depends on the river discharge and is so to be expected more important during La Niña periods.

Concerning turbidity near the seabed, suspended particulate matter concentrations are generally of the same order or higher than those of the surface waters, with the exception of the river plumes. The Benthic Boundary Layer (BBL) is essential in initiating and controlling the particle exchange between bottom sediments and the water column (McCave, 1986). Although its existence depends on hydrodynamic forcing its vertical stretch is constrained by the thermo-haline stratification.

A 3-5 m high BBL was observed in water depths of up to $30 \mathrm{~m}$ (Clavier et al., 1995). Magand (1998) also observed during rainy episodes the presence of a BBL of 5-6 $\mathrm{m}$ height near the river mouths overlain by an upper layer of riverine water. They also reported the presence of a BBL of 1-2 m height in the outer lagoon. During field campaigns, we also checked that the BBL, if any, was more distinct near shore. The examination of 89 turbidity depthprofiles performed in the SLNC during stationary trade wind conditions (from 18 to 24 September 2000 , dry season) showed that the BBL was clearly observable at 56 of these stations. The areas with no evident BBL (33 stations) corresponded to low or moderate mud bottoms (percentage lower than 20\%). The only exception was in the shallow Sainte-Marie Bay where wind- and bottom-induced mixing led to vertical homogeneity of the water column. The maximum measured height of BBL was $16 \mathrm{~m}$ at a station of $22 \mathrm{~m}$ depth. Surface turbid plumes were sometimes encountered in Dumbéa and Sainte-Marie Bays, and to the north near the Uitoé pass, however the thickness never exceeded $3 \mathrm{~m}$.

A global analysis of 19 field campaigns (1997-2001) indicated that thermal stratification was more often the origin of turbidity stratification than haline stratification. When stratification was present, the thermocline was the upper limit of the BBL. The propagation of internal waves in these configurations was shown to impact sediment resuspension and the formation of thin turbid layers (Wang et al., 2001). In our dataset, layers of a few centimetres thickness were frequently measured during strong thermal stratification however the frequency of CTD data acquisition $(4 \mathrm{~Hz})$ did not allow a more precise investigation of this phenomenon.

We observed no seasonal pattern in the temporal variability of turbidity stratification. However, a significant change in the vertical distribution of turbidity in the South Lagoon was found to be well-correlated with ENSO (Fig. 18). Higher winds and increased vertical mixing during El Niño events (with SOI <0) probably explain the lower stratification of turbidity during these episodes. Inter-annual variability in turbidity applies thus both to the mean turbidity level very sensitive to the flood occurrence and to its vertical distribution.

\subsection{Grain size distribution of suspended matter}

The concentration of SPM is usually assessed by measuring the dry weight of particles. However, characterization of the SPM pool also requires the determination of particle size distributions. Measuring the natural effective particle size distribution (EPSD) and the absolute particle size distribution (APSD, after disaggregation) is required to assess the importance of aggregation processes (Williams et al., 2007). EPSD measurements, which require aggregates to remain intact during analysis, have to be performed in situ. APSD and EPSD were monitored in the SLNC, compared and analyzed using a Sequoia LISST-100X instrument (Traykovski et al., 1999; Agrawal and Pottsmith, 2000; Mikkelsen and Pejrup, 2001; Curran et al., 2007). The LISST uses the diffraction of a laser by particles to perform a non intrusive measurement of the volume concentration of suspended particles per size bin. The results are detailed in Jouon et al. (2008). In situ parameters derived from LISST-100X were compared to other parameters used to describe SPM, such as turbidity and light attenuation (see Section 4.4.2). Other main results are reported hereafter.

The EPSD, normalized at each station to the total volumetric concentration, was averaged over all the measurements performed within the SLNC to provide a normalized particle volume concentration distribution representative of the SLNC (Fig. 19). Volume concentration was the highest for particles with a diameter around $6 \mu \mathrm{m}$ and the lowest volume concentration was obtained for particles between 1.9 and $2.6 \mu \mathrm{m}$. The high volume concentration recorded for particles of $1.6 \mu \mathrm{m}$ diameter may be an artifact. The mean relative volume concentration distribution decreased from the maximum reached around $6 \mu \mathrm{m}$ to the highest particle sizes (see Fig. 19). This decrease displays four loose modes between 6 and $60 \mu \mathrm{m}$. A second distinct mode concerned particles of size ranging from 60 to $120 \mu \mathrm{m}$.

Time, space and depth variability of SPM and EPSD were described in Jouon et al. (2008). In particular, small particles were shown to be more abundant in the bottom nepheloid layer than in the overlying water column. The concentration of suspended particles showed more variability over space than over time. Conversely, the particle size distribution of suspended particles showed higher variability at a given location over a month (temporal variability) than at a given moment over the whole lagoon (spatial variability).

In oceanic waters, the distribution of the number of particles per size, $n(D)$, generally fits a logarithmic curve (Mobley, 1994):

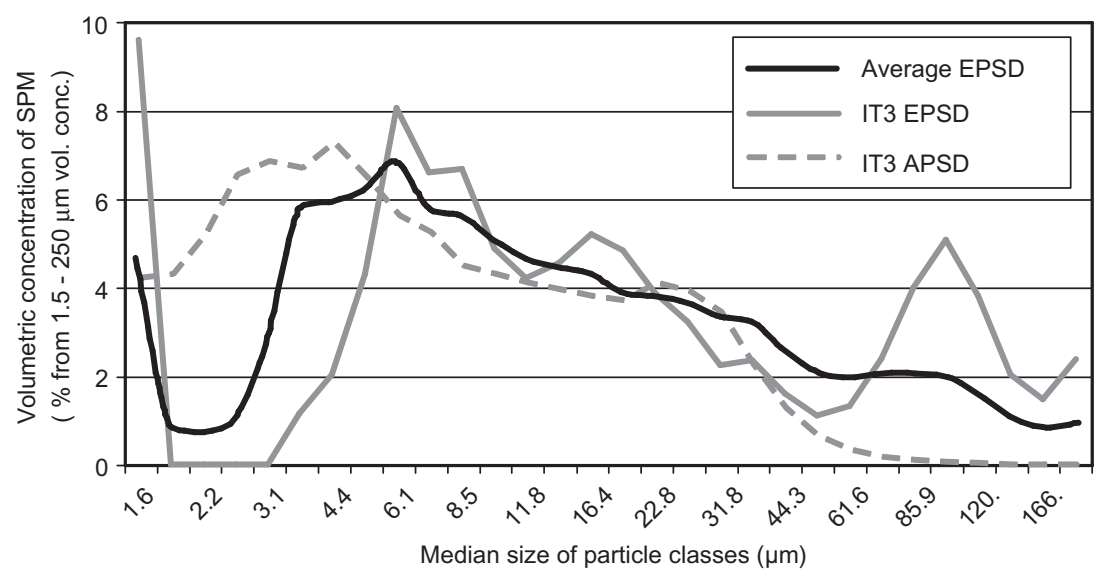

Fig. 19. Normalized volume concentration distribution on the SLNC (semi-log plots): average EPSD; EPSD and APSD at station IT3 (see location in Fig. 16). 
$n(D)=K_{1} D^{-s}$

where, $K_{1}$ is a constant, $D$ is the diameter of particles and $s$ is the slope of the best fitted linear relationship between $\log n(D)$ and $\log D . s$ is called the Junge parameter. It is a synthetical parameter characterizing the particle size distribution. High values correspond to SPM dominated by fine particles or aggregates while low values correspond to SPM dominated by macroflocs. $s=4$ generally fits the distribution of biological particles as they are encountered in open ocean waters (Mobley, 1994). The Junge parameter is also useful for calculations of radiative transfer in the water column and their applications to remote sensing. Jouon et al. (2008) mapped the Junge parameter in the SLNC. This parameter ranged from 2.6 to 3.5. These values were lower than in the open sea and show that large particles were relatively more abundant in SLNC waters than in the open ocean. The 2D Junge parameter distribution showed a distinct gradient from high values at the reef to decreasing values towards the coast.

The abundance of aggregates was estimated from the comparison between APSD and EPSD. Fig. 19 gives an example of both EPSD and APSD at station IT3 located in the outer lagoon between the Pirogues River mouth and the Dumbéa passage. All disaggregated samples had similar APSD, suggesting a similarity in size of the grains constituting the aggregates. In contrast, EPSDs were more scattered. The high percentage of individual particles of $<4 \mu \mathrm{m}$ in the APSD did not systematically appear in the EPSD, suggesting that these small grains were contained in aggregates. On the other hand, the APSD did not contain particles of diameters $>60 \mu \mathrm{m}$ suggesting these particles are aggregates in situ. The percentage of SPM contained in aggregates $>60 \mu \mathrm{m}$ always exceeded $38 \%$ in the SLNC and reached up to $90 \%$ in some cases. At 11 stations along

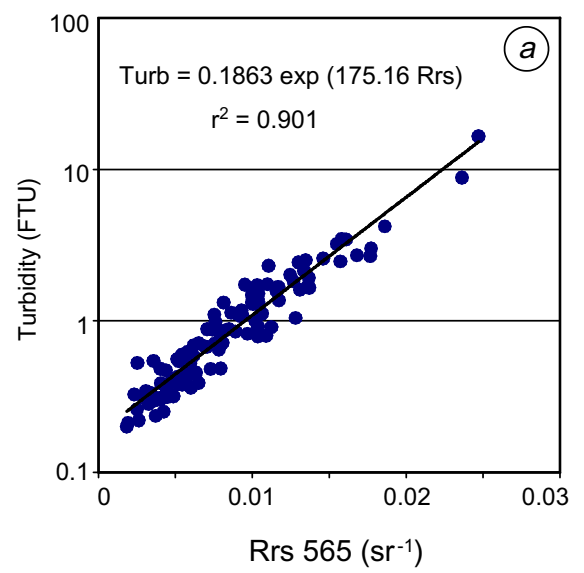

a reef-coast transect between the Boulari pass and the Pirogues River mouth, this value always exceeded $45 \%$. The higher values of relative abundance of large aggregates $(\sim 70 \%)$ were found in the vicinities of the barrier reef and coral islands. Aggregates thus represent a large fraction of the suspended particles and assuming that they were composed of only water and grains, their density was estimated to be $1.27 \mathrm{~kg} \mathrm{l}^{-1}$.

The origin of aggregation processes in the SLNC was discussed at the end of Jouon et al. (2008). Microscope visualization and chemical analysis of a sample suggested the inclusion of a transparent exopolymeric matrix. The relative abundance of aggregates relative to suspended particle volume concentration was found to increase as SPM decreased and the spatial distribution of aggregate relative abundance suggests that relative abundance is higher adjacent to the coral reefs. High concentrations of aggregates at low turbidity and the spatial distribution of relative abundance suggest that aggregation was induced by the presence of organic ligands. This assumption is consistent with other studies showing enhanced aggregation and reduced settling velocity around coral reefs (Wolanski et al., 2003; Hoitink, 2004). Finally, the study of Jouon et al. (2008) shows that in situ laser diffraction particle sizing provides a relevant optical measurement of suspended particulate matter in such aggregate-dominated systems and that these measurements are complementary to size sensitive optical backscattering and light attenuation measurements of SPM.

\subsection{Optical measurements of suspended particulate matter}

\subsubsection{Hyperspectral optical measurements}

Remote sensing provides an efficient tool for the monitoring of sediment transport and analysis of the fate and distribution of

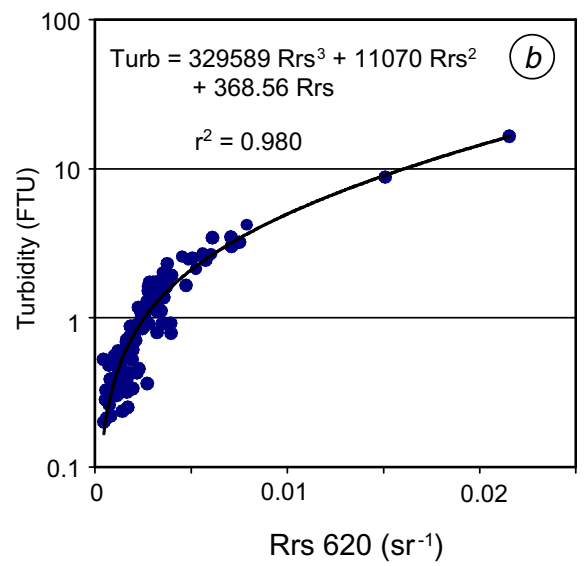

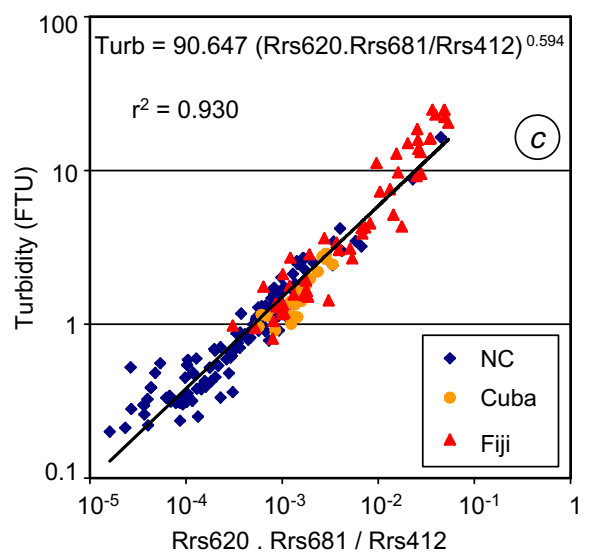

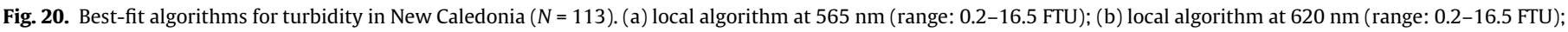
(c) three-band algorithm for tropical coastal waters based on merged data from New Caledonia (NC), Cuba and Fiji (range: 0.2-24.9 FTU). 
suspended matter in estuarine and coastal waters as it offers a synoptic and instantaneous field of the SPM concentration (e.g. Holyer, 1978; Curran and Novo, 1988; Doxaran et al., 2003; Bowers and Binding 2006). Satellite data makes it possible to gauge and validate models (Puls et al., 1994; Siegel et al., 1999) in integrated studies where numerical simulations of sediment transport and spatial imaging are coupled. However, the lack of a generic algorithm for quantifying SPM in coastal zones constitutes a major handicap for the development of SPM mapping by remote sensing (Acker et al., 2005).

A recent study mapped turbidity in the SLNC from ETM+ Landsat 7 data in order to support of calibration of a numerical model for fine suspended sediment transport (Ouillon et al., 2004). To build an algorithm, remote sensing reflectance (Rrs) spectra were deduced from radiance and irradiance measurements that were performed using an Ocean Optics USB2000 radiometer, and turbidity profiles were measured. Remote sensing reflectance just above the sea surface, Rrs, was measured using the protocol proposed by Mobley (1999). An empirical algorithm for turbidity in the SLNC was derived from an independent data set recorded from June 2002 to October 2003. The best-fit between Rrs and turbidity was established with the ETM+ band 2 (centered at $565 \mathrm{~nm}$ ) data. The algorithm was then applied to an ETM+ image acquired on October 23, 2002. A key element of this study was the availability of concurrent remote sensing and in situ data which enabled an estimation of the performance of the turbidity algorithm. The average difference between turbidity estimated from Landsat and turbidity measured at sea was $17.5 \%$ at 14 stations (with measurements at $+/-1 \mathrm{~h} 40$ from the satellite overpass).

Following on from this work, Ouillon et al. (2008) compared several turbidity algorithms at satellite wavebands useful for coastal applications, and for three tropical coastal zones selected for the diversity of their respective amounts of suspended matter and chlorophyll a (chl-a): oligotrophic and sediment-poor waters in the SLNC, eutrophic waters in Cienfuegos Bay (Cuba), and sediment-rich waters in Laucala Bay (Fiji). Turbidity values considered in this study were obtained from averaging turbidity profiles from the surface down to $3 \mathrm{~m}$ depth. Algorithms for the SLNC were based on 113 stations for the turbidity range 0.2-16.5 FTU. Amongst the one-band algorithms for turbidity, the best-fits were established with an exponential relationship at $565 \mathrm{~nm}$ (Fig. 20a) and with a cubic polynomial relationship at $620 \mathrm{~nm}$ (Fig. 20b). The mean bias and rms error were lower for the regression at $565 \mathrm{~nm}$ (3.11\% and $25.51 \%$, respectively) than for $620 \mathrm{~nm}(17.9 \%$ and $44.48 \%$, respectively), and the signal amplitude is higher at $565 \mathrm{~nm}$. However, the algorithm based at $620 \mathrm{~nm}$ induced a lower mean quadratic error ( $0.29 \mathrm{FTU})$ than at $565 \mathrm{~nm}$ (0.48 FTU). The algorithm at $620 \mathrm{~nm}$ is thus more suitable for high turbidity values. Therefore, in New Caledonia, the $565 \mathrm{~nm}$ exponential relationship seems to be more suitable in low turbid waters (dry season or fair weather conditions), and the $620 \mathrm{~nm}$ cubic polynomial algorithm is better for the highest turbidity waters (i.e. just after high discharge episodes or high resuspension events). This result was in agreement with the previous study which used ETM+ band 2 (centered at $565 \mathrm{~nm}$ ) data (Ouillon et al., 2004). This higher sensitivity of reflectance at low SPM concentration has already been reported for shorter wavelengths (Holyer, 1978).

The feasibility of a valid single algorithm for different tropical coastal sites was also investigated by Ouillon et al. (2008). Global one-, two- and three-band algorithms were derived for the merged data set composed of 113 stations in the SLNC, 24 in Cuba and 56 in Fiji. Two three-bands gave fair regression statistics, both globally and per site. Amongst them, the best algorithm for New Caledonia is based on Rrs at 412, 510 and $681 \mathrm{~nm}$ (Fig. 20c). This algorithm proved to be suitable for the $0.2-24.9$ FTU turbidity range and for the three sites sampled. In New Caledonia, its performances are comparable with those of the local algorithms (mean bias: $1.9 \%$, rms: $28.2 \%$, mean quadratic error: $0.35 \mathrm{FTU}$ ) and it is suitable for both low and high (but $<25$ FTU) turbidity values as encountered in the SLNC.

Hyperspectral optical measurements in the SLNC have also been used to study the optical properties of Trichodesmium sp. (Dupouy et al., 2008) and to monitor chlorophyll pigments in the lagoon (Dupouy et al., 2010). The comparison between distributions of inherent optical properties, sedimentological parameters and habitats in the lagoon waters is underway.

\subsubsection{Monochromatic optical measurements}

The relationship between SPM concentration and its main monochromatic optical proxies (turbidity and light attenuation) were studied in the SLNC by Jouon et al. (2008). Turbidimeters, also called nephelometers or Optical Backscatter Sensors (OBS), are known to provide turbidity measurements proportional to sediment concentrations at values less than $10 \mathrm{gl}^{-1}$ (Bunt et al., 1999) with the proportionality coefficient varying from a site to another. Based on 111 stations with concurrent measurements of turbidity, light attenuation at $670 \mathrm{~nm}$ (hereafter denoted c670) and SPM volume concentration, Jouon et al. (2008) showed that the determination coefficient between turbidity and mass concentration $\left(r^{2}=0.77\right)$ was better than the one obtained for volume concentration $\left(r^{2}=0.58\right)$ and $6670\left(r^{2}=0.48\right)$. Dispersed patches of points were obtained for low mass concentrations $\left(<1 \mathrm{mg} \mathrm{l}^{-1}\right)$. These rather low coefficients indicated that the relationship between mass concentration and bulk optical measurements of SPM is not straightforward. The slope of the linear regression between turbidity and mass concentration [Turbidity (FTU) $=1.85$ Mass Concentration ( $\left.\mathrm{mg} \mathrm{l}^{-1}\right)$ ] was about $85 \%$ higher than that usually encountered in turbid estuaries. This slope is strongly dependent on particle diameter and gets steeper with decreasing diameter (Bunt et al., 1999). Furthermore, for a given particle size, terrigenous particles and biogenic particles have different scattering and backscattering efficiencies due to their different refraction indexes. An example is given by Shifrin and Zolotov (1995): terrigenous clay particles with typical index of refraction $m_{r}=1.15$ have higher backscatter than biogenic clay particles with $m_{r}=1.03$ for a monochromatic carrier wave at $\lambda=532 \mathrm{~nm}$.

The comparison of correlation between the OBS signal and each class of the EPSD highlighted that turbidity was more sensitive to the smallest particles (between 2 and $22 \mu \mathrm{m}$ ). This result supports previous results suggesting a correction of OBS signal to derive SPM concentration by taking into account the median diameter of EPSD (e.g. Lynch et al., 1994). Aggregation increases the mean diameter of particles and is known to be responsible for lowering the turbidity signal at an equal mass concentration (Gibbs and Wolanski, 1992). The variability of the percentage of aggregates (see Section 4.3) therefore likely explains the low correlation between turbidity and mass concentration as compared to other coastal zones.

The highest correlations between c670 and SPM volume concentration were found in two size intervals which extend from ca. $3-5 \mu \mathrm{m}$ and from ca. $40-100 \mu \mathrm{m}$. The first size range (3$5 \mu \mathrm{m})$ is in accordance with previously published results: beam attenuation increases with decreasing mean grain size at the same SPM (Baker and Lavelle, 1984; Boss et al., 2001). The second interval of high correlation between c670 and LISST data EPSD ( 40$100 \mu \mathrm{m}$ ) corresponds approximately to the abundant, smallest particles identified as aggregates in the SLNC: these particles may not be large enough to efficiently attenuate light. The reduction of the correlation coefficients in the large bin sizes of LISST is probably due to the negligible contribution of the coarse particles to turbidity and mass concentration. This suggests that coarser particles backscatter light less efficiently and have a lower density. 


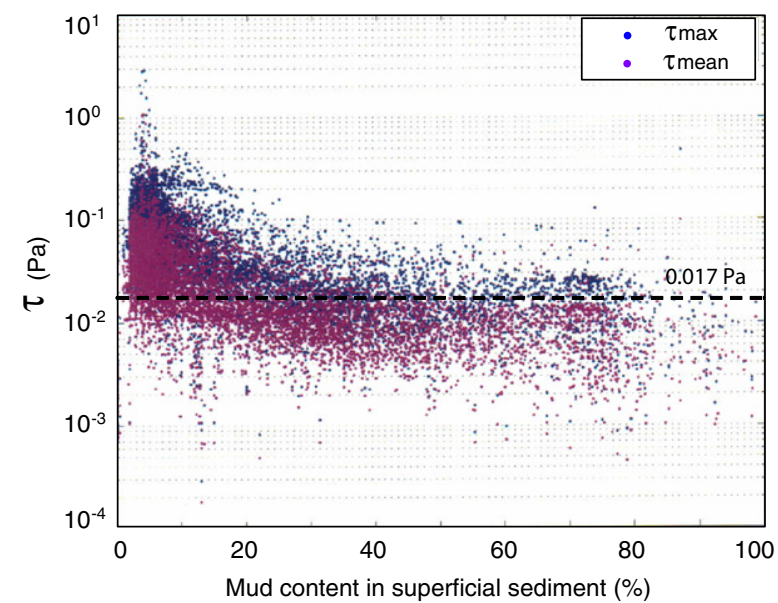

Fig. 21. Maximum and averaged shear stress versus percentage of mud in the superficial sediment at each grid point of the SLNC (M2 + S2 average tide; constant and uniform trade wind, $110^{\circ}, 8 \mathrm{~m} \mathrm{~s}^{-1}$ ).

\subsection{Modelling}

The study by Douillet et al. (2001) was, to our knowledge, the first numerical model based study of the transport of fine suspended sediments in a coral reef lagoon. The study considered the transport of fine sediment particles of equivalent diameter of $7 \mu \mathrm{m}$. This value corresponds to the most largest population of fine sediment deposits in the SLNC as determined in laboratory by laser (O'Callaghan, 1999), and also because it is similar to the $6-\mu \mathrm{m}$ diameter particles transported by river to the Dumbéa Bay during a cyclone event (Baltzer and Trescases, 1971a). At the time of model development, we did not have an estimation of aggregate size measurement in the water column.

A basic advection-diffusion equation calculated the concentration at every mesh grid under the influence of water velocity, particle fall velocity, and turbulent mixing. The particle fall velocity was estimated from the application of Stokes relationship to $7 \mu \mathrm{m}$ diameter spheres of density $2650 \mathrm{~kg} \mathrm{~m}^{-3}$. Vertical eddy diffusivity of particles was considered to be proportional to the vertical eddy viscosity from the bottom up to its maximum value, and thereafter constant in the upper layer, as suggested by van Rijn (1986). Exchanges at the bottom between flow and the seabed resulted from both deposition (Krone, 1962) and erosion (Partheniades, 1965). These parameterizations introduced three parameters for which calibration is needed: the critical shear stress for deposition, $\tau_{c d}$, above which no deposition occurs; the critical shear stress for erosion, $\tau_{c e}$, above which erosion occurs; and, the local erosion rate coefficient, $k_{e}$. A calibration of these parameters was proposed.

Initially, the critical shear stresses for deposition and erosion were assumed to be equal, a hypothesis that also adopted, e.g. Warner et al. (2008). Assuming that superficial sediment distribution is mainly controlled by trade winds (Larcombe and Woolfe, 1999), the critical shear stress was set as the bottom shear stress value at the limit of the mud-dominated areas for mean trade wind and tidal forcing, as calculated by the model (which did not take waves into account). The mean and maximum shear stress at each grid point of the lagoon was plotted against the mud content of the superficial sediment (Fig. 21). Mean shear stress appeared to be generally lower than $0.017 \mathrm{~Pa}$ (or $\mathrm{N} \mathrm{m}^{-2}$ ) over muddy areas (\% mud $>30 \%$ ) and higher than this value where sand was highly dominant (>80\%). The first estimate of a coarse critical shear stress for the entire lagoon was thus taken equal to $0.017 \mathrm{~Pa}$, corresponding to a critical shear velocity $u_{*}=0.4 \mathrm{~cm} \mathrm{~s}^{-1}$.
The erosion rate was assumed to equal a global fitting parameter multiplied by the local amount of mud in the superficial sediments (between 0 and 1 ) as the numerical simulation considered that only the muddy part of sediment could be resuspended. The bulk fitting parameter was estimated such that, during a tidal cycle and considering the entire SLNC, erosion equalled deposition.

Using these parameters, the computed deposition areas were in very good agreement with the distribution of the percentage of mud at the seabed (Fig. 5 and Fig. 6C in Douillet et al., 2001). The model permitted the analysis of the respective influences of tide and wind on deposition and erosion. In the case of average trade winds $\left(110^{\circ}, 8 \mathrm{~m} \mathrm{~s}^{-1}\right)$, the influence of wind was shown to predominate in the exchange at the seabed at depths $<20 \mathrm{~m}$; for the same meteorological condition, the tide was shown to mainly determine particulate transport, vertical mixing in the water column and deposition rates in the deeper areas. Bouron-Morin (2001) implemented a model of sand transport within the lagoon, however no data were available for its validation and only sensitivity analysis was performed.

The fine sediment transport model was applied to an episode for which both turbidity measurements and a map of SPM concentration deduced from Landsat data were available (Ouillon et al., 2004). Assuming an unchanged critical shear stress throughout the lagoon, we refined the distribution of the erosion rate coefficient. The deriving distribution showed much higher erosion rates in the bays, especially at the heads (Fig. 6 in Ouillon et al., 2004). This supported the idea of higher erodibility in the areas of high terrigenous particles, and thus that erodibility could be highly sensitive to the terrigenous vs. carbonate content of the superficial sediments.

However, as mentioned by Nikora et al. (2002), the mechanisms of exchange between the bottom and the water column are still poorly understood. Erosion is dependent not only on average hydrodynamics but also on fast and high-energy events like bursts, and the limitations of modelling reflect the limitations of our knowledge. To improve our understanding of resuspension processes and to propose ad hoc formulations to be integrated in the model, an experiment was conducted to measure the critical shear stress of erosion and the erosion flux according to sedimentological and hydrodynamic parameters. This was conducted on many representative sediment samples of the SLNC (see Section 4.6).

The fate of metals brought by the Coulée River in Boulari and Sainte-Marie Bays was studied by Fernandez et al. (2006) in another particulate transport modelling experiment. The Coulée's basin was subject to an ore production of $425 \times 10^{3}$ tons over a period of 100 years and many non rehabilitated mining sites still remain. This multi-disciplinary study combined sedimentological, geochemical and hydrodynamic (numerical model) approaches. $\mathrm{Ni}, \mathrm{Cr}, \mathrm{Zn}$ and $\mathrm{Mn}$ concentrations contained in various geochemical phases of the pelites were interpreted and compared to sedimentological data and to 3D numerical simulations of lagrangian transport of non settling particles throughout the lagoon. The results show that particle inputs by the Coulée River can reach SainteMarie Bay. Although quantitatively low $(1-4 \%$ of the pelite mass in the bay sediments), the terrigenous contribution of the Coulee River represents more than $7000(\mathrm{Ni})$ and more than $4200 \mathrm{mg} \mathrm{kg}^{-1}$ (Cr) of the exported particulate matter towards areas initially uncontaminated by mining activities. The study of the distribution of labile $\mathrm{Zn}$ also highlights the contribution of anthropogenic inputs in Sainte-Marie Bay. On the whole, this work underlines the impact of scrubbing of a non-remediated basin as compared to the recent extraction in New Caledonia (7.5 millions tons in 1998).

\subsection{Erodibility}

Erodibility of sediment beds depends on abiotic parameters such as type, porosity and consolidation of the surface sediments, 

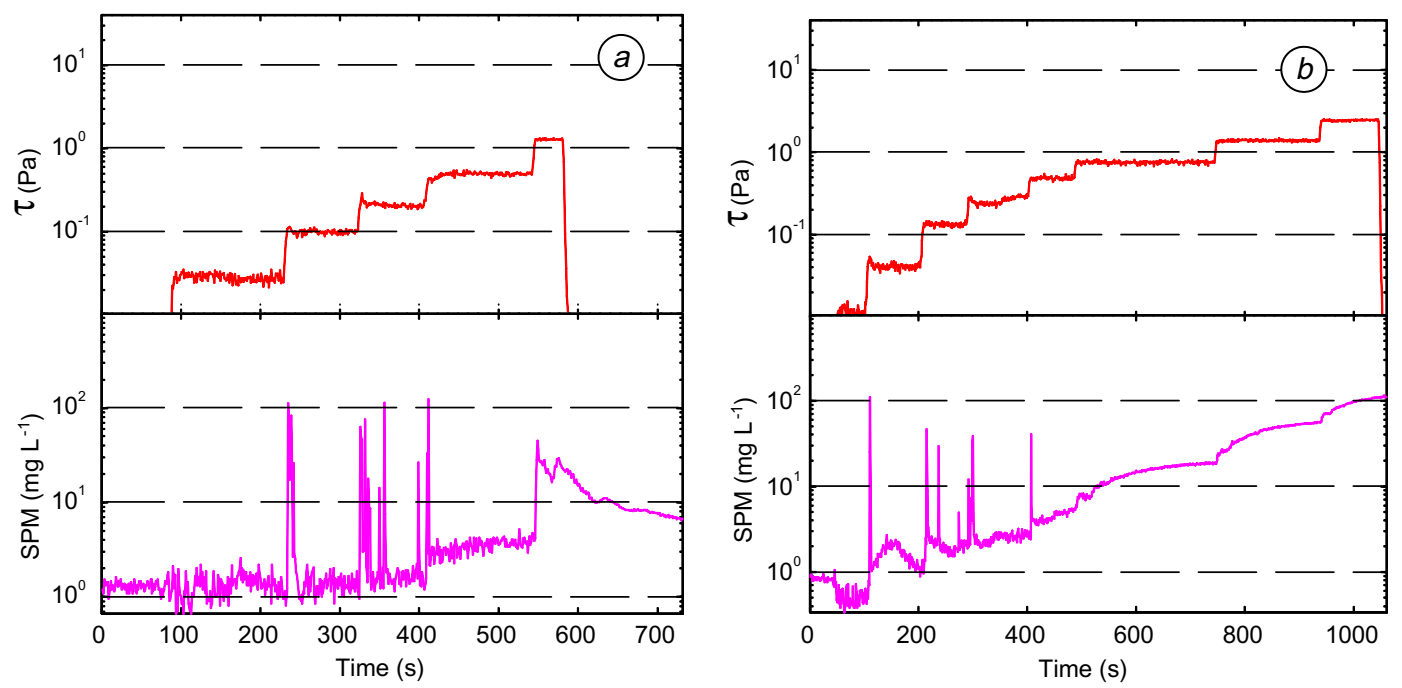

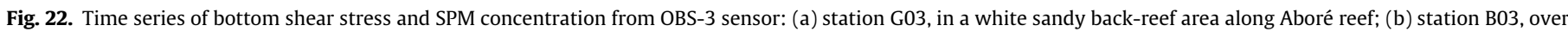
muddy bottom near the Coulée River mouth.

and on biotic factors such as the presence of bioturbators or biostabilizators. On heterogeneous beds, erodibility is dependent on the percentage of sand and mud (Mehta and Lee, 1994), and on the terrigenous or biogenic origin of the particles. Biogenic particles lithify more quickly than terrigenous particles and can form hard substrates (maërl or limestones) over large areas; marine muds are also more compacted and less fluid that terrigenous muds (Chevillon, 1996; Tixier, 2003; Ouillon et al., 2004). Benthic biological activity, often highly abundant in coral reef environments, can significantly modify the resuspension or retention of particles through the presence of seagrass, cyanobacteria, and bioturbation (Yahel et al., 2002). It is usually assumed that living organisms (animal and vegetal) exert a significant influence on physical processes such as erosion in tropical environments (Woodroffe, 2000).

Field measurements of soft bottom erodibility in the SLNC were conducted in October 2007. An erodimeter developed by Ifremer (Le Hir et al., 2007, 2008) was used to sample twenty-nine stations by scuba-diving. For each sample, erodibility was analysed at the sediment surface and at one or two horizons below the surface. The erosion parameters (critical stress shear, rate of erosion) are concurrently analyzed along with sedimentological parameters (grain size distribution, carbonate content, water content) and the microphytobenthos compartment (content in chl-a).

Two examples are given in Fig. 22, at station G03 in the white sand back-reef area (Fig. 22a), and at station B03 over muddy bottoms off the Coulée River mouth (Fig. 22b). Preliminary results show that two critical thresholds of shear stress can be observed at some stations. The lowest value likely corresponds to the erosion of the fluff layer (see Fig. 22a when $\tau=0.1 \mathrm{~Pa}$ ), the highest value to that of the underlying particles (see Fig. 22a when SPM sensitivity increases when $\tau=0.2 \mathrm{~Pa}$ ). The fluff layer, mainly present in near-shore areas, could be the source of resuspension, since this layer is very soft and highly erodible. A two-layer concept of the sediment interface which distinguishes between an underlying sediment layer and a more easily resuspendable surface aggregate layer has already shown by Thomsen and Gust (2000) on a continental margin. Future studies should examine the specific mechanical and chemical properties of the fluff layer in relationship to resuspension events. The preliminary results obtained for Dumbea Bay, Boulari Bay and the back-reef area show that the threshold for erosion of the fluff layer was generally less than 0.07 Pa while for the erosion of bed sediments varied between 0.03 and $0.6 \mathrm{~Pa}$.
The applicability of the unified erosion relationship proposed by Sanford and Maa (2001) is under discussion. Erosion peaks are observed not only at the onset of each shear stress level but also within each level (see Fig. 22a when $\tau=0.2 \mathrm{~Pa}$ and Fig. 22b when $\tau=0.13 \mathrm{~Pa}$ ). These latter peaks could correspond to the sudden erosion of "plates" that are not integrated into standard erosion formulas.

The comparison of the SPM concentrations at two stations (B03 and G03) with equivalent shear stress, confirms that erosion is higher over muddy areas with high amounts of terrigenous particles than it is over sandy areas dominated by biogenic particles. This data is being used to derive erosion formulas for the lagoon of New Caledonia that could be used in a numerical hydro-sedimentary model. A specific paper is being prepared.

\subsection{Particle inputs and attempt of sedimentary budget}

\subsubsection{Particle inputs}

The catchment area of Dumbéa and its marine prolongation (alluvial plain, mangroves and bay) were studied in detail by geologists and hydrologists in the 1960's and 70's (Baltzer and Trescases, 1971a, b; Launay, 1972). Baltzer and Trescases (1971a) gave the first estimates of solid discharge and specific degradation

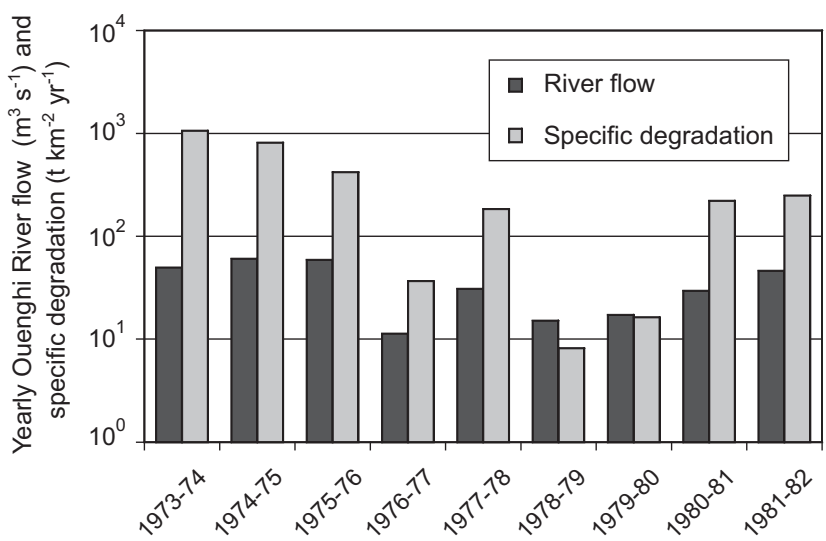

Fig. 23. Specific degradation of the Ouenghi River (1973-1982) and of the Pouembout River (1975-1982). 
of the Dumbéa River basin (without mining activity) taking into account cyclone activity. They estimated mechanical erosion to be around $20 \mathrm{t} \mathrm{km}^{-2} \mathrm{yr}^{-1}$ (i.e. $11 \mathrm{~mm}$ per millennium with density 1.8 ) and the chemical erosion to be around $89 \mathrm{t} \mathrm{km}^{-2} \mathrm{yr}^{-1}$ (i.e. $27 \mathrm{~mm}$ per millennium with density 3.3). Mechanical erosion was estimated from SPM and river discharge measurements during two cyclones and then extrapolated to all cyclones occurring during one century in New Caledonia. Chemical erosion was estimated from chemical analysis of water samples. These estimations were the only data available for more than 20 years. In 1994, Laganier (1994) published the results from nine years (1973-1982) of river flow and solid discharge measurements from several rivers on West Coast of New Caledonia, including the Ouenghi River whose mouth is just north of the SLNC. The Ouenghi basin has been exploited for mining ore since 1975 and Laganier quantified the change induced both naturally and by mining activities since 1975. Laganier also quantified the cumulated flux of particles in the Dumbea basin over a 20 years period from 1972-1992.

The values of Laganier (1994) show a high temporal variability of solid discharge. Because of highly irregular rainfall, solid discharge can be near zero during years of low rainfall and can reach extremely high values during high flow episodes like cyclones. These hydrological events favour resuspension of deposits in the river (scrubbing of accumulations on glacis and piedmonts, undermining of river banks). In the Ouenghi River, the annual solid discharge varied between $2 \times 10^{3}$ and $260 \times 10^{3}$ tonnes per year (average: 82; standard deviation: 111\%). In the Pouembout River, further North, the inter-annual variability was higher (standard deviation: $172 \%$ ). The specific degradation, which is the ratio of the solid discharge to the basin area, allows an inter-basin comparison; temporal variations of the river flow and of the specific degradation of the Ouenghi River are shown on Fig. 23. For each river, the standard deviation of solid discharge (in \%) was about twice that of river flow (54\% for the Ouenghi River, $97 \%$ for the Pouembout River). Solid discharge considerably amplifies the irregularity of flow. Due to their high variability at seasonal (Fig. 2) and inter-annual scales (Fig. 23), and because of the dominant influence of high-energy events like storms, the rivers of New Caledonia exactly behave like wadis in semi-arid environments (Achite and Ouillon, 2007).

The intra-annual variability was extremely high. The annual solid discharge was generally explained by only one high flow episode. Laganier (1994) showed a consistent relationship between the annual flux of particles and the maximum of the daily discharge during the year. He also quantified the rate of suspended flux associated with different events over the period 1973-1982. The highest flow event delivered $29.5 \%$ of the 9 -years cumulated total solid flux. The five highest flow episodes delivered $76.9 \%$, and the ten highest flows $87 \%$ of the total particulate output. The ten highest flow episodes lasted approximately 13 days in total as compared to 9 years of observation.

High solid discharge occurred during the warm and wet season, while it remained very low or zero during the cool and dry season when rivers deliver infiltrated waters and draining of ground waters which do not favor suspended particulate transport. Laganier (1994) gave estimates of specific degradation and compared values amongst adjacent lateritic basins with low and high mining activities. When rainfall was low, the specific degradation was low everywhere (between 8 and $200 \mathrm{t} \mathrm{km}^{2} \mathrm{yr}^{-1}$ ). A value of $1060 \mathrm{t} \mathrm{km}^{2}$ was reached in 1973-1974 in the Ouenghi basin when a new opencast mine came into service and during the construction of its main road. Following Laganier (1994), the solid discharge was three times higher during the opening phase of the mine (1973-1975) than during its exploitation (1975-1982). In the Pouembout basin, specific degradation averaged $160 \mathrm{t} \mathrm{km}^{2} \mathrm{yr}^{-1}$ from $1975-1976$ to $1980-1981$ and reached $1930 \mathrm{t} \mathrm{km}^{2}$ in 1981-1982 because of cyclone Gyan on 24th December 1981. Laganier (1994) also showed that, from dry to wet years, specific degradation was multiplied by higher factors over exploited areas than over non-exploited areas. Specific degradation over exploited sub-basins can be 12 times higher than its value over preserved sub-basins during a rainy year.

Assuming "averaging" is meaningful over such highly variable hydrological years, specific degradation can be considered to be around $240 \mathrm{t} \mathrm{km}^{2} \mathrm{yr}^{-1}$ in the exploited basin of the Ouenghi River for the period 1974-1982 (160 $\mathrm{t} \mathrm{km}^{2} \mathrm{yr}^{-1}$ for 1975-1982), and around $150 \mathrm{t} \mathrm{km}^{2} \mathrm{yr}^{-1}$ in the Dumbéa basin for the period 19721992. Laganier (1994) estimated the flux of dissolved matter to be around $50 \mathrm{t} \mathrm{km}^{2} \mathrm{yr}^{-1}$ in the Ouenghi basin, thus correcting the importance of fluxes of particulate versus dissolved matter as previously estimated by Baltzer and Trescases (1971a). Laganier (1994) also showed that when mining companies take mitigation measures, specific degradation can be reduced.

\subsubsection{Vertical fluxes of suspended particles}

Particle settlement is generally rapid in the lagoon. On October 2, 2001, $174 \mathrm{~mm}$ of water fell in Nouméa and around $200 \mathrm{~mm}$ in Dumbéa during a 5-h intense rainfall episode. The day after, a turbid plume was visible in Dumbéa Bay. The plume was restricted to the bay and a distinct front with lower turbidity was visible at the center of the bay. The following day the turbid plume was no longer visible, however a phytoplanktonic bloom extended out to the Dumbéa passage. Cyclone Erika which passed over Noumea on March 14, 2003 provided another illustration. Three days after the cyclone, turbidity values were five times higher than usual in the SLNC and seven days after the cyclone turbidity in the lagoon had returned to the usual levels.

Three sequential sediment traps were deployed in the lagoon over 24-day periods (12 successive sequences of $48 \mathrm{~h}$ ) during different seasons in order to measure deposition (Heussner et al., 1990). The first studies compared fluxes in the Dumbéa and Uitoé inlets, in the Dumbéa and Uitoé canyons, and in Dumbéa Bay (Magand, 1998, 1999). In May-June 1998, the averaged fluxes were $8.8 \mathrm{~g} \mathrm{~m}^{-2}$ day $^{-1}$ in Dumbéa Bay, $11.7 \mathrm{~g} \mathrm{~m}^{-2}$ day $^{-1}$ in the Dumbéa pass, and $4.9 \mathrm{~g} \mathrm{~m}^{-2}$ day $^{-1}$ in the Uitoé pass (Magand, 1998). The 24-day period of measurements encompassed three episodes of high deposit, one trade wind episode, one westerly wind episode, and one combination of trade wind and rain. At the beginning of the sequence, resuspended carbonate particles largely dominated. At the end of the sequence, concentrations were higher and terrigenous particles were also detected. The SPM contains a mix of resuspension and riverine contributions. Deposits were smaller in March-April 1999 with, on average, $6.3 \mathrm{~g} \mathrm{~m}^{-2}$ day $^{-1}$ in Dumbéa Bay, $9.9 \mathrm{~g} \mathrm{~m}^{-2}$ day $^{-1}$ in the Dumbéa canyon and $2.0 \mathrm{~g} \mathrm{~m}^{-2} \mathrm{day}^{-1}$ in the Uitoé canyon. The sequentially measured rainy period fluxes exhibited a four day lag between the post-flood reduction in vertical particulate flux in Dumbéa Bay and the reduction in vertical particulate flux in the Dumbéa canyon (Magand, 1999). Very high standard deviations (between $85 \%$ and $232 \%$ per trap and per period, for 1998-1999) demonstrated the strong variability of sedimentation flux in the lagoon and in the channels. Mineralogical analysis of particles collected in the traps showed a clear prevalence of carbonated minerals (in decreasing order: aragonite, magnesium calcite and calcite). The main minerals of detritic origin were quartz (most abundant mineral), vermiculite and antigorite (Magand, 1998).

Additional series of sedimentation flux measurements within the PNEC programme were performed during the dry season (November-December 2005) close to the river mouths in Boulari, Dumbéa and Saint-Vincent Bays (Fernandez et al., submitted for publication). The fluxes near the river mouths largely exceeded the values measured by Magand (1998, 1999), even during the dry season. The average fluxes were $22.2 \mathrm{~g} \mathrm{~m}^{-2}$ day $^{-1}$ at the head 
of Dumbéa Bay, $24.1 \mathrm{~g} \mathrm{~m}^{-2}$ day $^{-1}$ in Boulari Bay and $37.7 \mathrm{~g} \mathrm{~m}^{-2}$ day $^{-1}$ in Saint-Vincent Bay. These fluxes are mainly explained by wind variations in Boulari Bay, by the neap / spring tide cycle in Saint-Vincent Bay, and by the combined influence of wind and tide in Dumbéa Bay. Surprisingly, the standard deviation had similar absolute values as in 1998-1999 in the lagoon $\left(8.2 \mathrm{~g} \mathrm{~m}^{-2}\right.$ day $^{-1}$ on average versus 8.3 in average in 1998-1999), but were of less relative importance ( $27 \%$ vs $135 \%$, in average). Grain size distributions of the suspended particles in the vicinity of the traps were also measured. They showed that larger particles in Boulari Bay were collected after a resuspension event than during it, potentially because of aggregation. The average median diameter $\left(D_{50}\right)$ was $49 \mu \mathrm{m}$ at Boulari, 63 at Saint-Vincent and 67 at Dumbéa. The smaller median size at the Boulari station may be attributed to two possible reasons: a longer distance between the station and the river mouth, and the presence of less organic matter in Boulari Bay to serve as floc matrix.

\subsubsection{Sedimentation rate}

Clavier et al. (1995) measured net sedimentation rates averaging $3 \mathrm{~g} \mathrm{~m}^{-2}$ day $^{-1}$, which vary between 2 and $4 \mathrm{~g} \mathrm{~m}^{-2}$ day $^{-1}$ from one station to another and from $2 \mathrm{~g} \mathrm{~m}^{-2}$ day $^{-1}$ over grey sand bottoms (at $16 \mathrm{~m}$ depth, around Larégnère Island) to $4 \mathrm{~g} \mathrm{~m}^{-2}$ day $^{-1}$ over muddy bottoms (at $28 \mathrm{~m}$ depth, Rocher à la Voile). Care should be taken with the absolute values resulting from averaging between May 1986 and April 1987 as they show increasing concentrations in 1987 (see e.g. April 87 vs. May 86) that are partly due to stronger wind and enhanced resuspension during the $\mathrm{El}$ Niño event of 1987 . The given value of $3 \mathrm{~g} \mathrm{~m}^{-2}$ day $^{-1}$ should thus be considered as a high estimation of the sedimentation rate as compared to the neutral ENSO period. It is clear that a study similar to that of Clavier et al. (1995) conducted over a long period is required in order to characterize the inter-annual variability of resuspension and deposition.

The net sedimentation of Particulate Inorganic Matter (PIM) was estimated by Clavier et al. (1995) to be, in average, $400 \mathrm{~g} \mathrm{~m}^{-2} \mathrm{yr}^{-1}$ (i.e. $1.1 \mathrm{~g} \mathrm{~m}^{-2}$ day $^{-1}$ ). This very low value corresponds for a measured density (2.5) and average porosity (46.4\%) to an increase of the sediment layer of $0.34 \mathrm{~mm} \mathrm{yr}^{-1}$ on average (from 0.22 near the reef to 0.42 near the shore). It is mainly composed of terrigenous particles and confirms the generally low contribution of terrigenous input to the lagoon sedimentation in the SLNC.

Over the long term, temporal variations of sedimentation measured on sediment cores demonstrate the influence of mining activity during the twentieth century. In Sainte-Marie Bay which collects particles from the Coulée River basin, Fernandez et al. (2006) show that the sedimentation rate was multiplied by three after the beginning of mining activities during the twentieth century. This increase was attributed to the enhanced erosion due to the open-cast mines of the Coulee River basin. Even if sedimentation rates remained low, the metal input to the lagoon significantly increased. However, the effects of anthropogenic activities on coastal environments are not straightforward, as underlined by Debenay and Fernandez (2009) who recently showed that different tools used for assessing this impact (geochemistry and bioindicators) may lead to apparently contradictory interpretations, as evidenced by the increasing benthic Foraminifera species richness and diversity in Sainte-Marie Bay.

\section{Conclusion and recommendations for further research}

The variability of SPM concentrations and sedimentation fluxes results from the joint actions of tide, wind, precipitation and, for the reef and back-reef, oceanic swell. Very irregular precipitation brings sporadic inputs of terrigenous material. When swell is significant, the surge on the reef results in a significant entry of oceanic water into the lagoon and generates a current along the reef. In high-energy events, the back-reef receives carbonated particles from the reef. The coupling of tide and wind causes short, daily episodes of resuspension and transport (from a few minutes to a few hours) over short distances. Transport often occurs in the benthic nepheloid layer. Recurrent tide and wind conditions seem to organize the sedimentary facies which present very good correlations with hydrodynamics near the bottom, and, in particular, with bottom shear stress. Material of terrigenous origin is more easily resuspended than biogenic particles.

The PNEC programme made it possible to obtain detailed knowledge of the circulation in the SLNC and the study and parameterization of some processes like the wave set-up induced by the swell breaking on the reef barrier. Charting of residence time, which is important for ecological studies, the identification of some particularly sensitive areas (e.g. the southern gyre) and the improved description of suspended matter in the lagoon and its grain size distribution were also possible. The analysis of erodibility of heterogeneous soft bottoms, the mapping of surface SPM from multispectral remote sensing, and the understanding of the temporal evolution of SPM along with the calibration/validation of SPM modelling were also made possible by this program. The topical studies supported by the PNEC programme during the early 2000's enabled the complete or partial response to the initial questions listed in Section 1.2. These studies will help to guide future research programs in this area and as well as aiding its management. It is probable that these studies will also be useful for the understanding of other coastal reef environments.

Regarding hydrodynamic processes, turbulence remains to be studied in the lagoon since its impact on particle mixing, aggregation, disaggregation and particle settling is high. The study of turbulence in relation to stratification is essential for the improvement of hydrodynamic and sediment transport models. The study of waves breaking on the reef brought new and interesting results however, the question remains of their applicability to other reef portions of different outer slopes and angles to main swell direction. Future experiments such as that conducted in October 2005 are needed in reef sections with different topographical profiles and incidences to the oceanic swell. Friction coefficients over the reefs as well as over different substrates, and maps of ripples and other bedforms (possibly using acoustic measurements) would be also helpful for modelling. Concerning models, we now have all the pieces necessary to develop a full 3D hydrodynamic model of the lagoon that is forced at its boundaries by regional oceanic circulation, atmospheric and wave models and that integrates the wind waves-current interactions.

Regarding suspended particles, variability of grain size distribution should be analyzed against the hydrological regimes, seasons, ENSO-influence, turbulence, stratification, and their content in organic matter. Long time series of turbidity or SPM concentration, grain size distribution and other parameters should be measured in future programs as previous studies have demonstrated the high inter-annual variation in sediment inputs and climate or meteorological forcing.

A thorough study of the vertical distribution of suspended particles is needed in order to understand the impact of thermo-haline stratification, where and when does the benthic nepheloid layer develop, and to determine if thin turbid layers are present. Thomsen and McCave (2000) showed that the BBL height in the deep sea varies with time and was approximately equal to $4000 u_{*}$ (where the shear velocity $u_{*}$ is related to the bottom shear stress following $\left.\tau=\rho u_{*}^{2}\right)$. Unfortunately, no concurrent measurements of BBL height and velocity depth-profiles are available for the SLNC, and no modelling exercise has compared BBL height and $u_{*}$ variation. 
This exercise needs to be done in future studies. The detection of thin layers and a dedicated analysis of this process with ad hoc gauges is also required. These interfaces and internal wave activities are still only considered in an empirical way in models (Kantha and Clayson, 2004) and their horizontal wavelength is too short to be simulated and reproduced by numerical codes applied in coastal areas (Baumert et al., 2000). However, thin layers and internal wave activities are likely major processes which constrain the vertical distribution of SPM and their fluxes.

Understanding aggregation processes in clear-water coral reef environments is still a challenge. Studying processes involved in resuspension, like erodibility, and sediment trapping should continue against the significant parameters of both local hydrodynamics and subtrates, with a focus on the impact of benthic vegetation (algae, seagrass, cyanobacteria) and bioturbation of animal origin. Such process studies as well as continuous measurements of solid discharges at the river mouths are strongly encouraged. Linking modelling and measurements, the first numerical simulations by Douillet et al. (2001) estimated the sedimentation rate of 2600 tonnes per tidal cycle over the whole SLNC which corresponded to an average value of $2.5 \mathrm{~g} \mathrm{~m}^{-2} \mathrm{day}^{-1}$. This value resulted from an assumed balance between deposition and erosion. However, the net sedimentation rate is not zero (Section 4.7.3), and we now have of a series of sedimentation fluxes that were measured in the bays, in the lagoon and in the passages (Section 4.7.2). These measurements, along with new formulations for erosion (Section 4.6), the availability of satellite data, the introduction of a multi-class model of particulate transport (e.g. Blaas et al., 2007; Warner et al., 2008) mean that enhanced suspended sediment transport modelling in the lagoon is now possible.

Measurements, modelling and analysis of high-energy events (storms, strong precipitations, and cyclones) should not be ignored in the future. Adapted instruments and methodology could help to quantify radial displacement of sediment mass (Gagan et al., 1990). The technical solutions developed for measuring flash floods in arid or semi-arid environments (e.g. Alexandrov et al., 2007) could be adopted for the rivers of New Caledonia, as one single event can bring more particles than during the rest of the year. Monitoring could also be performed just after the peak of high energy, by use of common gauges and, if possible, of remote sensing. Moreover, the assessment of sediment fluxes above the reef requires attention.

The interactions between particulate transport and living organisms in tropical lagoons have several consequences. High biological activity is a factor of over-exposure of ecosystems to human activities which can potentially impact their dynamics (Hodgson, 1999). The interdependence between biology and physics means that these environments are highly sensitive to changes of anthropogenic origin, and thus require heightened monitoring. The context of global climate combined with local increases in mining activities should encourage public authorities to set up long term monitoring of the lagoon. Furthermore, as stated by Andrews and Pickard (1990), one major difficulty of studying reefs is finding physical datasets that are sufficiently long to determine the influence of processes at different scales. The observatory actually being set up between New Caledonia and French Polynesia ("Grand Observatoire du Pacifique Sud") should aid both coastal and land management and support follow-on scientific research.

The SLNC represents about $10 \%$ of the lagoonal area in New Caledonia. In order to have adequate tools for the integrated management of the entire coastal area and for studying specific sites in the context of climate change and anthropogenic pressure, the models need to be geographically extended.

Suspended particles have inhibiting effects on the reef communities through their abrasive capacity and the reduction in light penetration. Reef damage (bleaching and mortality) is enhanced during storms in areas where land development has increased soil erosion (Nowlis et al., 1997). Impacts of higher sediment inputs could induce alternative states of reef development (McLaughlin et al., 2003; Macdonald et al., 2005). It is clear that the authorities of New Caledonia must monitor turbidity, sediment inputs and sedimentation rates given the mining developments that are now taking place on the island. These measurements are necessary within the SLNC as well as in other hot spots such as Prony Bay, the Havannah channel, in the Voh-Koné-Pouembout district, and around the protected marine areas.

\section{Acknowledgements}

The research presented was funded by the program PNEC. Cofunding was also provided by ZoNéCo (Ph.D. grant of A. Jouon), ACI Observation de la Terre (remote sensing applications - BISSECOTE program), Previmer (operational modeling of hydrodynamics) and NASA Earth Observing System's Interdisciplinary Program (Grant NNG04F090G to Serge Andréfouët). We acknowledge Jacques Clavier who initiated an ambitious pluridisciplinary program on the south-west lagoon of New Caledonia which became the framework of the PNEC program; H. Chamley, A. Sournia, C. Alzieu and all other leaders and members of the scientific council of the PNEC who supported our work. We warmly everyone who participated in the physical part of the PNEC-Caledonia program, amongst them C. Grenz and R. Le Borgne, its current leader and deputy leader, the captains of research vessels used for short field campaigns (G. Bargibant, M. Clarque, N. Colombani, S. Tereua), captains (J.F. Barazer, H. Le Houarno, R. Proner) and crews of R.V. ALIS, divers (J.L. Menou, E. Folcher, P. Laboute, C. Geoffray), and many colleagues, researchers (X. Mari, C. Dupouy, J. Neveux, L. Schmied, J.P. Torréton, O. Pringault, E. Rochelle-Newall, Y. Gouriou, T. Delcroix, C. Payri, J.P. Debenay, P. Larcombe, F. Dugas), engineers (P. Gérard, S. Chifflet, P. Cann, P. Bretel, F. Gallois), technicians (J.P. Lamoureux, A. di Matteo, A. Belhandouz) and students (B. Bouron-Morin, E. Cordier, G. Dirberg). We also acknowledge three anonymous reviewers whose comments and suggestions were highly appreciated.

\section{References}

Achite, M., Ouillon, S., 2007. Suspended sediment transport in a semiarid watershed, Wadi Abd, Algeria (1973-1995). J. Hydrol. 343 (3-4), 187-202.

Acker, J., Ouillon, S., Gould Jr., R.W., Arnone, R.A., 2005. Measuring marine suspended sediment concentrations from space: history and potential. In: Proceedings of 8th International Conference Remote Sensing for Marine and Coastal Environments (CD-ROM). Altarum/AMRS, Halifax, Canada.

Agrawal, Y.C., Pottsmith, H.C., 2000. Instrument for particle size and settling velocity observations in sediment transport. Mar. Geol. 16, 89-114.

Alexandrov, Y., Laronne, J.B., Reid, I., 2007. Intra-event and inter-seasonal behaviour of suspended sediment in flash floods of the semi-arid northern Negev, Israel. Geomorphology 85, 85-97.

Andréfouët, S., Cabioch, G., Flamand, B., Pelletier, B., 2009. A reappraisal of the diversity of geomorphological and genetic processes of New Caledonian coral reefs: a synthesis from optical remote sensing, coring and acoustic multibeam observations. Coral Reefs 28, 691-707.

Andrews, J.C., Pickard, G.L., 1990. The physical oceanography of coral-reef systems. In: Dubinsky, Z. (Ed.), Ecosystems of the World, Coral Reefs, vol. 25. Elsevier, Amsterdam, pp. 11-48.

Atkinson, M.J., Smith, S.V., Stroup, E.D., 1992. Circulation in Enewetak Atoll lagoon. Limnol. Oceanogr. 37, 273-279.

Azetsu-Scott, K., 2004. Ascending marine particles: significance of transparent exopolymer particles (TEP) in the upper ocean. Limnol. Oceanogr. 49, 741-748.

Baker, E.T., Lavelle, J.W., 1984. The effect of particle size on the light attenuation coefficient of natural suspensions. J. Geophys. Res. 89, 8197-8203.

Baltzer, F., 1982. Géodynamique de la sedimentation et diagénèse précoce en domaine ultrabasique, Nouvelle-Calédonie. ORSTOM/IRD, Paris, France.

Baltzer, F., Trescases, J.J., 1971a. Erosion, transport et sédimentation liés aux cyclones tropicaux dans les massifs d'ultrabasites de Nouvelle-Calédonie. Cahiers ORSTOM Série Géologie III (2), 221-244.

Baltzer, F., Trescases, J.J., 1971b. Première estimation du bilan de l'altération, de l'érosion et de la sédimentation, sur péridotites, sous le climat tropical de la Nouvelle-Calédonie. CRAS 273, 2034-2037. 
Battistini, R., Bourrouilh, F., Chevalier, J.P., Coudray, J., Denizot, M., Faure, G., Fisher, J.C., Guilcher, A., Harmelin-Vivien, M., Jaubert, J., Laborel, J., Montaggioni, L. Masse, J.P., Mauge, L.A., Peyrot-Clausade, M., Pichon, M., Plante, R., Plaziat, J.C., Plessis, Y.B., Richard, G., Salvat, B., Thomassin, B.A., Vasseur, B., Weydert, P., 1975. Eléments de terminologie récifale indopacifique. Téthys 7, 1-111.

Baumert, H., Chapalain, G., Smaoui, H., McManus, J.P., Yagi, H., Regener, M., Sündermann, J., Szilagy, B., 2000. Modelling and numerical simulation of turbulence, waves and suspended sediments for pre-operational use in coastal seas. Coastal Eng. 41, 63-93.

Bird, E.C.F., Dubois, J.P., Iltis, J.A., 1984. The Impact of Opencast Mining on the Rivers and Coasts of New Caledonia. The United Nation University, NRTS-25/UNUP505, p. 53.

Blaas, M., Dong, C., Marchesiello, P., McWilliams, J.C., Stolzenbach, K.D., 2007. Sediment-transport modelling on Southern Californian shelves: a ROMS case study. Cont. Shelf Res. 27, 832-853.

Blumberg, A.F., Mellor, G.L., 1987. A description of the three-dimensional coastal ocean circulation model. In: Heaps, N.S. (Ed.), Three-dimensional Coastal Ocean Model. American Geophysical Union, Washington, DC, pp. 1-16.

Bonem, R.M., 1988. Recognition of storm impact on the reef sediment record. In: Choat, J.H., et al. (Ed.), Proceedings of 6th International Coral Reef Symposium, vol. 2. James Cook University North Queensland, Townsville, Australia, pp. 475478 .

Bonneton, P., Lefebvre, J.P., Bretel, P., Ouillon, S., Douillet, P., 2007. Tidal modulation of wave-setup and wave-induced currents on the Aboré coral reef, New Caledonia. J. Coastal Res. SI 50, 762-766.

Bonneton, P., Cienfuegos, R., Ouillon, S., Bretel, P., Lefevre, J.-P., Bonneton, N., 2008. Wave transformation and wave-induced currents on a submerged barrier reef: field observations and Boussinesq-type modelling. In: 9th International Coral Reef Symposium. St Petersburg, FL.

Boss, E., Pegau, W.S., Gardner, W.D., Zaneveld, J.R.V., Barnard, A.H., Twardowski, M.S., Chang, G.C., Dickey, T.D., 2001. Spectral particulate attenuation and particle size distribution in the bottom boundary layer of a continental shelf. J. Geophys. Res. 106, 9509-9516.

Bouron-Morin B., 2001. Modélisation de la dynamique sédimentaire dans le lagon Sud-Ouest de Nouvelle-Calédonie, Master Sci. Report, Univ. Paris 6, IRD.

Bowers, D.G., Binding, C.E., 2006. The optical properties of mineral suspended particles: a review and synthesis. Estuarine Coastal Shelf Sci. 67 (1-2), 219-230.

Bradbury, R.H., Young, P.C., 1981. The effects of a major forcing function, wave energy, on a coral reef ecosystem. Mar. Ecol. Prog. Ser. 5, 229-241.

Bujan, S., Grenz, C., Fichez, R., Douillet, P., 2000. Evolution saisonnière du cycle biogéochimique dans le lagon sud-ouest de Nouvelle-Caledonie. Application d'un modèle compartimental. Life Sci., Ecol. 323, 225-233.

Bunt, J.A.C., Larcombe, P., Jago, C.F., 1999. Quantifying the response of optical backscatter devices and transmissometers to variations in suspended particulate matter. Cont. Shelf Res. 19, 1199-1220.

Caires, S., Sterl, A., Komen, G., Swail, V., 2005. The KNMI/ERA-40 Wave Atlas Derived from 45-Years of ECMWF Reanalysis Data. <http://www.knmi.nl/waveatlas>

Callaghan, D.P., Nielsen, P., Gourlay, M.R., Ballock, T.E., 2006. Atoll lagoon flushing forced by waves. Coastal Eng. 53, 691-704.

Castaing, P., Froidefond, J.M., Lazure, P., Weber, O., Prud'homme, R., Jouanneau, J.M., 1999. Relationship between hydrology and seasonal distribution of suspended sediments on the continental shelf of the Bay of Biscay. Deep-Sea Res. II 46, 1979-2001.

Chardy, P., Chevillon, C., Clavier, J., 1988. Major benthic communities of the southwest lagoon of New-Caledonia. Coral Reefs 7, 69-75.

Chevillon, C., 1992. Biosédimentologie du grand lagon nord de la NouvelleCalédonie. Etudes and Thèses. ORSTOM, Paris, p. 224.

Chevillon, C., 1996. Skeletal composition of modern lagoon sediments in NewCaledonia: coral, a minor constituent. Coral Reef 15, 199-207.

Clavier, J., Chardy, P., Chevillon, C., 1995. Sedimentation of particulate matter in the south-west lagoon of New Caledonia: spatial and temporal patterns. Estuarine Coastal Shelf Sci. 40, 281-294.

Coudray, J., 1975. Recherches sur le néogène et le quaternaire marin de la NouvelleCalédonie - Expéditions françaises sur les récifs de Nouvelle-Calédonie, vol. VIII. Fondation Singer-Polignac, p. 275.

Curran, P.J., Novo, E.M.M., 1988. The relationship between suspended sediment concentration and remotely sensed spectral reflectance: a review. J. Coastal Res. 4, 351-368.

Curran, K.J., Hill, P.S., Milligan, T.G., Mikkelsen, O.A., Law, B.A., Durrieu de Madron, X., Bourrin, F., 2007. Settling velocity, effective density, and mass composition of suspended sediment in a coastal bottom boundary layer, Gulf of Lions, France. Cont. Shelf Res. 27, 1408-1421.

Dandonneau, Y., Debenay, J.P., Dugas, F., Fourmanoir, P., Magnier, Y., Rougerie, F., 1981. Le lagon de la Grande Terre, Présentation d'ensemble, Sédimentologie et hydrologie du sud-ouest. In: Atlas de Nouvelle-Calédonie et dépendances. ORSTOM, Paris, pp. 21-24

Debenay, J.P., 1987. Sedimentology in the south-west lagoon of New-Caledonia, SW Pacific. J. Coastal Res. 3, 77-91.

Debenay, J.P., Fernandez, J.M., 2009. Benthic foraminifera records of complex anthropogenic environmental changes combined with geochemical data in a tropical bay of New Caledonia (SW Pacific). Mar. Pollut. Bull. 59 (8-12), 311322

Douillet, P., 1998. Tidal dynamics of the south-west lagoon of New Caledonia: observations and 2D numerical modelling. Oceanol. Acta 21 (1), 69-79.

Douillet, P., Bargibant, G., Hoffchir, C., Laboute, P., Menou, J.L., Panché, J.Y., Tirard, P., 1989. Mesures de courant, de marée et de vent dans le lagon sud-ouest de
Nouvelle Calédonie. 1ère partie: octobre 1988 à juillet 1989. Rapp. Sci. Tech. ORSTOM Nouméa, Sci. Mer., Biol. Mar. 53, p. 271.

Douillet, P., Bargibant, G., Hamel, P., Hoffschir, C., Menou, J.L., Panché, J.Y., Tirard P., 1990. Mesures de courant, de marée et de vent dans le lagon sud-ouest de Nouvelle-Calédonie. 2ème partie: juillet 1989 à octobre 1990. Rapp. Sci. Tech. ORSTOM Nouméa, Sci. Mer., Biol. Mar. 58, p. 722.

Douillet, P., Ouillon, S., Cordier, E., 2001. A numerical model for fine suspended sediment transport in the south-west lagoon of New Caledonia. Coral Reefs 20 361-372.

Doxaran, D., Froidefond, J.M., Castaing, P., 2003. Remote sensing reflectance of turbid sediment-dominated waters. Reduction of sediment type variations and changing illumination conditions effects by use of reflectance ratios. Appl. Opt. 42 (15), 2623-2634.

Droppo, I.G., 2001. Rethinking what constitutes suspended sediments. Hydrol. Proc $15,1551-1564$

Droppo, I.G., 2004. Structural controls on floc strength and transport. Can. J. Civil Eng. 31 (4), 569-578.

Dugas, F., Debenay, J.P., 1982. Carte sédimentologique et carte annexe du lagon de Nouvelle Calédonie au 1/50000 - Mont Dore, Tontouta, Prony, Nouméa. Notices explicatives n 76, 86, 91 et 95. ORSTOM, Paris.

Dupouy, C., Neveux, J., Dirberg, G., Tenório, M.M.B., Röttgers, R., Ouillon, S., 2008 Bio-optical properties of marine cyanobacteria Trichodesmium spp. J. Appl. Rem. Sensing 2, 023503.

Dupouy, C., Neveux, J., Ouillon, S., Frouin, R., Murakami, H., Hochard, S., Dirberg, G. 2010. Inherent optical properties and satellite retrieval of chlorophyl concentration in the lagoon and open ocean waters of New Caledonia. Mar. Pollut. Bull. 61, 503-518.

Fernandez, J.M., Ouillon, S., Chevillon, C., Douillet, P., Fichez, R., Le Gendre, R., 2006 A combined modelling and geochemical study of the fate of terrigenous inputs from mixed natural and mining sources in a coral reef lagoon (New Caledonia). Mar. Pollut. Bull. 52, 320-331.

Fernandez, J.M., Meunier, J.D., Ouillon, S., Moreton, B., Dolbecq, M., Belhandouz, A. Lamoureux, J.P., submitted for publication. Impact of past and present open cast $\mathrm{Ni}$ mining on sediment composition and fluxes into a lagoonal environment. Sci. Total Environ.

Folk, R.L., Ward, W.C., 1957. Brazos River bar: a study in the significance of grain size parameters. J. Sediment. Petrol. 27 (1), 3-26.

Frith, C.A., Mason, L.B., 1986. Modelling wind driven circulation One Tree Reef Southern Great Barrier Reef. Coral Reefs 4, 201-211.

Gagan, M.K., Chivas, A.R., Herczeg, A.L., 1990. Shelf-wide erosion, deposition and suspended sediment transport during cyclone Winifred, central Great Barrier Reef, Australia. J. Sediment. Petrol. 60, 456-470.

Gibbs, R.J., Wolanski, E., 1992. The effect of flocs on optical backscattering measurements of suspended material concentration. Mar. Geol. 107 (4), 289291.

Gouriou, Y., Delcroix, T., 2002. Seasonal and ENSO variations of sea surface salinity and temperature in the South Pacific Convergence Zone during 1976-2000. J. Geoph. Res. 107 (C12), 8011.

Gourlay, M.R., 1996. Wave induced set-up on coral reefs. 2: Set-up on reefs with various profiles. Coastal Eng. 28, 17-55.

Gourlay, M.R., Colleter, G., 2005. Wave-generated flow on coral reefs - An analysis for two-dimensional horizontal reef-tops with steep faces. Coastal Eng. 52, 353387.

Hamilton, L.J., 1994. Turbidity in the northern Great Barrier Reef lagoon in the wet season, March 1989. Aust. J. Freshwater Res. 45, 585-615.

Hamner, W.M., Wolanski, E., 1988. Hydrodynamic forcing functions and biological processes on coral reefs: a status review. In: Choat, J.H., et al. (Ed.), Proceedings of 6th International Coral Reef Symposium, vol. 1. James Cook University North Queensland, Townsville, Australia, pp. 103-113.

Hardy, T.A., 1993. The Attenuation and Spectral Transformation of Wind Waves on a Coral Reef, Ph.D. Thesis. James Cook University North Queensland, Townsville, Australia, p. 336

Hearn, C.J., 1999. Wave-breaking hydrodynamics within coral reef systems and the effects of changing relative sea level. J. Geophys. Res. 104 (C12), 3000730019.

Hearn, C.J., 2001. Introduction to the special issue of coral reefs on "Coral Reef Hydrodynamics". Coral Reefs 20, 327-329.

Hearn, C.J., Parker, I.N., 1988. Hydrodynamic processes on the Ningaloo Reef, western Australia. In: Choat, J.H., et al. (Ed.), Proceedings of 6th Internationa Coral Reef Symposium, vol. 2. James Cook University North Queensland Townsville, Australia, pp. 497-502.

Heussner, S., Ratti, C., Carbonne, J., 1990. The PPS 3 time-series sediment trap and the trap sample processing techniques used during the ECOMARGE experiment. Cont. Shelf Res. 10 (9-11), 943-958.

Hodgson, G., 1999. A global assessment of human effects on coral reefs. Mar. Pollut. Bull. 38 (5), 345-355.

Hoitink, A.J.F., 2004. Tidally-induced clouds of suspended sediment connected to shallow-water coral reefs. Mar. Geol. 208, 13-31.

Holyer, R.J., 1978. Toward universal multispectral suspended sediment algorithms. Rem. Sensing Environ. 7, 323-338.

Jacquet, S., Delesalle, B., Torréton, J.P., Blanchot, J., 2006. Response of phytoplankton communities to increased anthropogenic influences (southwest lagoon, New Caledonia). Mar. Ecol. Prog. Ser. 320, 65-78.

Jarrige, F., Radok, R., Krause, G., Rual, P., 1975. Courants dans le lagon de Nouméa (Nouvelle Calédonie). Déc.74-janv. 75. Rapp. ORSTOM (Nouméa) and H. Lamb Inst. Oceanogr., Flinders Univ S Australia, p. 6. 
Jouon, A., Douillet, P., Ouillon, S., Fraunié, P., 2006. Calculations of hydrodynamic time parameters in a semi-opened coastal zone using a 3D hydrodynamic model. Cont. Shelf Res. 26 (12-13), 1395-1415.

Jouon, A., Ouillon, S., Douillet, P., Lefebvre, J.P., Fernandez, J.M., Mari, X., Froidefond, J.M., 2008. Spatio-temporal variability in suspended particulate matter concentration and the role of aggregation on size distribution in a coral reef lagoon. Mar. Geol. 256, 36-48.

Jouon, A., Lefebvre, J.P., Douillet, P., Ouillon, S., Schmied, L., 2009. Wind wave measurements and modelling in a fetch-limited semi-enclosed lagoon. Coastal Eng. 56 (5-6), 599-608.

Kantha, L.H., Clayson, C.A., 2004. On the effect of surface gravity waves on mixing in the oceanic mixed layer. Ocean Model. 6 (2), 101-124.

Kennedy, A.B., Thomas, D., 2004. Drifter measurements in a laboratory rip current. J Geophys. Res. 109, C08005. doi:10.1029/2003JC001927.

Kraines, S.B., Yanagi, T., Isobe, M., Komiyama, H., 1998. Wind-wave driven circulation on the coral reef at Bora Bay, Miyako Island. Coral Reefs 17, 133-143.

Kraines, S.B., Suzuki, A., Yanagi, T., Isobe, M., Guo, X., Komiyama, H., 1999. Rapid water exchange between the lagoon and the open ocean at Majuro Atoll due to wind, waves and tide. J. Geophys. Res. 104, 15635-15653.

Kraines, S., Isobe, M., Komiyama, H., 2001. Seasonal variations in the exchange of water and water-borne particles at Majuro Atoll, the Republic of the Marshall Islands. Coral Reefs 20, 330-340.

Krone, R.B., 1962. Flume Studies of the Transport of Sediment in Estuarial Shoaling Processes. Tech. Rep., Hydraulic Eng. Lab. and Sanitary Eng. Res. Lab., University of California, Berkeley, CA.

Labrosse, P., Fichez, R., Farman, R., Adams, T., 2000. New Caledonia. In: C. Sheppard (Ed.), Seas at the Millenium, An Environmental Evaluation, vol. 2. Elsevier, Amsterdam, p. 723-736.

Laganier, R., 1994. Contribution à l'étude des processus d'érosion et des risques naturels dans les îles du Sud-Ouest Pacifique (Nouvelle-Calédonie et îles Salomon), Ph.D. thesis report. University of Science and Technology, LilleFlandres-Artois, ORSTOM.

Larcombe, P., Woolfe, K., 1999. Increased sediment supply to the Great Barrier Reef will not increase sediment accumulation at most coral reefs. Coral Reefs 18 , 163-169.

Larcombe, P., Ridd, P.V., Prytz, A., Wilson, B., 1995. Factors controlling suspended sediment on inner-shelf coral reefs, Townsville, Australia. Coral Reefs 14, 163175 .

Larcombe, P., Costen, A., Woolfe, K.J., 2001. The hydrodynamic and sedimentary setting of nearshore coral reefs, central Great Barrier Reef shelf, Australia: Paluma Shoals, a case study. Sedimentology 48, 811-835.

Latif, M., Kleeman, R., Eckert, C., 1997. Greenhouse warming, decadal variability, or El Niño ? An attempt to understand the anomalous 1990s. Climate 10, 22212239.

Launay, J., 1972. La sédimentation en baie de Dumbéa. Cahiers ORSTOM, Sér. Géol IV (1), 25-51.

Lazure, P., Dumas, F., 2008. An external-internal mode coupling for a 3D hydrodynamical model for applications at regional scale (MARS). Adv. Water Resour. 31 (2), 233-250.

Lazure, P., Salomon, J.C., 1991. Coupled 2-D and 3-D modelling of coastal hydrodynamics. Oceanol. Acta 14 (2), 173-180.

Le Borgne, R., Douillet, P., Fichez, R., Torréton, J.P., this issue. Hydrography and plankton temporal variabilities at different time scales in the southwest lagoon of New Caledonia: a review. Mar. Pollut. Bull. doi:10.1016/j.marpolbul.2010. 06.022

Le Hir, P., Monbet, Y., Orvain, F., 2007. Sediment erodability in sediment transport modelling: can we account for biota effects? Cont. Shelf Res. 27 (8), 1116-1142.

Le Hir, P., Cann, P., Waeles, B., Jestin, H., Bassoullet, P., 2008. Erodibility of natural sediments: experiments on sand/mud mixtures from laboratory and field erosion tests. In: Kusuda, T., et al. (Eds.), Sediment and Ecohydraulics: INTERCOH 2005. Elsevier, pp. 137-153.

Lefèvre, J., Marchesiello, P., Jourdain, N., Menkès, C., Leroy, A., 2010. Weather regimes and orographic circulation around New Caledonia. Mar. Pollut. Bull. 61 413-431.

Lillie, A.R., Brothers, R.N., 1970. The geology of New-Caledonia. New Zealand J. Geol. Geophys. 13 (1), 159-167.

Liston, P., Furnas, M.J., Mitchell, A.W., Drew, E.A., 1992. Local and mesoscale variability of surface water temperature and chlorophyll in the northern Great Barrier Reef, Australia. Cont. Shelf Res. 12, 907-921.

Lynch, J.F., Irish, J.D., Sherwood, C.R., Agrawal, Y.C., 1994. Determining suspended sediment particle size information from acoustical and optical backscatte measurements Cont Shelf Res. 14, 1139-1165.

Macdonald, I.A., Perry, C.T., Larcombe, P., 2005. Comment on "Rivers, runoff, and reefs" by McLaughlin et al. [Global Planetary Change 39 (2003) 191-199]. Global Planet. Change 45, 333-337.

Magand, O., 1998. Contribution à la modélisation du transport de la matière particulaire dans le lagon sud-ouest de Nouvelle-Calédonie: étude des flux détermination des signatures minéralogiques et évolution spatiale, Master thesis report. Université de Perpignan, p. 50.

Magand, O., 1999. Recherche et définition des signatures géochimiques (métaux lourds et lanthanides) des sources terrigènes du lagon sud-ouest de NouvelleCalédonie, Master thesis report. Université Aix-Marseille II, p. 48.

Mari, X., Rochelle-Newall, E., Torréton, J.P., Pringault, O., Jouon, A., Migon, C., 2007. Water residence time: a regulatory factor of the DOM to POM transfe efficiency. Limnol. Oceanogr. 52, 808-819.

Maxwell, W.G.H., 1968. Atlas of the Great Barrier Reef. Elsevier, Amsterdam. p. 258
McCave, I.N., 1986. Local and global aspects of the bottom nepheloid layers in the world ocean. Neth. J. Sea Res. 20, 167-181.

McLaughlin, C.J., Smith, C.A., Buddemeier, R.W., Bartley, J.D., Maxwell, B.A., 2003. Rivers, runoff, and reefs. Global Planet. Change 39, 191-199.

Mehta, A.J., Lee, S.C., 1994. Problems in linking the threshold condition for the transport of cohesionless and cohesive sediment grain. J. Coastal Res. 10 (1), 170-177.

Migon, C., Ouillon, S., Mari, X., Nicolas, E., 2007. Geochemical and hydrodynamic constraints on the distribution of trace metal concentrations in the lagoon of Noumea, New Caledonia. Estuarine Coastal Shelf Sci. 74 (4), 756-765.

Mikkelsen, O.A., Pejrup, M., 2001. The use of LISST-100 in-situ laser particle sizer for estimates of floc size, density and settling velocity. Geo-Mar. Let. 20, 187-195.

Mobley, C.D., 1994. Light and Water Radiative Transfer in Natural Water. Academic Press, San Diego. p. 592.

Mobley, C.D., 1999. Estimation of the remote-sensing reflectance from abovesurface measurements. Appl. Opt. 38, 7442-7455.

Morlière, A., 1985. Assainissement de Nouméa. Mesures de courant. Rap. Sci. Tech. ORSTOM, p. 50.

Morlière, A., Crémoux, J.L., 1981. Observations de courant dans le lagon, de Février à Août 1981. Rap. Sci. Tech. ORSTOM, p. 50

Nadaoka, K., Nihei, Y., Wakaki, K., Kumano, R., Kakuma, S., Moromizato, S., Omija, T., wao, K., Shimoike, K., Taniguchi, H., Nakano, Y., Ikema, T., 2001a. Regional variation of water temperature around Okinawa coasts and its relationship to offshore thermal environments and coral bleaching. Coral Reefs 20, 373-384.

Nadaoka, K., Nihei, Y., Kumano, R., Yokobori, T., Omija, T., Wakaki, K., 2001b. A field observation on hydrodynamic and thermal environments of a fringing reef at Ishigaki Island under typhoon and normal atmospheric conditions. Coral Reefs 20, 387-398.

Nicet, J.B., Delcroix, T., 2000. ENSO-related precipitation changes in New Caledonia, southwestern tropical Pacific: 1969-98. Mon. Wea. Rev. 128, 3001-3006.

Niiler, P.P., Sybrandy, A.S., Kenong, B., Poulain, P.M., Bitterman, D., 1995. Measurement of the water-following capability of holey-sock and TRISTAR drifters. Deep-sea Res. I 42 (11-12), 1951-1964.

Nikora, V., Goring, D., Ross, A., 2002. The structure and dynamics of the thin nearbed layer in a complex marine environment: a case study in Beatrix Bay, New Zealand. Estuarine Coastal Shelf Sci. 54 (5), 915-926.

Nowlis, J.S., Roberts, C., Smith, A., Sirila, E., 1997. Human-induced impacts of a tropical storm on nearshore coral reefs. Ambio 26 (8), 515-521.

O'Callaghan, J., 1999. The oceanography an sedimentology of a coastal embayment: Dumbea Bay, Noumea, New-Caledonia. B.Sc. Thesis report. School of Earth Sciences, James Cook University, Townsville, Australia, p. 86.

Orpin, A.R., Ridd, P.V., Stewart, L.K., 1999. Assessment of the relative importance of major sediment-transport mechanisms in the central Great Barrier Reef lagoon. Aust. J. Earth Sci. 46, 883-896.

Ouillon, S., 1998. Erosion et transport solide: ampleur et enjeux. La Houille Blanche 2, 52-58.

Ouillon, S., Douillet, P., Andrefouet, S., 2004. Coupling satellite data with in situ measurements and numerical modeling to study fine suspended sediment transport: a study for the lagoon of New Caledonia. Coral Reefs 23 (1), 109-122.

Ouillon, S., Douillet, P., Fichez, R., Panché, J.Y., 2005. Enhancement of regional variations in salinity and temperature in a lagoon, New Caledonia. CR Geosci. 337, 1509-1517.

Ouillon, S., Douillet, P., Petrenko, A., Neveux, J., Dupouy, C., Froidefond, J.M., Andréfouët, S., Muñoz-Caravaca, A., 2008. Optical algorithms at satellite wavelengths for total suspended matter in coastal tropical waters. Sensors 8 , 4165-4185.

Paris, J.P., 1981. Les ressources minérales de Nouvelle-Calédonie. Mémoire 113, BRGM, Orléans, pp. 219-224.

Partheniades, E., 1965. Erosion and deposition of cohesive soils. J. Hydraulics Div. 91, 105-139.

Perry, C., Taylor, K. (Eds.), 2006. Environmental Sedimentology. Blackwell Scientific Publications.

Pesin, E., Blaize, S., Lacoste, D., 1995. Atlas climatique de la Nouvelle Calédonie, Météo France. Nouméa, New Caledonia.

Pinazo, C., Bujan, S., Douillet, P., Fichez, R., Grenz, C., Maurin, A., 2004. Impact of wind and freshwater inputs on phytoplankton biomass in the coral reef lagoon of New Caledonia during the summer cyclonic period: a coupled threedimensional biogeochemical modeling approach. Coral Reefs 23 (2), 281-296.

Prager, E.J., 1991. Numerical simulation of circulation in a Caribbean-type backreef lagoon. Coral Reefs 10, 177-182.

Puls, W., Doerffer, R., Sündermann, J., 1994. Numerical simulation and satellite observations of suspended matter in the North Sea. IEEE J. Ocean Eng. 19, 3-9.

Reniers, A.J.H.M., MacMahan, J., Thornton, E.B., Stanton, T.P., 2007. Modeling surf zone eddies on a rip-channel beach. J. Geophys. Res. 112 (C7), C07013.

Roberts, H.H., Wilson, P.A., Lugo-Fernandez, A., 1992. Biologic and geologic responses to physical processes: examples from modern reef systems of the Caribbean-Atlantic region. Cont. Shelf Res. 12, 809-834.

Rogers, C.S., 1990. Responses of coral reefs and reef organisms to sedimentation. Mar. Ecol. Prog. Ser. 62, 185-202.

Rougerie, F., 1985. The New Caledonian south-west lagoon: circulation, hydrological specificity and productivity. In: Proceedings of the 5th International Coral Reef Congress, vol. 6. Tahiti, French Polynesia, pp. 17-22.

Sanford, L., Maa, J.P.-Y., 2001. A unified erosion formulation for fine sediments. Mar. Geol. 179, 9-23.

Sasal, P., Mouillot, D., Fichez, R., Chifflet, S., Kulbicki, M., 2007. The use of fish parasites as biological indicators of anthropogenic influences in coral-reef 
lagoons: a case study of Apogonidae parasites in New-Caledonia. Mar. Pollut. Bull. 54, 1697-1706.

Schoellhamer, D.H., 2002. Variability of suspended-sediment concentration at tidal to annual time scales in San Francisco Bay, USA. Cont. Shelf Res. 22, 1857-1866.

Shifrin, K.S., Zolotov, I.G., 1995. Optical characteristics of suspended marine particles for short light pulses. J. Geophys. Res. 100 (C7), 13369-13372.

Siegel, H., Gerth, M., Mutzke, A., 1999. Dynamics of the Oder River plume in the southern Baltic Sea: satellite data and numerical modelling. Cont. Shelf Res. 19, 1143-1159.

Smith, N.P., 1985. The decomposition and simulation of the longitudinal circulation in a coastal lagoon. Estuarine Coastal Shelf Sci. 21, 623-632.

Smith, S.V., Buddenmeier, R.W., 1992. Global change and coral reef ecosystems. Annu. Rev. Ecol. Sys. 23, 89.

Sterl, A., Caires, S., 2005. Climatology, variability and extrema of ocean waves: the Web-based KNMI/ERA-40 wave atlas. Int. J. Climatol. 25 (7), 963-977.

Stumm, W., Morgan, J.J., 1981. Aquatic chemistry: an introduction emphasizing chemical equilibria in natural waters, second ed. Wiley-Interscience, New-York. p. 780.

Symonds, G., Black, K.P., Young, I.R., 1995. Wave-driven flow over shallow reefs. J. Geophys. Res. 100 (C2), 2639-2648.

Tait, R.J., 1972. Wave set-up on coral reefs. J. Geophys. Res. 77 (12), 2207-2211.

Tartinville, B., Rancher, J., 2000. Wave-induced flow over Moruroa atoll reef. J. Coastal Res. 16, 776-781.

Tartinville, B., Deleersnijder, E., Rancher, J., 1997. The water residence time in the Mururoa atoll lagoon: sensitivity analysis of a three-dimensional model. Coral Reefs 16, 193-203.

Thomas, S., Ridd, P.V., Day, G., 2003. Turbidity regimes over fringing coral reefs near a mining site at Lihir Island, Papua New Guinea. Mar. Pollut. Bull. 46, 10061014

Thomsen, L., Gust, G., 2000. Sediment erosion thresholds and characteristics of resuspended aggregates on the western European continental margin. Deep-Sea Res. I 47, 1881-1897.

Thomsen, L., McCave, I.N., 2000. Aggregation processes in the benthic boundary layer at the Celtic Sea continental margin. Deep-Sea Res. I 47, 1389-1404.

Tixier, N., 2003. Approche des propriétés rhéologiques de suspensions biologiques floculées. Ph.D. Thesis. University of Limoges, France.

Tolman, H.L., 1991. A third-generation model for wind waves on slowly varying, unsteady and inhomogeneous depths and currents. J. Phys. Oceanogr. 21, 782797.

Tolman, H.L., 1999. User Manual and System Documentation of WAVEWATCH III Version 1.18. NOAA/NWS/NCEP/OMB Technical Note 151, p. 97.

Torréton, J.-P., Rochelle-Newall, E., Jouon, A., Faure, V., Jacquet, S., Douillet, P., 2007. Correspondence between the distribution of hydrodynamic time parameters and the distribution of biological and chemical variables in a semi-enclosed coral reef lagoon. Estuarine Coastal Shelf Sci. 74 (4), 667-677.

Traykovski, P., Latter, R., Irish, J.D., 1999. A laboratory evaluation of the LISST instrument using natural sediments. Mar. Geol. 159, 355-367.
Trenberth, K.E., Hoar, T.J., 1996. The 1990-1995 El Niño-southern oscillation event: longest on record. Geoph. Res. Lett. 23, 57-60.

Trescases, J.J., 1973. L'évolution geochimique supergène des roches ultrabasiques en zone tropicale. Formation des gisement nickélifères de Nouvelle-Calédonie. Ph.D. Thesis OA 8708. Université Louis Pasteur, Strasbourg.

van Rijn, L.C., 1986. Mathematical modelling of suspended sediment in non-uniform flows. J. Hydraulic Eng. 112, 433-455.

Vold, R.D., Vold, M.J., 1983. Colloid and Interface Chemistry. Addison-Wesley, Reading, MA, p. 694.

von Arx, W.S., 1948. The circulation systems of Bikini and Rongelap lagoons. Trans. Am. Geophys. Union 29, 861-870.

Wang, B.J., Bogucki, D.J., Redekopp, L.G., 2001. Internal solitary waves in a structured thermocline with implications for resuspension and the formation of thin particle-laden layers. J. Geophys. Res. 106, 9565-9585.

Warner, J.C., Sherwood, C.R., Signell, R.P., Harris, C.K., Arango, H.G., 2008 Development of a three-dimensional, regional, coupled wave, current, and sediment transport model. Comput. Geosci. 34, 1284-1306.

Wiberg, P.L., Drake, D.E., Harris, C.K., Noble, M., 2002. Sediment transport on the Palos Verdes shelf over seasonal to decadal time scales. Cont. Shelf Res. 22 (67), 987-1004.

Williams, N.D., Walling, D.E., Leeks, G.J.L., 2007. High temporal resolution in situ measurement of the effective particle size characteristics of fluvial suspended sediment. Water Res. 41 (5), 1081-1093.

Wing, S.R., Leichter, J.J., 1997. Storm-generated physical variability on Conch Reef Florida Keys, USA. In: Lessios, H.A., Macintyre, I.G. (Ed.), Proceedings of 8 th International Coral Reef Symposium, vol. 2. Smithsonian Tropical Research Institute, Balboa, Panama, pp. 1097-1101.

Wolanski, E., 1994. Physical oceanographic processes of the Great Barrier Reef Marine Science Series. CRC Press, Boca Raton, Flor.

Wolanski, E. (Ed.), 2001. Oceanographic Processes of Coral Reefs: Physical and Biological Links in the Great Barrier Reef. CRC Press, Boca Raton, Flor.

Wolanski, E., Pickard, G.L., 1985. Long-term observations of currents on the central Great Barrier Reef continental shelf. Coral Reefs 4, 47-57.

Wolanski, E., Richmond, R.H., Davis, G., Bonito, V., 2003. Water fine sediment dynamics in a transient river plumes in a small, reef-fringed bay, Guam. Estuarine Coastal Shelf Sci. 56, 1029-1040.

Woodroffe, C.D., 2000. Biogeomorphological response to tropical coasts to environmental change. In: Mimura, N., Yokoki, H. (Eds.). Proceedings of APN/ Survas/LOICZ Joint Conference on Coastal Impacts of Climate Change and Adaptation in the Asia-Pacific Region. CD-Rom and on-line, Kobe.

Woodruff, J.D., Geyer, W.R., Sommerfield, C.K., Driscoll, N.W., 2001. Seasonal variation of sediment deposition in the Hudson River estuary. Mar. Geol. 179, 105-119.

Yahel, R., Yahel, G., Genin, A., 2002. Daily cycles of suspended sands at coral reefs: a biological control. Limnol. Oceanogr. 47 (4), 1071-1083.

Young, Y.R., 1999. Seasonal variability of the global ocean wind and wave climate. Int. J. Climatol. 19, 931-950. 